\title{
THE CRYSTAL STRUCTURE DETERMINATIONS OF 2,2'-BIPYRIDYL- \\ AMINE AND THREE COPPER(II) COMPLEXES WITH \\ 2,2'-BIPYRIDYLAMINE
}

Ph. D. Thes is Submitted to lowa State University,

November, 1972

J. E. Johnson

\author{
Ames Laboratory, USAEC \\ lowa State University \\ Ames, lowa 50010
}

This report was prepared as an account of work
sponsored by the United States Government. Neither
the United States nor the United States Atomic Energy
Commission, nor any of their employees, nor any of
their contractors, subcontractors, or their employees,
makes any warranty, express or implied, or assumes any
legal liability or responsibility for the accuracy, com-
pleteness or usefulness of any information, apparatus,
product or process disclosed, or represents that its use
would not infringe privately owned rights.

Date of Manuscript: November, 1972

PREPARED FOR THE U. S. A TOMIC ENERGY COMMISSION DIVISION OF RESEARCH UNDER CONTRACT NO. W-7405-eng-82 


\section{DISCLAIMER}

This report was prepared as an account of work sponsored by an agency of the United States Government. Neither the United States Government nor any agency Thereof, nor any of their employees, makes any warranty, express or implied, or assumes any legal liability or responsibility for the accuracy, completeness, or usefulness of any information, apparatus, product, or process disclosed, or represents that its use would not infringe privately owned rights. Reference herein to any specific commercial product, process, or service by trade name, trademark, manufacturer, or otherwise does not necessarily constitute or imply its endorsement, recommendation, or favoring by the United States Government or any agency thereof. The views and opinions of authors expressed herein do not necessarily state or reflect those of the United States Government or any agency thereof. 


\section{DISCLAIMER}

Portions of this document may be illegible in electronic image products. Images are produced from the best available original document. 
This report was prepared as an account of work sponsored by the United States Government. Neither the United States nor the United States Atomic Energy Commission, nor any of their employees, nor any of their contractors, subcontractors, or their employees, makes any warranty, express or implied, or assumes any legal liability or responsibility for the accuracy, completeness or usefulness of any information, apparatus, product or process disclosed, or represents that its use would not infringe privately owned rights.

Available from: National Technical Information Service Department $A$

Springfield, VA 22151

Price: Microfiche $\$ 0.95$ 

The crystal structure determinations of 2,2'bipyridylamine and three copper (II) complexes wi th 2,2'bipyridylamine
by

John Emi I Johnson

A Dissertation Submitted to the

Graduate Faculty, in Partial Fulfillment of

The Requirements for the Degree of

DOCTOR OF PHILOSOPHY

Department: Chemistty

Major: Physical Chemistry

Approved:
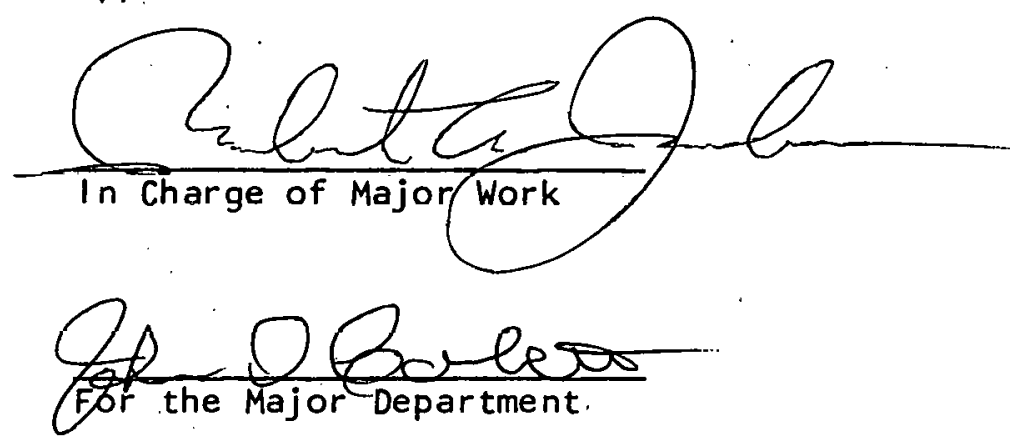

For the duaduate college

lowa State University
Amés, lowa 
TABLE OF CONTENTS

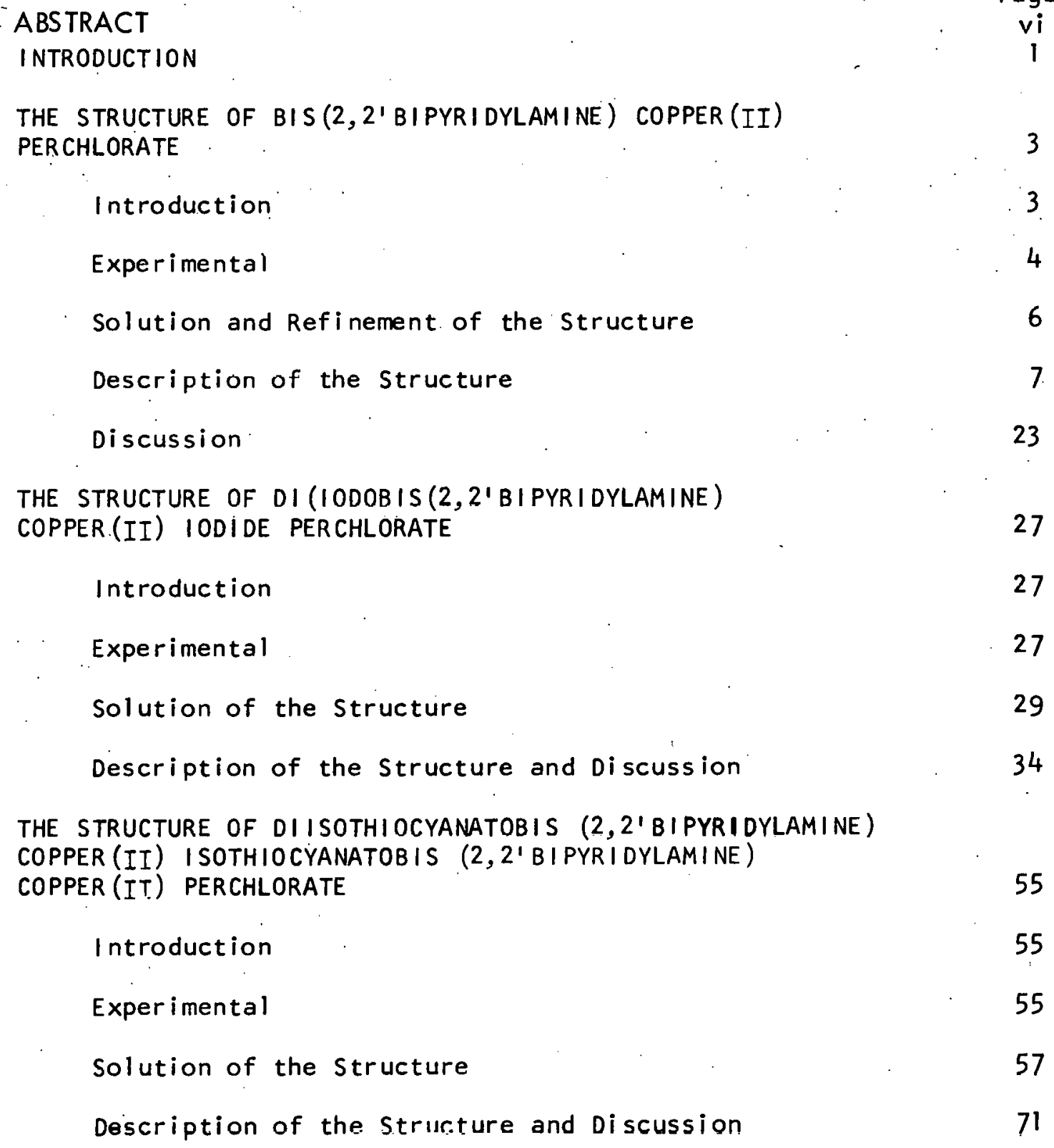




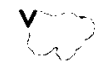

Page

THE STRUCTURE OF 2, 2'BIPYRIDYLAMINE 82

Introduction : 82

Experimental $\cdot 82$

Solution and Refinement $\quad 84$

Description of the Structure and Discussion 95

$\begin{array}{lr}\text { LITERATURE CITED } & 102\end{array}$

$\begin{array}{ll}\text { ACKNOWLEDGMENTS } & 105\end{array}$

APPENDIX A: DIRECT PHASE DETERMINATION BY USE OF
LINEAR PROGRAMMING

$\begin{array}{ll}\text { Introduction } & 106\end{array}$

$\begin{array}{ll}\text { Theory } & 107\end{array}$

$\begin{array}{ll}\text { Experimental } & 1.10\end{array}$

Discussion $\quad 111$

APPENDIX B: RESEARCH PROPOSALS ' 113 
The crystal structure determinations of 2,2'bipyridylamine and three copper(II) complexes with 2,2'bipyridylamine

John Emil Johnson

Under the supervision of R. A. Jacobson

From the Department of Chemistry lowa State University

The structure of bis (2, 2'bipyridylamine) copper (IT) perchlorate has been determined by three dimensional $X$-ray analysis $\left(\mathrm{Cu}\left(\mathrm{C}_{10} \mathrm{H}_{9} \mathrm{~N}_{3}\right)_{2}\left(\mathrm{ClO}_{4}\right)_{2}, C_{2 / c}, a=9.35, b=12.88, c=19.69 \AA\right.$, $\left.\beta=102.8^{\circ}, Z=4\right)$. The structure was refined to a final discrepancy factor of $R=9.4 \%$. The two-fold axis of the space group is utilized by the complex with pyridine nitrogens coordinating to the copper in a pseudo tetrahedral arrangement. The $\mathrm{CU}-\mathrm{N}$ band lengths are 1.94 and $1.99 \AA$ with the dihedral angle between the two $N-C u-N$ planes of $55.6^{\circ}$ Distorted trigonal bipyramidal coordination geometry was found in the single crystal $x$-ray analysis of di (iodobis (2,2'bipyridylamine) copper(II)) iodide perchlorate $\left(\left(\mathrm{Cu}\left(\mathrm{C}_{10} \mathrm{H}_{9} \mathrm{~N}_{3}\right)_{2} \mathrm{I}\right)_{2} \mathrm{IClO}_{4}, \mathrm{P}_{2} / \mathrm{c}\right.$, a $=19.22$, $b=13.47, c=19.50 \AA, \beta=11.87, Z=4)$. Nitrogen atoms from two different bidentate ligands and an iodine atom occupy the equatorial positions with the remaining nitrogens at the axial positions. The Cu-N distances range from 1.98 to $2.09 \AA$ with a tendency toward elongation of the metal-equatorial nitrogen bonds relative to the axial bonds. The structure was refined by block diagonal least squares technique to a discrepancy factor of $8.60 \%$. 
The co-crystallized complexes di isothiocyanato-bis $(2,21-$ bipyridylamine) copper (IT) and isothiocyanato-bis (2, 2'bipyridylamine) copper (II) perchlorate $\left(\mathrm{Cu}\left(\mathrm{C}_{10} \mathrm{H}_{9} \mathrm{~N}_{3}\right)_{2}(\mathrm{NCS})_{2}, \mathrm{Cu}\left(\mathrm{C}_{10} \mathrm{H}_{9} \mathrm{~N}_{3}\right)_{2} \mathrm{NCSClO}_{4}\right.$, $P_{2 / / c} a=12.82, b=14.51, c=19.44 \AA, B=93.80^{\circ}$ ) display tetragonally distorted and square pyramidal geometries respectively. The octahedrally coordinated copper(IT) atom occupies a centrosymmetric. position of the space group with the bidentate ligands and the isothiocyanate groups coordinated trans to each other, the $\mathrm{Cu}-\mathrm{N}$ isothiocyanate distance being $2.55 \AA$ and distances of 2.01 and $2.02 \AA$ to the bidentate ligand nitrogens. The square pyramidal copper (II) complex occupies a four-fold general position with three nitrogens from the bidentate ligands and the nitrogen of the isothiocyanate group occupying the base positions and the remaining nitrogen at the apex. The structure was refined to a crystallographic discrepancy factor of $R=14.0 \%$.

Hydrogen bonded molecules of 2,2'bipyridylamine form dimeric units possessing two-fold crystallographic symmetry in the low melting polymorph of this compound. The structure was solved by direct methods and refined to a discrepancy factor of $6.2 \%$ using all 807 reflections measured (c $\left.10^{H} 9 N_{3}, P_{c c n}, a=18.416, b=12.294, c=7.691 \AA, Z=8\right)$. All nine hydrogen atoms were located and refined.

A method for direct phase determination employing linear programming is outlined and preliminary results reported. 


\section{INTRODUCTION}

The crystal structures of a series of copper(II) complexes with the ligand 2,2'bipyridylamine were determined by single crystal X-ray diffraction techniques.

In any complex containing the ligand 2,2'bipyridylamine ligandligand repulsions are important and in fact essentially eliminate the possibility of a trans planar conflguration without severe ligand distortion. In this way the ligand is simllar to 2,2'bipyridyl, 1,2 but the amine ligand is more flexible and can adapt to a greater variety of geometries.

Although many copper(II) complexes have been formed containing this ligand few have been characterized structurally and in some cases even the stoichiometry is in doubt. There is also considerable current interest in the electronic properties of copper(II) and their correlation with structure. ${ }^{3}$ with this in mind a series of three complexes of this type were studied and were shown to display four different coordination geometries depending on the anion present. The geometries found were: a distorted cetrahedron, a trigonal bipyrakid, a square pyramid and a distorted octahedron. The first configuration occurs in $\mathrm{CuL}_{2}\left(\mathrm{ClO}_{4}\right)_{2}$ where $\mathrm{L}=2,2$ 'bipyridylamine, the second in ( $\mathrm{CuL}_{2} \mathrm{I}_{2} \mathrm{IClO}_{4}$, and the third and fourth, respectively, in the cocrystallized complexes $\mathrm{CuL}_{2} \mathrm{NCSClO}_{4}$ and $\mathrm{CuL}_{2}$ (NCS) ${ }_{2}$.

In order to provide structural data for the free ligand, the crystal structure of the low melting polymorph of 2,2'bipyridylamine was determined. In this crystal structure hydrogen bonds between 
molecules result in discrete dimeric units possessing two-fold crystallographic symmetry.

In addition to the crystal structure work performed, a me thod for crystal structure determination involving linear programming is outlined in an Appendix. 
THE STRUCTURE OF BIS $\left(2,2^{\prime}\right.$ 'BI PYRI DYLAMINE)

COPPER (TT) PERCHLORATE

\section{Introduction}

The crystal structure determination of bis (2, $2^{\prime}$ bipyridylamine) copper (11) perchlorate ${ }^{4}$ was undertaken because of the dearth of structural information available on coordination complexes with the 2,2'bipyridylamine ligand and due to the conflicting evidence regarding the coordination geometry of the copper (11) perchlorate complex. ${ }^{5}$ While a previous crystal structure determination involving this ligand has been reported, ${ }^{6}$ the amine protons of the ligand had been removed in the formation of a neutral palladium complex leaving the ligand with a net charge in the square planar complex. ${ }^{7}$. The present study is the first report of an X-ray single crystal structure determination of a complex with the neutral ligand.

Previous $X$-ray powder diffraction studies show that $\mathrm{CuL}_{2}\left(\mathrm{ClO}_{4}\right)_{2}$ $\left(L=2,2^{\prime}\right.$ bitpyridylamine $)$ is isomorphous with $\mathrm{ZnL}_{2}\left(\mathrm{ClO}_{4}\right)_{2}$ in which zinc is presumably in a tetrahedral environment. 5 Infrared and electronic spectral studies have indicated, however, that whlle the perchlorate anion is not coordinated, there is no evidence for gross departure from a planar geometry about the copper. ${ }^{4,5}$. Of additional interest is a comparison between this structure and that of the palladium complex, revealing two, quite different, means of relieving the steric strain in trans-coordinated ligands of this type. 


\section{Experimental}

Bis (2,2'bipyridylamine) copper(II) perchlorate was prepared as. follows: 0.013 moles of $\mathrm{Cu}\left(\mathrm{ClO}_{4}\right)_{2} \cdot 6 \mathrm{H}_{2} \mathrm{O}$ was dissolved in $12.5 \mathrm{ml}$ of absolute ethanol. To this was added a solution of 0.027 moles 2,21 bipyridylamine dissolved in $175 \mathrm{ml}$ of acetone. Deep blue microcrystals precipated immediately. The copper complex was then recrystallized using hot water. On slow cooling very small blue plate-like.crystals and larger rod-like crystals were formed. Although the latter crystals did not have well formed faces, they were found to be single crystals and were used for this investigation. Weissenberg photographs taken of the plate-like crystals indicate that the unit cells of the two types of crystals are identical. Preliminary Weissenberg photographs exhibited $2 / m$ Laue symmetry, indicating a monoclinic space group.

Crystal Data. $--\mathrm{C}_{20} \mathrm{H}_{18} \mathrm{~N}_{6} \mathrm{CuCl}_{2}{ }^{\mathrm{O}} 8, \underline{M}=604.9$, monoclinic, $\underline{a}=9.35 \pm 0.02, \underline{b}=12.88 \pm 0.01, \underline{c}=19.69 \pm 0.02 \AA, \beta=102.8 \pm 0.3^{\circ}$, $\underline{V}=2313 \AA^{3}, \underline{D}_{m}=1.74 \mathrm{~g} / \mathrm{cc}, \underline{D}_{c}=1.74 \mathrm{~g} / \mathrm{cc}, \underline{z}=4, \underline{F}(000)=1288 \mathrm{e}$, $\mu=12.8 \mathrm{~cm}^{-1}$, for Mo $k \alpha$ radiation. Space group $c c\left(c_{s}^{4}\right)$ or $c 2 / c\left(c_{2 h}^{6}\right)$ from systematic absences $\underline{h k} \ell$ for $\underline{h}+\underline{k}=2 n+1$, and $\underline{h} \underline{\ell}$ for $\ell=2 n+1$.

The unit cell parameters were determined from the $2 \theta$ values of high order reflections whose centers were determined from left-right, top-bottom beam splitting on a previously aligned Hilger-Watts. four circle diffractometer. (Mo $K \alpha$ radiation, $\lambda=.7107 \AA$ )

For data collection, a crystal having approximate dimensions $0.2 \times 0.12 \times 0.12 \mathrm{~mm}$ was mounted with the elongated direction (b axis) along the spindle axis of the gonlometer head. Data were collected 
at room temperature utilizing an automated Hilger-Watts four circle diffractometer equipped with a scintillation counter and using $\mathrm{Zr}$ filtered Mo Ka radiation. Wi thin a $2 \theta$ sphere of $40^{\circ}$, all data in each of two octants were recorded using a $\theta-2 \theta$ scan technique. The steps were $0.01^{\circ}$ in $\theta$ and the counting time per step was 0.4096 sec. The symmetric scan range consisted of fifty steps plus two steps per degree $2 \theta$. Stationary crystal, stationary counter background counts of one half the total scan time were made at the beginning and end of each scan.

As a general check on crystal and electronic stability, the intensities of three large reflections (222, 006, and 131) were remeasured periodically during the data collection, period. No significant decrease in intensities was detected during the data collection period for these intensities and therefore no correction was made for crystal decomposition.

The intensity data were corrected for Lorentz-polarization effects, but no correction was made for absorption since $\mu=12.80 \mathrm{~cm}^{-1}$, wi th associated maximum and minimum transmission factors of 0.86 and 0.77 .

Equivalent reflections were averaged to yield 2078 independent intensities. The estimated error in the intensity was calculated from

$$
[\sigma(I)]^{2}=\underline{c}_{T}+\underline{c}_{B}+\left(\underline{k}_{T} \underline{c}_{T}\right)^{2}+\left(\underline{K}_{B} \underline{c}_{B}\right)^{2}
$$


where $\underline{c}_{T}$ and $\underline{c}_{B}$ are the total count and background count, respectively. $\underline{K}_{T}$ and $\underline{K}_{B}$ are the fractional random errors in $\underline{c}_{T}$ and $\underline{c}_{B}$, respectively, and were both assigned values of .05 . The estimated standard deviation in the structure factor was calculated from $\sigma(I)$ by the finite difference method. ${ }^{8}$. Of all the independent reflections measured, 1167 had $I \geq 3 \sigma(I)$ and these were considered observed.

Solution and Refinement of the Structure

A Patterson map ${ }^{9}$ was computed and analysis indicated that the probable space group was $\mathrm{C}_{2} / \mathrm{c}$ with the copper atom occupying a position of two-fold crystallographic symmetry. The centrosymmetric space group was also indicated by a statistical test ${ }^{10}$ and later confirmed by successful refinement in this space group. Initial positions for the copper and chlorine atoms were determined from this Patterson map and the remaining atoms were found from successive electron density map calculations. The atoms were refined first isotropically and then, since evidence of anisotropic motion was evident from a difference Fourier map; anisotropically to a final conventional discrepancy factor of $R=9.4 \%$ and a weighted discrepancy factor $R_{\omega}=\left[\Sigma \omega\left(\left|F_{0}\right|-\left|F_{c}\right|\right)^{2} / \Sigma \omega\left|F_{0}\right|^{2}\right]^{\frac{1}{2}}=9.4 \%$. Scattering factors used were those of Hansen et al. " with copper and chlorine atoms modified for the real and imaginary parts of anomolous dispersion. 12 During the latter stages of refinement, 31 reflections where $\left|F_{0}\right| \leq \frac{1}{2}\left|F_{c}\right|$ were removed and the weights were checked by an $\overline{\omega \Delta}^{\overline{2}}$ plot against $\left|\bar{F}_{0}\right|$; and subsequently, slightly modified to give a more constant value of 
$\overline{a D^{2}}$. A difference electron density map at this stage indicated that all nonhydrogen atom positions had been accounted for. It was impossible to determine hydrogen positions from the map; however, the positions of the aromatic hydrogen positions were calculated assuming a benzoid geometry and treated as parameters in the final least squares refinement. A carbon hydrogen distance of $1.05 \AA$ was assumed and the atoms were assigned an isotropic temperature factor of $6.0 \AA^{2}$.

The final standard deviation for an observation of unit weight $\left[\Sigma \omega \Delta^{2} /(N O-N V)\right]^{\frac{1}{2}}$, where $\Delta=\left|F_{o}\right|-\left|F_{c}\right|$, NO is the number of observations (1135) and NV is the number of variables (168), was 0.97 electrons. During the final cycle of least squares the largest shift in any parameter was less than 0.2 times its standard deviation. The final values of positional and thermal parameters are listed in Tables. I and II, along with their standard deviations as derived from the inverse matrix of the final least squares cycle. ${ }^{13}$ In Figure 1 are listed the magnitudes of the observed and calculated structure factors in electrons $x$ 10. The computer drawings used throughout the text were produced by OR TEP. ${ }^{14}$ Distances and angles with their standard derivations were calculated using the variance-covariance matrix from the final least squares cycle and OR FFE program. 15

\section{Description of the Structure}

The structure of bis (2,2'bipyridylamine) copper(II) perchlorate consists of discrete monomers of the complex in which each copper atom is bound in a bidentate fashion to two ligand groups. There 
Table I. Final atomic coordinates ${ }^{a}$ with estimated standard deviations ${ }^{b}$ in parenthesis.

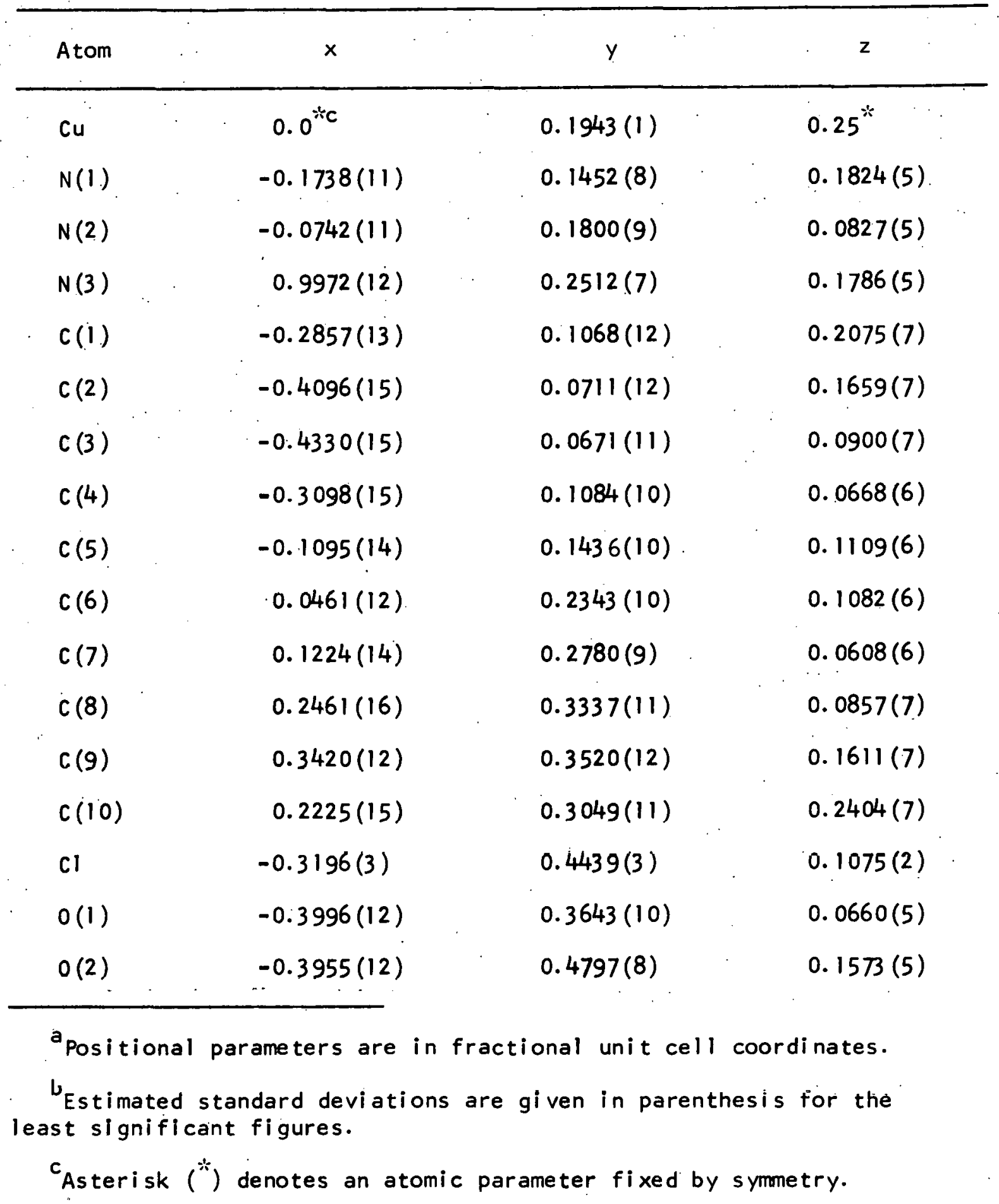


Table I (continued)

\begin{tabular}{cccc}
\hline Atom & $x$ & $y$ & $z$ \\
\hline $0(3)$ & $-0.2961(14)$ & $0.5263(8)$ & $0.0650(6)$ \\
\hline$(4)$ & $-0.1834(12)$ & $0.4027(9)$ & $0.1422(6)$ \\
$H(1)^{d}$ & -0.275 & 0.105 & 0.266 \\
$H(2)$ & -0.499 & 0.043 & 0.189 \\
$H(3)$ & -0.521 & 0.040 & 0.060 \\
$H(4)$ & 0.316 & 0.111 & 0.007 \\
$H(7)$ & 0.082 & 0.267 & 0.005 \\
$H(8)$ & 0.306 & 0.367 & 0.050 \\
$H(9)$ & 0.398 & 0.394 & 0.179 \\
$H(10)$ & 0.263 & 0.314 & 0.264 \\
\hline
\end{tabular}

'Positions calculated for aromatic hydrogen atoms. The number of the hydrogen atom corresponds to the carbon atom to which it is bonded. All hydrogen atoms have been assigned an isotropic temperature factor of $6.0 \AA$. 
Table II. Anistropic temperature ${ }^{\text {a }}$ factors with standard deviations in parentheses

\begin{tabular}{|c|c|c|c|c|c|c|}
\hline Atom & $\beta_{11}$ & $\beta_{22}$ & $\beta_{33}$ & $\beta_{12}$ & $\beta_{13}$ & $\beta_{23}$ \\
\hline $\mathrm{Cu}$ & $706(30)$ & $604(19)$ & $136(6)$ & $00^{*}$ & $135(12)$ & $00^{*}$ \\
\hline$N(1)$ & $839(156)$ & $412(73)$ & $167(30)$ & $-56(95)$ & $132(57)$ & $-10(42)$ \\
\hline N (2) & $966(167)$ & $763(101)$ & $2.15(34)$ & $-358(114)$ & $289(64)$ & $103(50)$ \\
\hline$N(3)$ & $974(170)$ & $518(83)$ & $191(32)$ & $11(106)$ & $224(61)$ & $46(45)$ \\
\hline$c(1)$ & $637(193)$ & $571(109)$ & $334(51)$ & $-213(127)$ & $226(83)$ & $-10(64)$ \\
\hline$c(2)$ & $1061(230)$ & $796(132)$ & $305(51)$ & $-33(160)$ & $280(92)$ & $43(73)$ \\
\hline$c(3)$ & $1016(207)$ & $728(123)$ & $252(45)$ & $-222(146)$ & $196 .(80)$ & $-47(65)$ \\
\hline$c(4)$ & $1033(211)$ & $410(104)$ & $243(43)$ & $-117(131)$ & $-31(83)$ & $-111(57)$ \\
\hline$c(5)$ & $1066(209)$ & $353(92)$ & $220(4 I)$ & $-66(120)$ & $188(77)$ & $32(56)$ \\
\hline$c(6)$ & $399(143)$ & $485(95)$ & $176(37)$ & $69(111)$ & $68(59)$ & $-14(52)$ \\
\hline$c(7)$ & $800(177)$ & $376(93)$ & $221(39)$ & $-78(1.16)$ & $200(71)$ & $52(52)$ \\
\hline$c(8)$ & $1174(231)$ & $467(112)$ & $319(50)$ & $49(136)$ & $303(87)$ & $3(61)$ \\
\hline$c(9)$ & $851(194)$ & $730(117)$ & $259(45)$ & $-140(135)$ & $256(79)$ & $11(64)$ \\
\hline$c(10)$ & $950(200)$ & $523(103)$ & $338(50)$ & $-299(139)$ & $236(86)$ & $134(69)$ \\
\hline Cl & $984(51)$ & $527(27)$ & $208(10)$ & $-97(32)$ & $210(20)$ & $3(14)$ \\
\hline $0(1)$ & $1942(199)$ & $1260(113)$ & $328(38)$ & $-763(130)$ & $234(70)$ & $-331(58)$ \\
\hline $0(2)$ & $2056(199)$ & $831(92)$ & $402(41)$ & $3(121)$ & $567(79)$ & $-49(53)$ \\
\hline $0(3)$ & $2446(240)$ & $785(98)$ & $633(54)$ & $349(130)$ & $744(99)$ & $369(63)$ \\
\hline $0(4)$ & $1176(178)$ & $893(100)$ & $570(51)$ & $245(120)$ & $109(76)$ & $176(60)$ \\
\hline
\end{tabular}

$a_{\beta^{\prime}} s \times 10^{5}$; the form of the anisotropic temperature factor is $\exp \left[-\left(\beta_{11} h^{2}+\beta_{22} k^{2}+\beta_{33} \ell^{2}+2 \beta_{12} h k+2 \beta_{13} h \ell+2 \beta_{23} k \ell\right)\right]$. 
Figure 1. Observed and calculated structure factors $(x 10)$ for bis (2,2'bipyridylamine) copper(11) perchlorate 


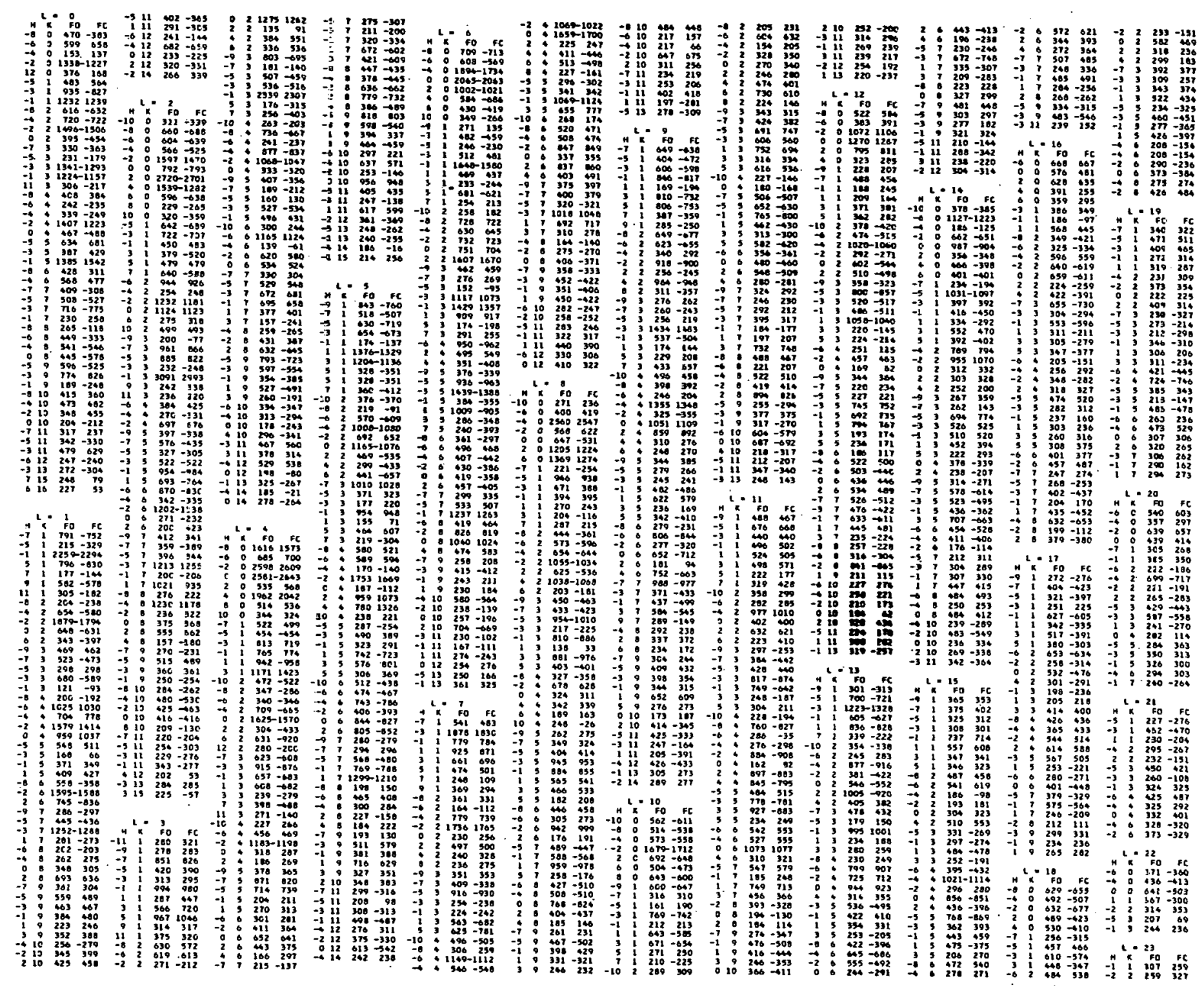


is no indication of coordination of the perchlorate group, the closest oxygen copper distance being $3.6 \AA$.

The copper atom lies on the grystallographic two-fold axis and therefore the exact point group symmetry of the cation is $C_{2}$. However, the geometry can best be described as a distorted tetrahedron (Figure 2) with point group symmetry being nearly $\mathrm{D}_{2 \mathrm{~d}}$ if only the atoms bound to the copper are considered. The significant bond distances and angles are given in Table III, with signiflcant nonbonded distances in Table IV. Figure 4 is a stereoscopic view of the unit cell.

The two independent copper-nitrogen distances are somewhat different, 1.94 (1) vs 1.99 (1) $\AA$. This difference probably results from steric effects evident in other parts of the molecule and has been observed in a similar 2,2'bipyridyl complex of copper(II). ${ }^{16}$ The copper-amine nitrogen distance is $3.19 \AA$, indicating no appreciable interaction between these atoms. The bond distances within the 2,2'bipyridylamine ligand are similar to those reported in the palladium complex involving this ligand. The closest approach between carbon atoms of different ligands is $3.06 \AA$ between $c(1)$ and $c(10)$ (Table IV). The distance between the associated hydrogen atoms is $2.76 . \AA$ indicating that the geometry of the cation has reduced interligand crowding. The mean carbon-carbon and carbon-nitrogen bond distances in the pyridine groups of the ligand are 1.40 and $1.35 \AA$ respectively. These averages agree quite well with those reported for pyrldine. 17 There is distortion about the bridging nitrogen as evidenced by the 
Figure 2. A view displaying the pseudotrahedral geometry of the bis $(2,2$ 'bipyridylamine) copper (II) moiety 


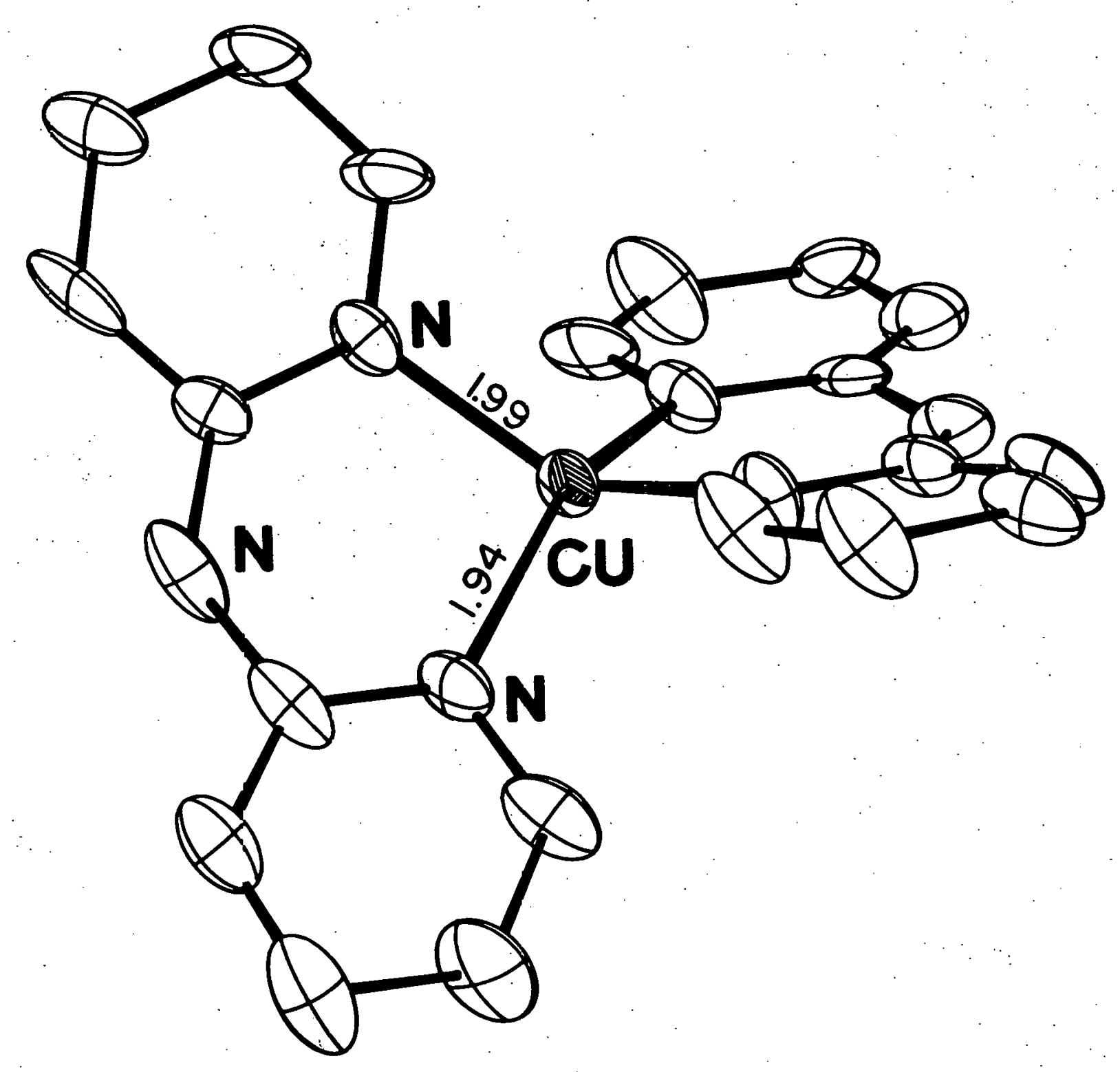


Table III. Bond lengths (angstroms) and bond angles (degrees) with. estimated standard deviations in parentheses

\begin{tabular}{llll}
\hline & Distances & \\
$N(1)-C(1)$ & $1.35(1)$ & $N(2)-C(5)$ & $1.41(1)$ \\
$C(1)-C(2)$ & $1.33(2)$ & $N(2)-C(6)$ & $1.32(1)$ \\
$C(2)-C(3)$ & $1.45(2)$ & & \\
$C(3)-C(4)$ & $1.44(2)$ & $C u-N(1)$ & $1.94(1)$ \\
$C(4)-C(5)$ & $1.32(2)$ & $C u-N(3)$ & $1.99(1)$ \\
$C(5)-N(1)$ & $1.37(2)$ & & \\
$C(6)-C(7)$ & $1.41(2)$ & & \\
$C(7)-C(8)$ & $1.35(2)$ & & $1.41(1)$ \\
$C(8)-C(9)$ & $1.47(2)$ & $C 1-0(1)$ & $1.41(1)$ \\
$C(9)-C(10)$ & $1.41(2)$ & $C 1-0(2)$ & $1.39(1)$ \\
$C(10)-N(3)$ & $1.33(1)$ & $C 1-0(4)$ & $1.40(1)$ \\
$C(6)-N(3)$ & $1.37(2)$ & &
\end{tabular}

Angles

$\begin{array}{llll}N(1)-C(1)-C(2) & 123(1) & C(5)-N(2)-C(6) & 134(1) \\ C(1)-C(2)-C(3) & 122(1) & N(3)-C u-N(1) & 95.6(4) \\ C(2)-C(3)-C(4) & 112(1) & N(1)-C u-N(1), a & 142.0(6) \\ C(3)-C(4)-C(5) & 123(1) & N(3)-C u-N(3) 1: & 137.3(6) \\ C(4)-C(5)-N(1) & 123(1), & 0(1)-C 1-O(2) & 110(1) \\ C(5)-N(1)-C(1) & 117(1) & 0(1)-C 1-O(3) & 110(1) \\ C(6)-C(7)-C(8) & 120(1) & 0(1)-C 1-O(4) & 108(1)\end{array}$

aprimed atom numbers refer, to atoms primed in Figure 3. 
Table III (continued)

\begin{tabular}{llll}
\hline & & \\
$C(7)-C(8)-C(9)$ & $123(1)$ & Angles & $110(1)$ \\
$C(8)-C(9)-C(10)$ & $113(1)$ & $0(2)-C 1-0(4)$ & $109(1)$ \\
$C(9)-C(10)-N(3)$ & $118(1)$ & $0(3)-C 1-0(4)$ & $109(1)$ \\
$N(3)-C(8)-C(9)$ & $118(10)$ & & \\
$C(10)-N(3)-C(6)$ & $122(1)$ & & \\
\hline
\end{tabular}


Table IV. Nonbonded interatomic distances (angstroms)

\begin{tabular}{llll}
\hline$N(2) \ldots O(1)$ & $3.81(2)$ & $C(1) \ldots C\left(10^{I}\right)^{a}$ & $3.06(1)$ \\
$N(2) \ldots O(2)$ & $5.29(2)$ & $H(1) \ldots H\left(10^{I}\right)$ & 2.76 \\
$N(2) \ldots O(3)$ & $4.89(2)$ & $C u \ldots O(1)$ & $5.09(1)$ \\
$N(2) \ldots O(4)$ & $3.34(2)$ & $C u \ldots O(2)$ & $5.24(1)$ \\
$C\left(10^{I}\right) \ldots C\left(1^{I I I}\right)$ & $3.88(2)$ & $C u \ldots O(3)$ & $5.90(1)$ \\
$C\left(9^{I}\right) \ldots N\left(1^{I I I}\right)$ & $3.82(2)$ & $C u \ldots O(4)$ & $3.61(1)$ \\
$N\left(3^{I}\right) \ldots C\left(2^{I I I}\right)$ & $4.12(2)$ & $C u \ldots C l$ & 4.84 \\
$C\left(6^{I}\right) \ldots C\left(3^{I I I}\right)$ & $4.32(2)$ & $C u \ldots C u$ & $7.95(1)$ \\
$C\left(8^{I}\right) \ldots C\left(5^{I I I}\right)$ & $4.07(2)$ & $C u \ldots N(2)$ & $3.19(1)$ \\
\hline
\end{tabular}

${ }^{a}$ The following symmetry related positions are referred to: I - $x, y, \frac{1}{2}-z$; II $-\frac{1}{2}+x, \frac{1}{2}+y, z$; III $-\frac{1}{3}-x, \frac{1}{3}+y, \frac{1}{2}-z$. 
Figure 3. Projection of the bis (2,2'bipyridylamine) copper(II) moiety on the ac plane, with some relevant distances 


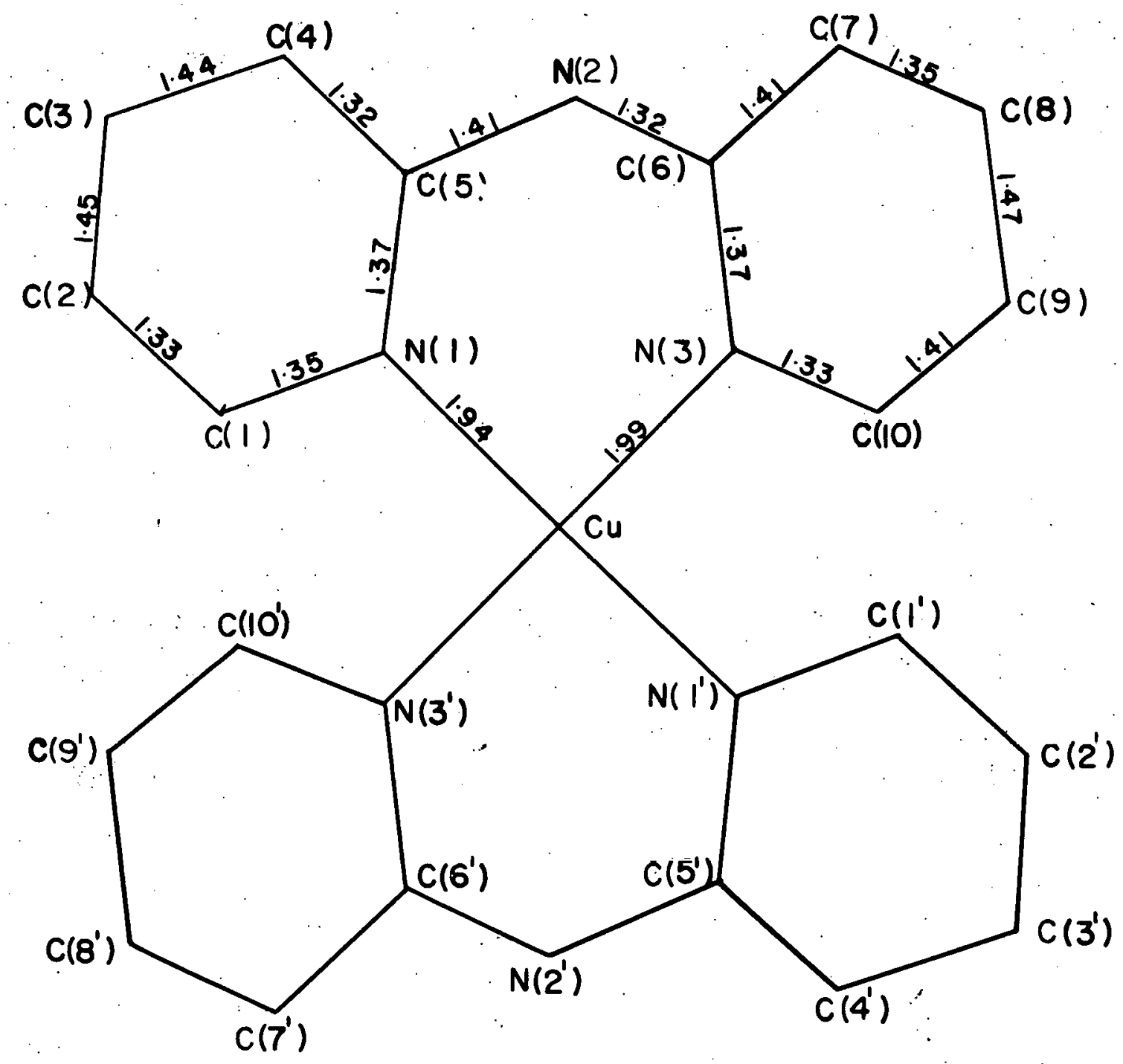


significant difference between the two carbon-nitrogen distances,

\subsection{1 and $1.32 \AA$.}

Least squares plane calculations (Table V) indicate that the individual pyridine rings are essentially planar but the ligand as a whole is not with a $9.6^{\circ}$ angle between the normals to the least squares planes of the pyridine rings.

The dihedral angle between the planes defined by $N(1), \mathrm{Cu}, \mathrm{N}(3)$, and $\mathrm{N}(1)^{\prime}, \mathrm{Cu}, \mathrm{N}(3)^{\prime}$ is $55.6^{\circ}$, while the dihedral angle between planes defined by $N(1), \mathrm{Cu}, \mathrm{N}(1)^{\prime}$, and $N(3), \mathrm{Cu}, \mathrm{N}(3)^{\prime}$, is $92.6^{\circ}$. The first dihedral angle is somewhat closer to the $90^{\circ}$ angle expected for the tetrahedral geometry than the $0^{\circ}$ angle expected for the square planar configuration. The chelate ring formed by $\mathrm{Cu}, \mathrm{N}(1), \mathrm{C}(5), \mathrm{N}(2), \mathrm{C}(6)$, $N(3)$ is in a boat configuration with $C u$ and $N(2)$ below the level of the plane defined by the other four atoms (Table V).

There appears to be no significant hydrogen bonding in the structure, the closest approach between likely atoms being $3.3 \AA$ between $N(2)$ and $O(4)$ of the perchlorate group. The location of the perchlorate group relative to the amine nitrogen (Figure 4 ) would lead one to discount the importance of hydrogen bonding.

The cations of the complex are stacked in the $y$ direction of the unit cell with the perchlorate sandwiched between. alternate layers of the pyridyl rings (Figure 4 ). The closest approach between two pyridyl rings of different cations is $3.82 \AA$ (Table IV). The closest approach between two copper atoms is $7.95 \AA$. 
Table V. Least squares planes ${ }^{a}$

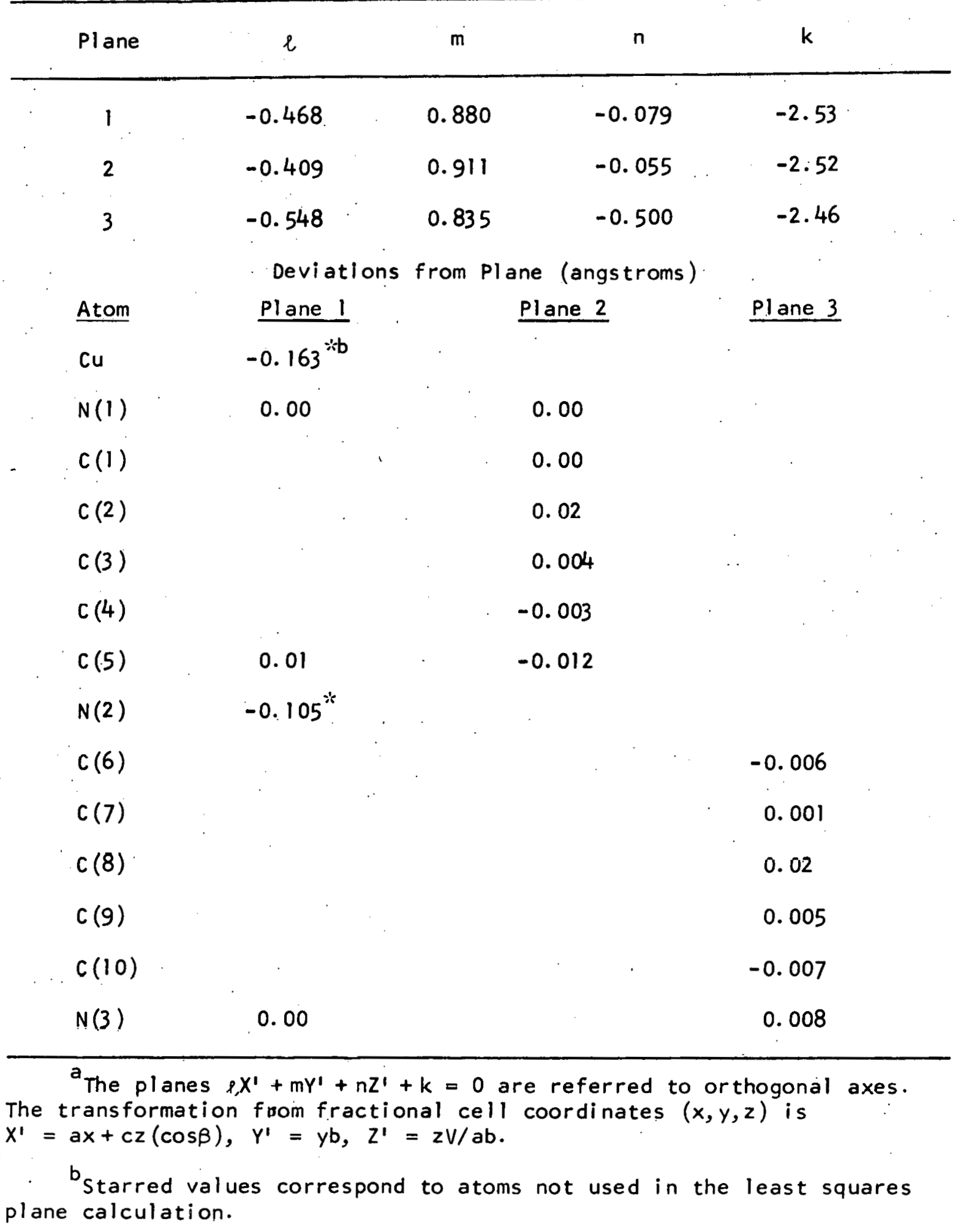




\section{Discussion}

The geometry about the copper in this complex can best be described as a tetrahedron whlch has been compressed along the crystallographlc two-fold axis to give the observed geometry; this geometry probably results from steric interaction between the ligands.

The original reflectance spectra was interpreted as resulting from a square planar or tetragonally distorted geometry. In a recent analysis of the spectra, Lancaster proposed that the reflectance spectra would be consistent with a nonplanar geometry if the high frequency peak at $18.11 \mathrm{KK}$ were not, in fact, a $d \leftrightarrow d$ transition, but of some other origin such as charge transfer. ${ }^{5}$ Dudley et al. ${ }^{18}$ have reported the single crystal polarized spectra, however, and conclude that the peak at $18.11 \mathrm{KK}$ is a $\mathrm{d} \longmapsto \mathrm{d}$ transition and, from the electronic properties, propose that the observed steriochemistry results from a tetrahedrally distorted square planar geometry.

It is of interest to compare the structure of the bipyridylamine copper complex wi th that of the bipyridylaminato palladium complex. Both crystallize in the same space group, but the palladium occupies a $\bar{T}$ symmetry site, while the copper atom is on a two-fold site. The mechanism invoked to reduce the steric hindrance between the two ligands in each complex is quite different. In the palladium complex the ligand bends about the bridging nitrogen such that the dihedral angle between the pyridine rings is $38.2^{\circ}$, while the coordination geometry is strictly square planar. In the copper complex, however, a more tetrahedral geometry is assumed, allowing the ligand as a whole 
to be nearly planar with only a $9.8^{\circ}$ dihedral angle between the pyridine rings. The pyridine rings are somewhat less distorted from planarity in the copper relative to the palladium moiety, maximum deviations being .02 in the former compared to .04 $\AA$ in the latter. There is, however, more variation in the carbon-bridging nitrogen distances in the copper complexes relative to those in the palladium moiety: 1.41 and 1.32 vs 1.37 and $1.33 \AA$, respectively, and the $\mathrm{C}-\mathrm{N}-\mathrm{C}$ angle in the copper salt $\left(134^{\circ}\right)$ shows greater distortion from the expected value than that found in the more aromatic palladium compound $\left(123^{\circ}\right)$ 
Figure 4. Stereoscopic view of the packing in the unit cell of bis (2,2'bipyridylamine) copper(II) perchlorate. The origin is at the bottom left hand corner of the enclosure, and $z$ lies across the page, $x$ upward, and $y$ out of the page 

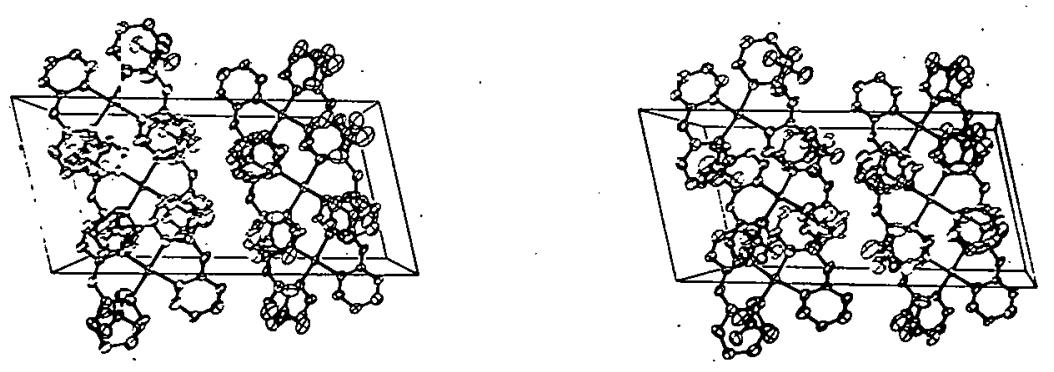
THE STRUCTURE OF DI (IODOBIS $(2,2$ 'BIPYRIDYLAMINE)

COPPER (II)) . IODIDE PERCHLORATE

Introduction

The crystal and molecular structure of di (i.odobis (2, 2'bipyridylamine) copper(II)) iodide perchlorate was undertaken to provide additional structural data on the coordination of 2,2'bipyridylamine with copper(II) in the presence of various anions. The compound $\left(\mathrm{CuL}_{2} \mathrm{I}\right)_{2} \mathrm{IClO}_{4}$ was prepared by the method reported by McWhinnie ${ }^{4}$ for $\mathrm{CuL}_{2} \mathrm{IClO}_{4}$. A recent study of the visible, infrared and electron spin resonance spectra of the latter compound indicated a five coordinate copper(II) species and a square pyramidal geometry was postulated. 5

\section{Experimental}

The preparation given by McWhinnie for $\mathrm{CuL}_{2} \mathrm{IClO}_{4}$ was followed; 4 al though the reaction appeared to proceed as had been reported and small dark green crystals similar to those reported by McWhinnie were obtained, analysis, later confirmed by the single crystal $x$-ray investigation, indicated a greater percentage of iodine $(28.5 \%$ compared to $20 \%$ ) than expected for the simple stoichiometry $\mathrm{CuL}_{2} \mathrm{IClO}_{4}$. The crystals, however, displayed a reflectance spectra similar to that reported by McWhinnie.

Crystal Data. $-\mathrm{C}_{40} \mathrm{~N}_{12} \mathrm{H}_{36} \mathrm{Cu}_{2} \mathrm{~T}_{3} \mathrm{ClO}_{4}, \mathrm{M}=1292 \mathrm{~g} / \mathrm{m}$, monoclinic, $\underline{a}=19.21 \pm .01, \underline{b}=13.47 \pm .01, \underline{c}=19.50 \pm .05 \AA, \beta=11.88 \pm .15^{\circ}$, $V=4687 \AA^{3}, D_{m}=1.85 \mathrm{~g} / c c, \underline{z}=4, D_{c}=1.83 \mathrm{~g} / \mathrm{cc}, F(000)=2504 \mathrm{e}$, 
space group $P_{2}, \quad\left(C_{2 h}^{5}\right)$ from systematic absences hol for $\&=2 n+1$ and $0 \underline{k} 0$ for $\underline{k}=2 n+1$, Mo- $K_{\alpha} X$-radiation, $\lambda=.7107 \AA$, $\mu\left(\right.$ Mo $\left.-K_{\alpha}\right)=29.47 \mathrm{~cm}^{-1}$.

The unit cell parameters and their standard deviations were determined by a least squares fit to twelve independent reflection angles whose centers were determined by left-right top-bottom beam splitting on a previously aligned Hilger and Watts four-circle diffractometer. $^{19}$ Any error in the instrumental zero was eliminated by centering the reflection at both $+2 \theta$ and $-2 \theta$. For data collection a crystal having approximate dimensions $0.25 \times 0.25 \times 0.15 \mathrm{~mm}$ was mounted with the $\underline{b}$ axis aligned along the spindle axis of the goniometer.

Data were collected at room temperature utilizing a Hilger and Watts four-circle diffractometer equipped with scintillation counter and using Zr-filtered MoK $\alpha$ radiation. Within a $2 \theta$ sphere of $40^{\circ}$, all data in the $\underline{h k l}$ and $\underline{\bar{h}_{k l}}$ octants were collected using a stationary counter-stationary crystal technique. Intensities were measured by counting at the peak center $\theta\left(\mathrm{hkl}_{\mathrm{f}}\right)$ for ten seconds and subtracting two five-second background counts at $\theta\left(h_{k \ell}\right) \pm\left[0.25+.01 \times \theta\left(h_{k \ell}\right)\right]$. A total of 8477 reflections were measured in this manner. Also 100 reflections covering a range of $\sin \theta / \lambda$ values were remeasured via the step scan method (moving-crystal moving-counter) for later use in a peakheight to stepscan conversion. 20 The plot of the ratio of $I_{\text {integrated }} / I_{\text {peakheight }} \underline{\text { s }} \sin \theta / \lambda$ of these reflections increased 
smoothly from 0.95 at low values of $\sin \theta$ to 1.60 at large values and no chi or phi dependencies were indicated.

As a general check on electronic and crystal stability, the intensity of three large reflections (551, 600, 004) were checked periodically during the data collection. No significant decrease in the intensity of these reflections was observed. The intensities were corrected for Lorentz-polarization effects, but no absorption correction was deemed necessary.

Equivalent reflections were averaged to yield 8259 independent intensities. The estimated error in each intensity was calculated from

$$
[\sigma(I)]^{2}=\underline{c}_{t}+\underline{c}_{b}+\left(\underline{K}_{t} \underline{c}_{t}\right)^{2}+\left(\underline{K}_{b} \underline{c}_{b}\right)^{2}
$$

where $\underline{c}_{t}$ and $\underline{c}_{b}$ are the total and background counts, $\underline{K}_{t}$ and $\underline{K}_{b}$ are estimates for nonstatistical errors in $\underline{c}_{t}$ and $\underline{C}_{b}$ and both were assigned values of .05 . The estimated deviations in the structure factors were calculated from the finite difference method. ${ }^{8}$ of all the measured independent reflections, 3921 had $I \geq 3 \sigma(\tau)$ and these were considered observed and used for the structure determination.

\section{Solution of the structure}

A sharpened Patterson map 21 was computed and initial positions of the two copper atoms and three iodine atoms were determined. A structure factor calculation with these atoms and the chlorine atom produced a conventional discrepancy 
factor of $27.8 \%$. The remaining atoms were located from successive structure factor and electron density map calculations, except for the perchlorate oxygen atoms which could not be located or refined because of severe disorder. With ali the atoms isotropic, the structure refined at $R=12.5 \%$. At this point a difference electron density map indicated anisotropic motion, especially about the copper and iodine atoms. Refinement with these heavy atoms anisotropic produced an $R$ factor of $9.16 \%$. The perchlorate oxygen atoms were taken into account by allowing both the occupation parameter and the isotropic temperature factor of the chlorine to increase. All atoms, except the chlorine, were now refined with anisotropic temperature factors. The discrepancy factor at this stage was $8.80 \%$. A difference electron density map at this stage showed no significant peaks other than some diffuse electron density in the area of the perchlorate.

Hydrogen positions for the aromatic rings were calculated assuming a benzoid structure with a $\mathrm{C}-\mathrm{H}$ distance of $1.05 \AA$. The hydrogen atoms were assigned the isotropic temperature factor of the attached carbon. A final structure factor calculation with these atoms present produced a discrepancy factor $R=\Sigma|| F_{o}|-| F_{c}|! / \Sigma| F_{0} \mid$ of $8.63 \%$ and a weighted discrepancy factor $R_{\omega}=\left[\Sigma \omega\left(\left|F_{o}\right|-\left|F_{c}\right|\right)^{2} / \Sigma \omega\left|F_{0}\right|^{2}\right]^{\frac{1}{2}}$ of $9.8 \%$. The scattering factors used are those of Hansen et al. 11 with copper, iodine, and chlorine modified for the real and imaginary parts of anomalous dispersion. $^{12}$ Due to the large number of variables, block diagonal least squares was used throughout. ${ }^{22}$ In Figure 5 are listed the magnitudes of the observed and calculated structure factors in 


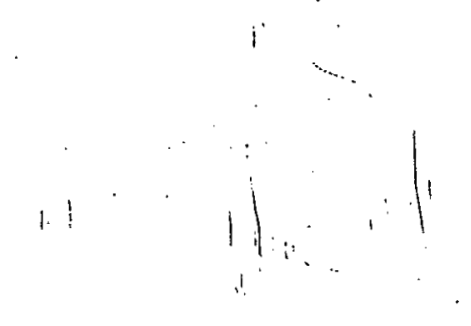

Figure 5. Observed and calculated structure factors $(x 10)$ 


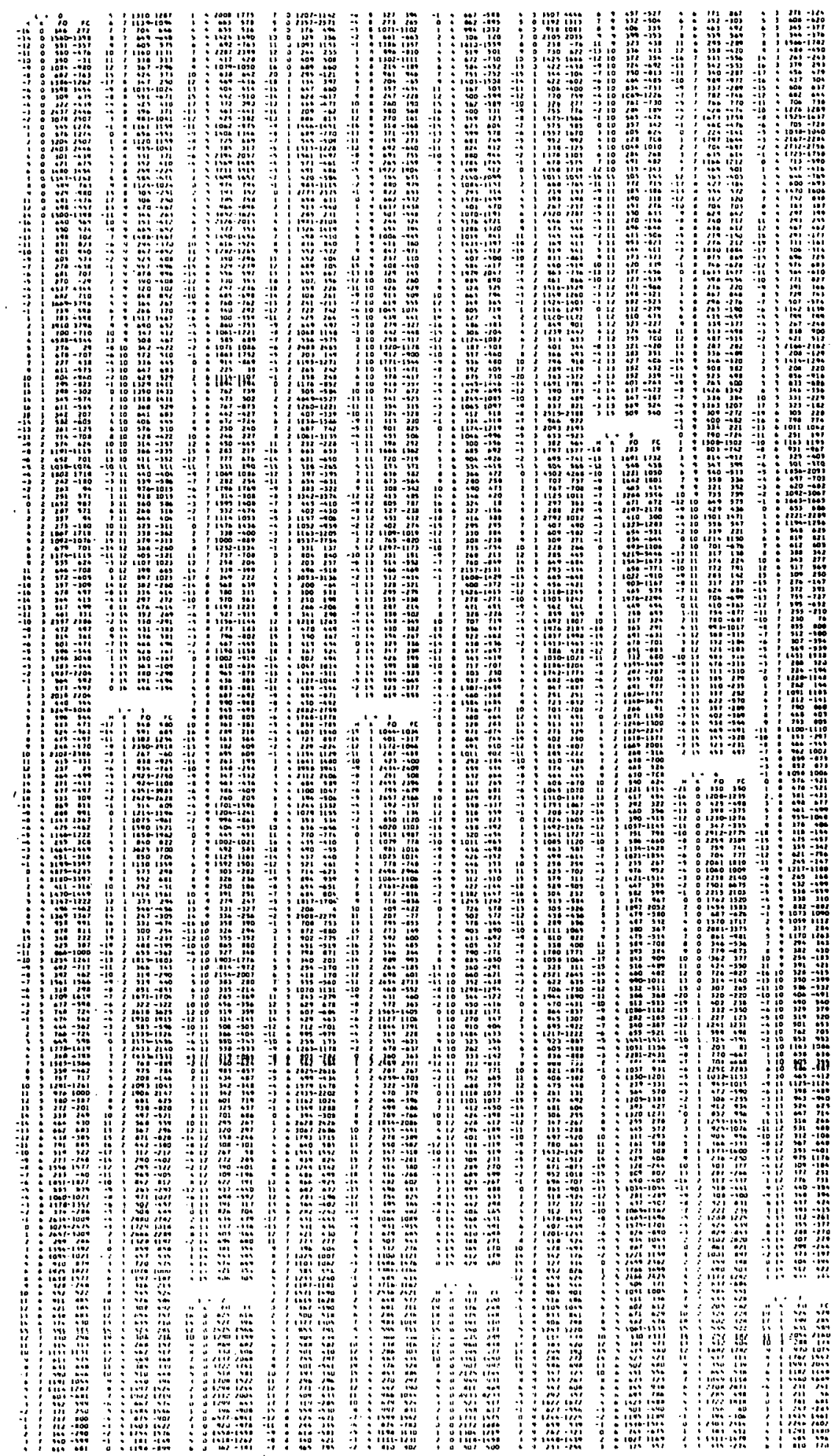




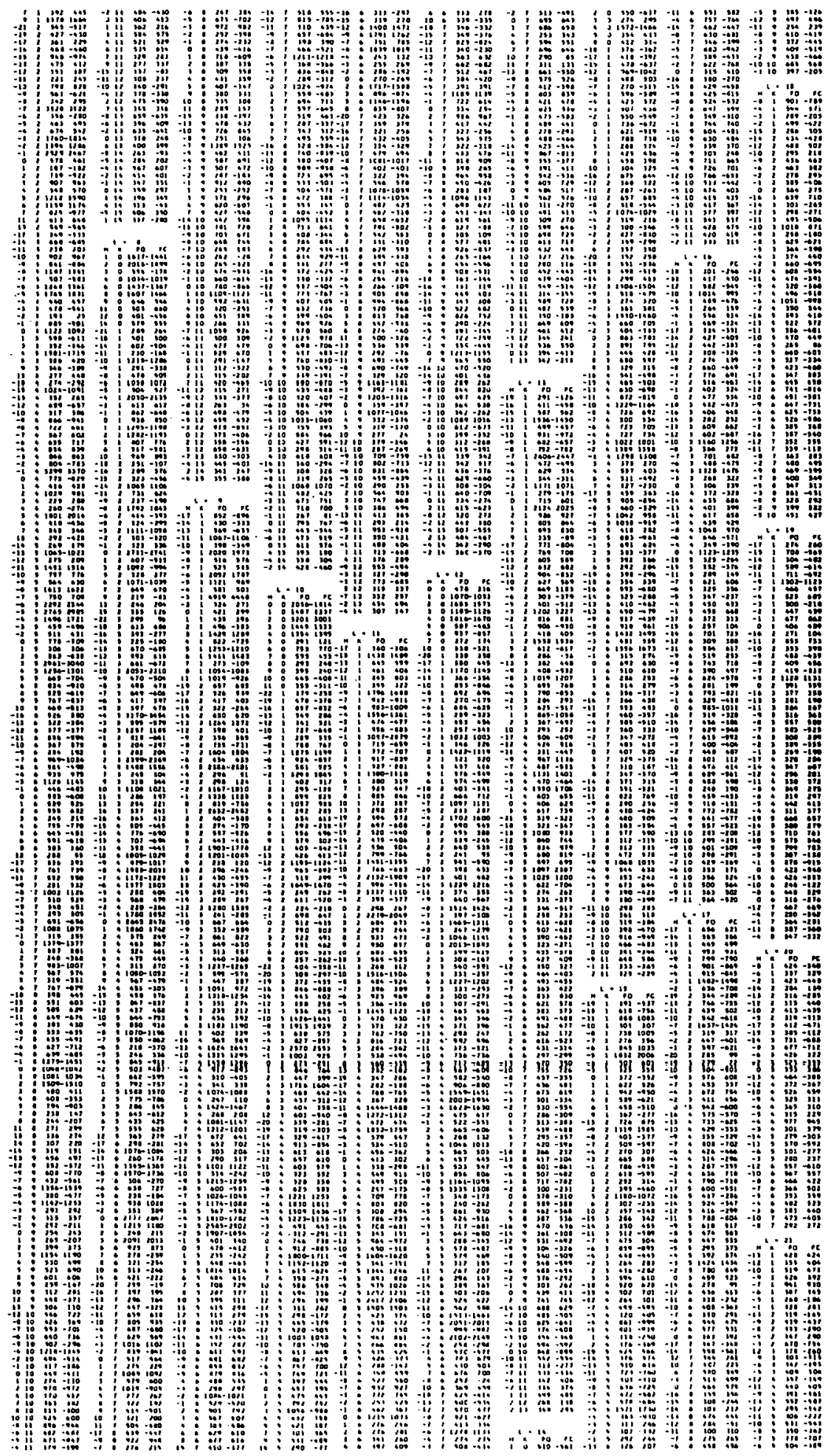

Figure 5 (Continued) 
electrons $\times 10$. The final positional parameters and anisotropic thermal parameters for nonhydrogen atoms are given in Tables VI and VII respectively, and the calculated hydrogen positions are listed in Table VIII.

\section{Description of the Structure and Discussion}

The crystal and molecular structure of di (iodobis (2,2'bipyridylamine) copper(II)) iodide perchlorate consists of two crystallographically-independent five-coordinate copper (II) moieties in the asymmetric unit along with nonbonded iodide and perchlorate anions. The two five-coordinate species are both slightly distorted trigonal bipyramids with no structurally significant differences between them.

The geometry and chemical constitution of chromophore I Is shown in Figure 6 while Figure 7 is a view of the asymmetric unit displaying the two cations, the iodide and the chloride ion of the perchlorate group. Table IX lists all distances and angles about the two copper atoms and the mean distances for chemically equivalent bonds within the ligands. In the following discussion all structural data quoted will be for chromophore I (containing $\mathrm{Cu}(1)$ and $I(1)$ ), with the equivalent data for chromophore II in parenthesis where significant.

The equatorial atoms of each trigonal bipyramid consists of two nitrogen atoms from different bidentate ligands and an iodine atom, all of which lie within .01 $i$ of the equatorial plane containing the copper (TI) ion. The axial positions are occupied by the remaining 
Table VI. Final atomic coordinates with estimated standard deviations in parentheses ${ }^{a}$

\begin{tabular}{|c|c|c|c|c|}
\hline Atom. & $x$ & $y$ & $z$ & \\
\hline$I(1)$ & $.3214(1)$ & $.0794(1)$ & $.4382(1)$ & \\
\hline$I(2)$ & $.033(1)$ & $.4096(1)$ & $.1820(1)$ & \\
\hline$I(3)$ & $-.1767(1)$ & $.3858(1)$ & $.4414(1)$ & \\
\hline $\mathrm{Cu}(1)$ & $.3855(1)$ & $.1652(2)$ & $.3526(1)$ & \\
\hline $\mathrm{Cu}(2)$ & $.0540(1)$ & $.6094(2)$ & $.1897(1)$ & \\
\hline $\operatorname{cl}(1)$ & $.5274(2)$ & $.0373(3)$ & $.1663(2)$ & \\
\hline$N(1)$ & $.3493(9)$ & $.2958(11)$ & $.3739(9)$ & \\
\hline$N(2)$ & $.4554(9)$ & $.3206(12)$ & $.4794(9)$ & \\
\hline$N(3)$ & $.4936(9)$ & $.2246(13)$ & $.4005(10)$ & \\
\hline$N(4)$ & $.3595(9)$ & $.1923(11)$ & $.2420(9)$ & \\
\hline$N(5)$ & $.3180(10)$ & $.0285(11)$ & $.2089(9)$ & \\
\hline$N(6)$ & $.4144(9)$ & $.0300(12)$ & $.3312(9)$ & $\because$ \\
\hline$N(7)$ & $.1226(9)$ & $.5897(11)$ & $.1362(10)$ & \\
\hline$N(8)$ & $.0250(10)$ & $.6185(15)$ & $.0183(10)$ & \\
\hline$N(9)$ & $-.0083(9)$ & $.7087(13)$ & $.1102(10)$ & \\
\hline$N(10)$ & $.1244(11)$ & $.7053(14)$ & $.2642(10)$ & \\
\hline$N(11)$ & $.0870(10)$ & $.6324(14)$ & $.3599(10)$ & \\
\hline$N(12)$ & $-.0143(8)$ & $.6162(12)$ & $.2473(8)$ & \\
\hline$c(1)$ & $.2777(12)$ & $.3233(17)$ & $.3333(14)$ & \\
\hline
\end{tabular}


Table VI (continued)

\begin{tabular}{|c|c|c|c|c|}
\hline Atom & $x$ & $y$ & z & . \\
\hline$c(2)$ & $.2403(13)$ & $.3964(17)$ & $.3488(13)$ & \\
\hline$\therefore \quad c(3)$ & $.2763(14)$ & $.4471(18)$ & $.4151(13)$ & \\
\hline$c(4)$ & $.3485(14)$ & $.4181(18)$ & $.4589(12)$ & \\
\hline$c(5)$ & $.3847(11)$ & $.3427(15)$ & $.4358(11)$ & \\
\hline$c(6)$ & $.5116(11)$ & $.2867(15)$ & $.4594(12)$ & \\
\hline$c(7)$ & $.5854(12)$ & $.3165(17)$ & $.4948(13)$ & \\
\hline$c(8)$ & $.6406(13)$ & $.2873(18)$ & $.4691(16)$ & \\
\hline$c(9)$ & $.6233(13)$ & $.2246(19)$ & $.4093(16)$ & \\
\hline$c(10)$ & $.5463(12)$ & $.1939(18)$ & $.3769(14)$ & \\
\hline$c(11)$ & $.3696(12)$ & $.2852(17)$ & $.2197(13)$ & \\
\hline$c(12)$ & $.3477(13)$ & $.3133(16)$ & $.1426(13)$ & \\
\hline$c(13)$ & $.3131(15)$ & $.2424(18)$ & $.0938(12)$ & \\
\hline$c(14)$ & $.2990(13)$ & $.1514(16)$ & $.1144(10)$ & \\
\hline$c(15)$ & $.3237(10)$ & $.1269(14)$ & $.1889(11)$ & \\
\hline$c(16)$ & $.3763(12)$ & $-.0169(13)$ & $.2705(12)$ & \\
\hline$c(17)$ & $.3882(14)$ & $. \quad-.1188(16)$ & $.2630(14)$ & \\
\hline$c(18)$ & $.4421(14)$ & $-.1669(17)$ & $.3206(15)$ & \\
\hline$c(19)$ & $.4870(15)$ & $-.1172(16)$ & $.3828(14)$ & \\
\hline$C(20)$ & $.4720(14)$ & $-.0212(18)$ & $.3869(15)$ & \\
\hline$c(21)$ & $.1931(12)$ & $.5670(14)$ & $.1738(16)$ & \\
\hline$c(22)$ & $.2368(13)$ & $.5352(19)$ & $.1430(14)$ & \\
\hline
\end{tabular}


Table VI (continued)

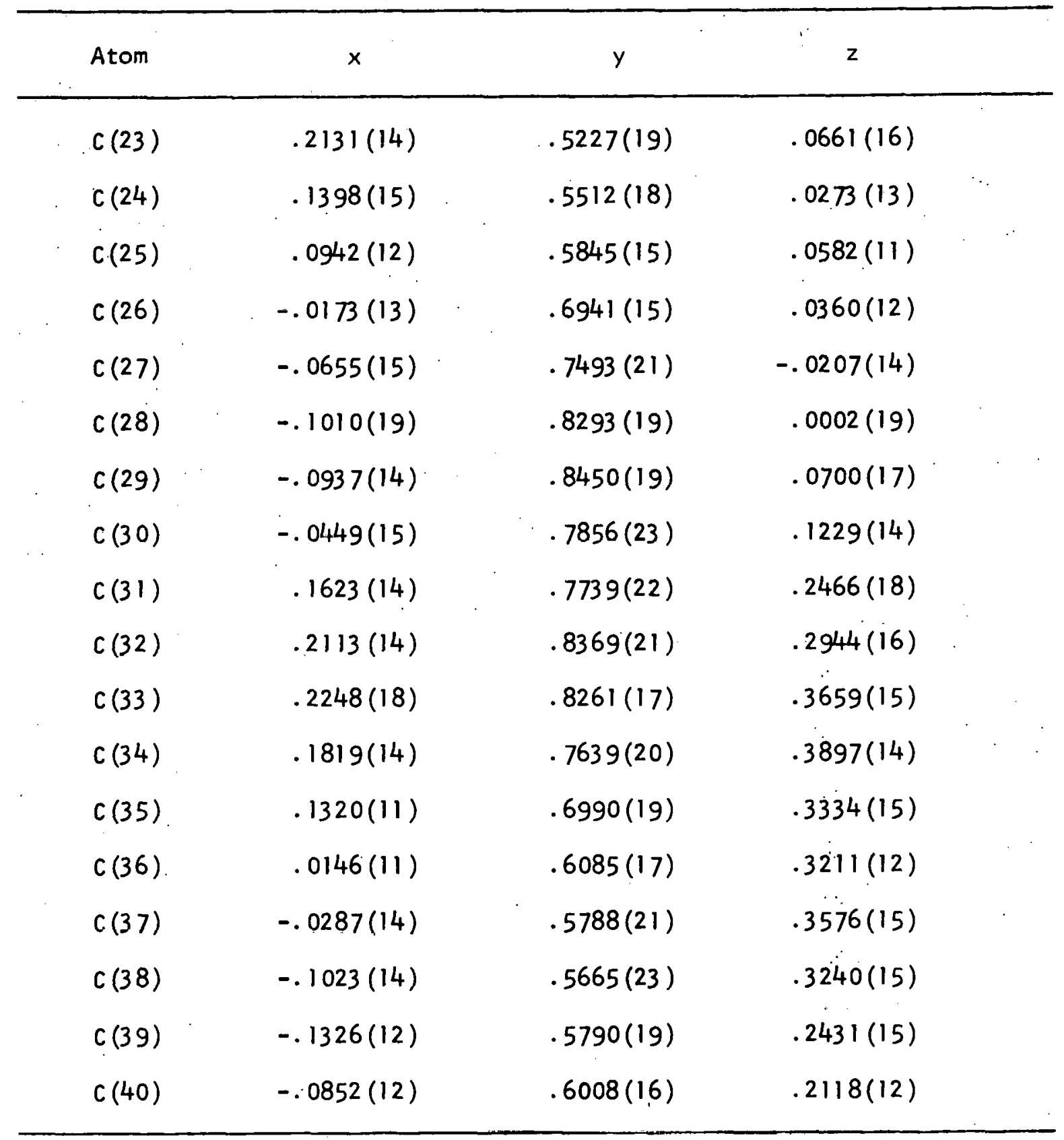


Table VII. Anisotropic thermal parameters ${ }^{a}$

\begin{tabular}{|c|c|c|c|c|c|c|}
\hline A tom & $10^{4} \beta_{11}$ & $10^{4} \beta_{22}$ & $10^{4} \cdot \beta_{33}$ & $10^{4} \beta_{23}$ & $10^{4} \beta_{13}$ & $10^{4} \beta_{12}$ \\
\hline$I(1)$. & $59(1)$ & $64(1)$ & $40(1)$ & $-23(1)$ & $61(12)$ & $-40(2)$ \\
\hline$I(2)$ & $69(1)$ & $55(1)$ & $30(1)$ & $-2(1)$ & $38(1)$ & $-21(2)$ \\
\hline$I(3)$ & $64(1)$ & $95(1)$ & $37(1)$ & $11(2)$ & $38(1)$ & $-10(2)$ \\
\hline $\mathrm{Cu}(1)$ & $34(1)$ & $51(2)$ & $25(1)$ & $0(2)$ & $22(2)$ & $2(2)$ \\
\hline $\operatorname{cu}(2)$ & $37(1)$ & $61(2)$ & $24(1)$ & $-2(2)$ & $28(2)$ & $-9(2)$ \\
\hline $\mathrm{Cl}$ & $6.57(13)^{b}$ & 0 & 0 & 0 & 0 & 0 \\
\hline$N(1)$ & $35(8)$ & $54(11)$ & $28(7)$ & $-28(14)$ & $9(12)$ & $-18(14)$ \\
\hline$N(2)$ & $32(7)$ & $53(12)$ & $31(7)$ & $3(14)$ & $24(12)$ & $13(14)$ \\
\hline$N(3)$ & $35(8)$ & $70(14)$ & $38(8)$ & $19(16)$ & $30(13)$ & $0(16)$ \\
\hline$N(4)$ & $35(7)$ & $37(10)$ & $36(7)$ & $-7(13)$ & $50(12)$ & $-37(13)$ \\
\hline$N(5)$. & $48(8)$ & $33(11)$ & $30(7)$ & $20(13)$ & $22(12)$ & $6(15)$ \\
\hline$N(6)$ & $40(8)$ & $64(13)$ & $26(7)$ & $23(15)$ & $22(12)$ & $17(16)$ \\
\hline$N(8)$ & $49(7)$ & $105(11)$ & $41(16)$ & $-17(13)$ & $57(13)$ & $-12(15)$ \\
\hline$N(9)$ & $26(7)$ & $85(15)$ & $40(8)$ & $-24(18)$ & $16(13)$ & $3(16)$ \\
\hline$N(10)$ & $55(9)$ & $90(16)$ & $29(8)$ & $25(17)$ & $44(14)$ & $-26(19)$ \\
\hline$N(11)$ & $45(9)$ & $93(17)$ & $40(9)$ & $4(14)$ & $42 \cdot(14)$ & $-25(18)$ \\
\hline$N(12)$ & $25(7)$ & $81(14)$ & $24(14)$ & $-27(15)$ & $27(10)$ & $-18(15)$ \\
\hline$c(1)$ & $42(11)$ & $76(19)$ & $50(10)$ & $12(22)$ & $51(17)$ & $30(23)$ \\
\hline$c(2)$ & $46(11)$ & $82(21)$ & $36(9)$ & $19(22)$ & $21(18)$ & $23(24)$ \\
\hline$c(3)$ & $53(11)$ & $101(21)$ & $32(9)$ & $4(22)$ & $51(22)$ & $45(24)$ \\
\hline$c(4)$ & $69(13)$ & $99(21)$ & $34(9)$ & $-5(22)$ & $92(19)$ & $1(25)$ \\
\hline
\end{tabular}


Table VIT. (continued)

\begin{tabular}{|c|c|c|c|c|c|c|}
\hline Atom & $10^{4} \beta_{11}$ & $10^{4} \beta_{22}$ & $10^{4} B_{33}$ & $10^{4} \beta_{23}$ & $10^{4} B_{13}$ & $19^{4} \beta_{12}$ \\
\hline$c(5)$ & $28(8)$ & $60(15)$ & $28(8)$ & $-11(17)$ & $35(14)$ & $-20(18)$ \\
\hline$c(6)$ & $34(9)$ & $48(15)$ & $33(9)$ & $59(19)$ & $-12(15)$ & $-14(18)$ \\
\hline$c(7)$ & $27(9)$ & $77(18)$ & $46(11)$ & $53(22)$ & $-18(16)$ & $-25(20)$ \\
\hline$c(8)$ & $35(11)$ & $75(20)$ & $86(17)$ & $36(29)$ & $40(22)$ & $2(21)$ \\
\hline$c(9)$ & $41(11)$ & $104(24)$ & $75(15)$ & $-3(30)$ & $70(22)$ & $-6(25)$ \\
\hline$c(10)$ & $38(10)$ & $93(21)$ & $51(12)$ & $37(24)$ & $50(19)$ & $16(22)$ \\
\hline$c(11)$. & $34(9)$ & $83(20)$ & $41(11)$ & $-22(22)$ & $24(17)$ & $23(21)$ \\
\hline$c(12)$ & $61(12)$ & $62(17)$ & $43(11)$ & $54(21)$ & $58(19)$ & $28(22)$ \\
\hline$c(13)$ & $89(15)$ & $77(18)$ & $22(9)$ & $-2(20)$ & $43(20)$ & $-24(27)$ \\
\hline$c(14)$ & $60(12)$ & $85(18)$ & $9(7)$ & $-26(18)$ & $28(15)$ & $11(23)$ \\
\hline$c(15)$ & $25(7)$ & $49(14)$ & $34(9)$ & $4(18)$ & $22(14)$ & $-3(16)$ \\
\hline$c(16)$ & $46(10)$ & $32(13)$ & $37(9)$ & $4(17)$ & $45(16)$ & $-18(17)$ \\
\hline$c(17)$ & $64(13)$ & $53(17)$ & $54(12)$ & $-20(22)$ & $60(21)$ & $-19(23)$ \\
\hline$c(18)$ & $66(13)$ & $52(17)$ & $64(14)$ & $33(24)$ & $60(22)$ & $-3(24)$ \\
\hline$c(19)$ & $80(14)$ & $49(17)$ & $48(11)$ & $30(21)$ & $69(21)$ & $55(24)$ \\
\hline$C(20)$ & $62(13)$ & $79(20)$ & $57(13)$ & $62(25)$ & $70(22)$ & $27(25)$ \\
\hline$c(21)$ & $35(10)$ & $29(14)$ & $94(16)$ & $23(22)$ & $64(21)$ & $47(18)$ \\
\hline$c(22)$ & $43(11)$ & $91(20)$ & $50(12)$ & $-9(26)$ & $-4(19)$ & $78(25)$ \\
\hline
\end{tabular}


Table VII. (continued)

\begin{tabular}{|c|c|c|c|c|c|c|}
\hline Atom & $10^{4} \beta_{11}$ & $10^{4} \beta_{22}$ & $10^{4} B_{33}$ & $10^{4} B_{23}$ & $10^{4} \beta_{13}$ & $10^{4} \beta_{12}$ \\
\hline$c(23)$ & $40(11)$ & $107(23)$ & $80(16)$ & $4(29):$ & $87(22)$ & $-5(25)$ \\
\hline$c(24)$ & $82(15)$ & $73(18)$ & $41(11)$ & $-31(22)$ & $92(21)$ & $3(26)$ \\
\hline$c(25)$ & $41(9)$ & $51(14)$ & $24(8)$ & $30(17)$ & $18(14)$ & $24(19)$ \\
\hline$c(26)$ & 49 (11) & $48(15)$ & $33(9)$ & $-5(19)$ & $3(17)$ & $-17(20)$ \\
\hline$c(27)$ & $69 .(14)$ & $126(25)$ & $32(11)$ & $49(25)$ & $29(20)$ & $84(31)$ \\
\hline$c(28)$. & $115(20)$ & $64(20)$ & $\log (21)$ & $61(32)$ & $168(35)$ & $52(32)$ \\
\hline$c(29)$ & $56(13)$ & $87(21)$ & $85(16)$ & $6(29)$ & $94(24)$ & $.52(26)$ \\
\hline$c(30)$ & $63(14)$ & $171(32)$ & $31(11)$ & $-26(29)$ & $12(20)$ & $121(33)$ \\
\hline$c(31)$ & $40(11)$ & $135(28)$ & $93(18)$. & $33(35)$ & $85(24)$ & $-29(28)$ \\
\hline$c(32)$ & $49(12)$ & $116(25)$ & $71(16)$ & $80(32)$ & $36(23)$ & $-9(28)$ \\
\hline$c(33)$ & $116(19)$ & $41(17)$ & $55(14)$ & $10(14)$ & $52(27)$ & $-58(29)$ \\
\hline$c(34)$ & $63(13)$ & $111(24)$ & $37(26)$ & $-5(20)$ & $22(20)$ & $22(29)$ \\
\hline$c(35)$ & $20(9)$ & $1.05(22)$ & $59(13)$ & $-60(28)$ & $-13(17)$ & $-1(21)$ \\
\hline$c(36)$ & $31(9)$ & $81(19)$ & $31(9)$ & $-5(20)$ & $23(15)$ & $-28(20)$ \\
\hline$c(37)$ & $49(12)$ & $127(27)$ & $49(13)$ & $-22(28)$ & $28(20)$ & $-42(28)$ \\
\hline$c(38)$ & $48(12)$ & $165(31)$ & $59(14)$ & $28(32)$ & $72(22)$ & $-54(30)$ \\
\hline$c(39)$ & $30(9)$ & $92(21)$ & $61(13)$ & $29(28)$ & $3(18)$ & $-20(22)$ \\
\hline$c(40)$ & $53(11)$ & $69(17)$ & $35(9)$ & $-29(20)$ & $62(17)$ & $-37(22)$ \\
\hline
\end{tabular}


Table VIII. Fractional coordinates and isotropic thermal parameters for calculated hydrogen atoms. The atom number and temperature factor are those of the carbon atom to which it is attached

\begin{tabular}{|c|c|c|c|c|c|}
\hline Atom & $x$ & y & $z$ & & b \\
\hline$H(1)$ & .2490 & .2819 & .2840 & & 4.51 \\
\hline$H(2)$ & .1848 & .4158 & .3124 & & 5.29 \\
\hline$H(3)$ & .2491 & .5065 & .4316 & & 4.32 \\
\hline$H(4)$ & .3767 & .4538 & .5109 & & 4.24 \\
\hline$H(7)$ & .6001 & .3628 & .5427 & & 5.32 \\
\hline$H(8)$ & .6968 & .3136 & .4959 & . & 5.99 \\
\hline$H(9)$ & .6645 & .2003 & .3883 & & 5.53 \\
\hline$H(10)$ & .5306 & .1435 & .3313 & .. & 5.11 \\
\hline$H(11)$ & .3946 & .3508 & .2607 & & 4.14 \\
\hline$H(12)$ & .3592 & .3832 & .1259 & & 4.47 \\
\hline$H(13)$ & .2956 & .2593 & .0362 & & 5.20 \\
\hline$H(14)$ & .2689 & .0981 & .0733 & & 4.62 \\
\hline$H(17)$ & .3559 & -.1578 & .2135 & & 5.06 \\
\hline$H(18)$ & .4493 & -.2452 & .3168 & & 5.68 \\
\hline$H(19)$ & .5318 & -.1536 & .4258 & & 5.11 \\
\hline$H(20)$ & .5055 & .0193 & .4351 & & 4.91. \\
\hline$H(21)$ & .2146 & .5756 & .2326 & & 5.58 \\
\hline$H(22)$ & .2935 & .5172 & .1770 & & 7.15 \\
\hline$H(23)$ & .2488 & .4937 & .0399 & & 5.90 \\
\hline$H(24)$ & .1189 & .5458 & -.0317 & & 5.40 \\
\hline
\end{tabular}


Table VIIT. (continued)

\begin{tabular}{lcccc}
\hline Atom & $x$ & $y$ & $z$ & $B\left(\AA^{2}\right)$ \\
\hline$H(27)$ & -.0757 & .7328 & -.0773 & 6.77 \\
$H(28)$ & -.1349 & .8791 & -.0417 & 7.81 \\
$H(29)$ & -.1249 & .9019 & .0841 & 6.07 \\
$H(30)$ & -.0353 & .8024 & .1793 & 7.92 \\
$H(31)$ & .1540 & .7811 & .1894 & 6.25 \\
$H(32)$ & .2384 & .8934 & .2753 & 7.41 \\
$H(33)$ & .2699 & .8665 & .4056 & 7.19 \\
$H(34)$ & .1850 & .7633 & .4456 & 6.98 \\
$H(37)$ & -.0032 & .5645 & .4157 & 6.00 \\
$H(38)$ & -.1373 & .5487 & .3539 & 6.68 \\
$H(39)$ & -.1912 & .5704 & .2113 & 4.39 \\
$H(40)$ & -.1064 & .6064 & .1528 & \\
\hline & & & & .82 \\
\hline
\end{tabular}




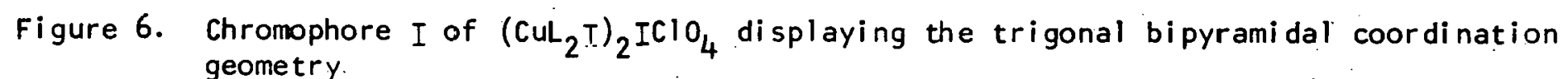




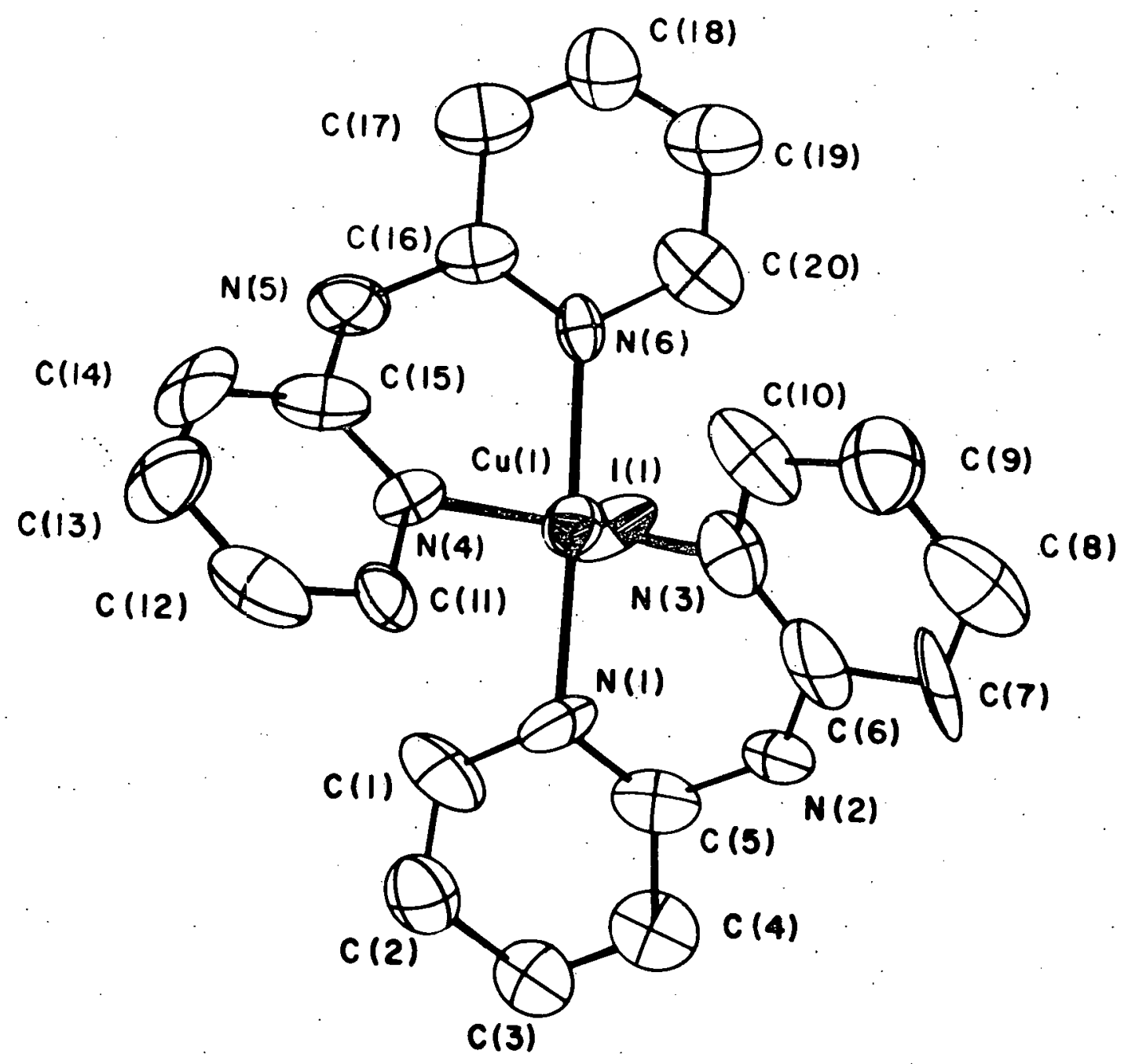


Figure 7. A formula unit of $\left(\mathrm{CuL}_{2} \mathrm{I}\right)_{2} \mathrm{IClO}_{4}$ 


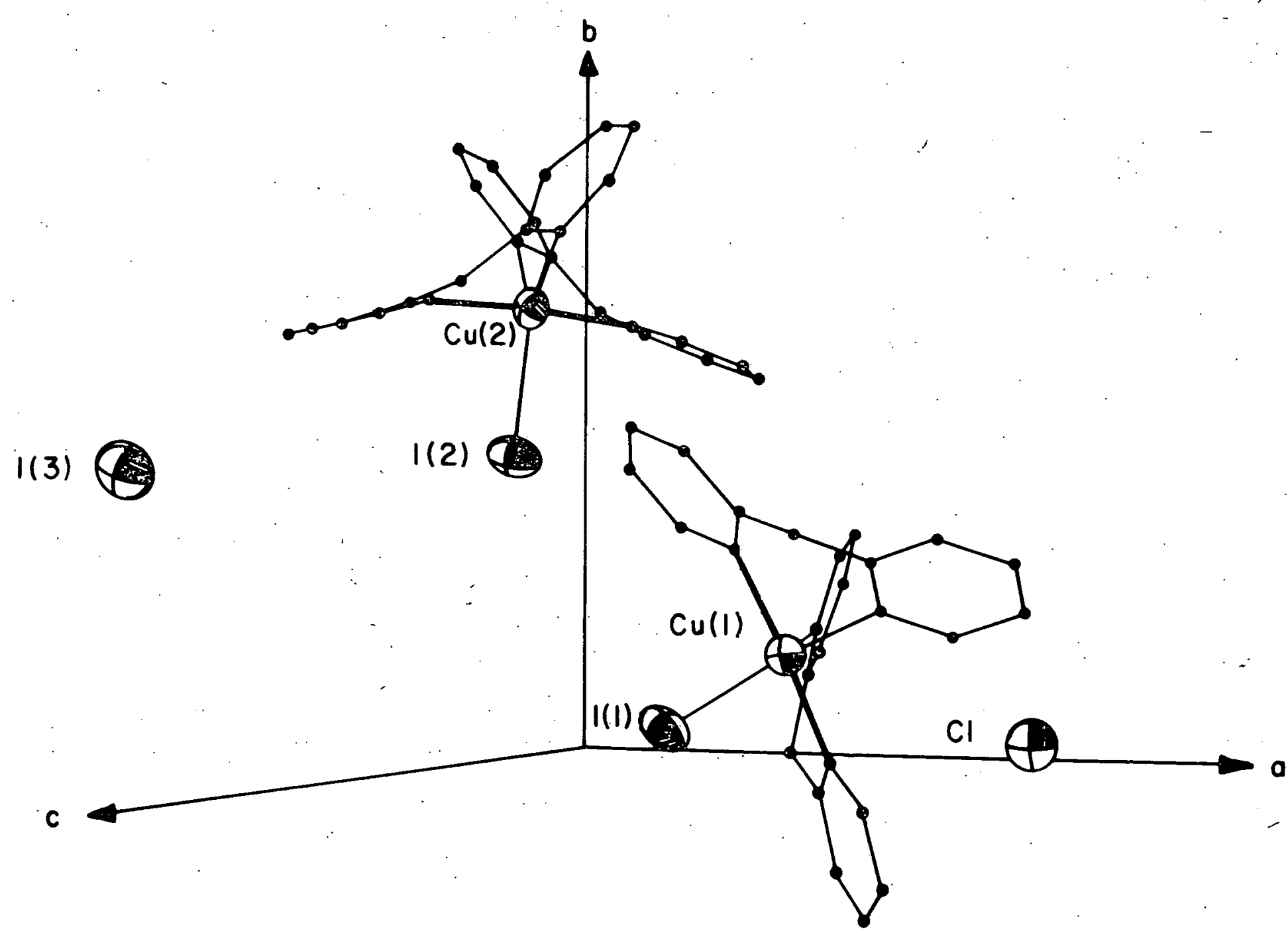


Table IX. Bond lengths (angstroms) and bond angles (degrees) wi th standard deviations in parentheses

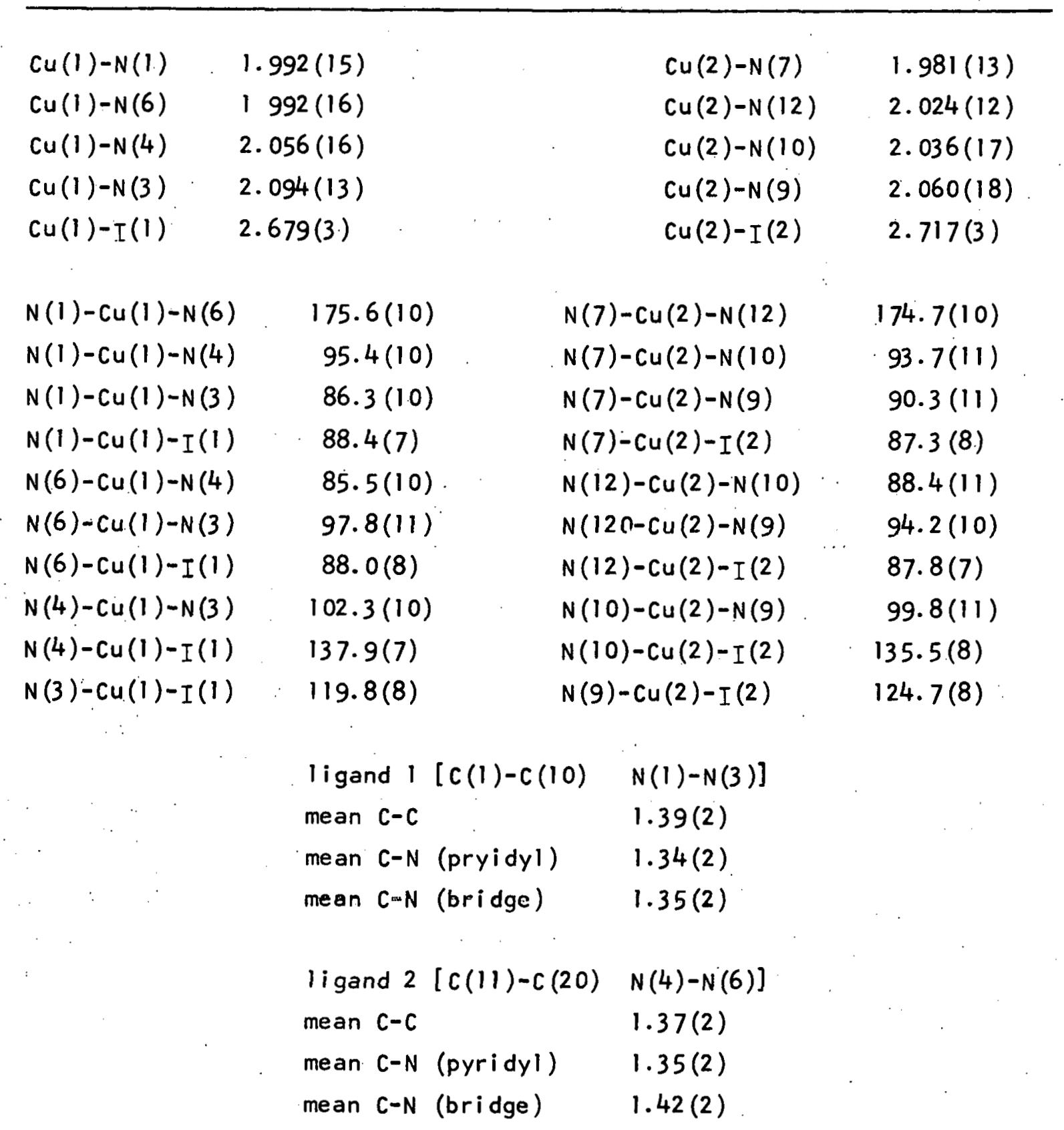


Table IX (continued)

$\begin{array}{ll}\text { ligand } 3[C(21)-C(30) & N(7)-N(9)] \\ \text { mean } C-C & 1.36(2) \\ \text { mean } C-N \text { (pryidyl) } & 1.36(2) \\ \text { mean } C-N \text { (bridge) } & 1.39(2) \\ & \\ \text { ligand } 4[C(31)-C(40) & N(10)-N(12)] \\ \text { mean C-C } & 1.37(2) \\ \text { mean C-N (pryidyl) } & 1.31(2) \\ \text { mean C-N (bridge) } & 1.41(2)\end{array}$


two nitrogen atoms. By adopting this geometry, ligand-ligand nonbonded repulsions are minimized. The copper-nitrogen equatorial bonds appear to be slightly but significantly elongated compared to the axial ones, the average equatorial distance being $2.06 \AA$ vs $2.00 \AA$ for the average axial distance. This type of equatorial elongation has been observed to various degrees in other complexes of this type 23 and has been discussed by Raymond et al. ${ }^{24}$ The copper-iodide distances agree well with that reported by Barclay et al. 25 . The bound iodide atoms display pronounced anisotropic thermal motions (Figure 6); the smallest component, approximately in the direction of the copper-iodide bond, is $0.193 \AA$ $(0.201 \AA)$ and the largest, $0.324 \AA(0.350 \AA)$, is at an angle of $41^{\circ}$ $\left(50^{\circ}\right)$ with the equatorial plane. This pattern of motion is quite consistent with the steric restrictions imposed by the axial nitrogens and the other ligand repulsions.

The deviation from trigonal-bipyramidal geometry manifests itself primarily in angular distortions about the equator. Although the $I(1)-\mathrm{Cu}(1)-\mathrm{N}(3)$ angle is normal at $119.8^{\circ}\left(124.7^{\circ}\right)$, the $I(1)-\mathrm{Cu}(1)-\mathrm{N}(4)$ is $137.9^{\circ}\left(135.5^{\circ}\right)$ reducing the $N(3)-\mathrm{Cu}(1)-N(4)$ angle to $102.3^{\circ}$ $\left(99.8^{\circ}\right)$.

In the ligand itself, the carbon-nitrogen bond distances within the pyridine rings average $\mathrm{I} .34 \AA$. while the bridging $\mathrm{C}-\mathrm{N}$ distances average $1.39 \AA$; the carbon-carbon distances average $1.37 \AA$. The individual pyridine rings are planar within standard deviations. The ligands themselves are bent considerably about the bridging nitrogen atoms with dihedral angles between the pyridine rings of 
$33^{\circ}\left(33^{\circ}\right)$ and $37^{\circ}\left(40^{\circ}\right)$. In $\mathrm{CuL}_{2}\left(\mathrm{ClO}_{4}\right)_{2}$ the dihedral angle was found to be $9.6^{\circ}$; the variation in this angle illustrates the flexibility of the ligand. The six-membered chelate rings formed by the copper and the bidentate ligands are all in a boat configuration, with the copper atom $0.78 \AA$ below the plane of the other four atoms of the ring on the average, and the bridging nitrogen $0.29 \AA$ below this plane. The shorter nonbonded distances between atoms in the same coordination species are llsted In Table V, the minimum distance being $2.80 \AA$ be tween $H(10)$ and $H(20)$.

The nonbonded iodide is located $6.78 \AA$ from $\mathrm{Cu}(1)$ and $5.52 \AA$ from Cu(2) while the chloride of the perchlorate group is located $5.56 \AA$ and $7.35 \AA$ from $C u(1)$ and $C u(2)$, respectively. There are no unusually short contacts between the two chromophores, the shortest being $2.34 \AA$ between $H(14)$ and $H(28)$.

There are no apparent steric effects that would lead to the nearly identical distortions from the trigonal-bipyramidal geometry displayed by both chromophores; therefore electronic effects must be considered. Hathaway and his coworkers have proposed that in the similar compound iodobis $\left(2,2^{\prime}\right.$ bipyridyl) copper(IT) iodide. ${ }^{25}$ the bound iodide may be occupying two coordination sites of a cis-distorted octahedron, thereby explaining the reduction of the equatorial $\mathrm{N}-\mathrm{Cu}-\mathrm{N}$ bond angle from $120^{\circ}$ to $114^{\circ} .26,27$ This cis-distorted geometry has been observed in nitritobis (2,2'bipyridyl) copper(II) nitrate where the angle is $102^{\circ} .16$ 
In Figure 8 the coordination geometries of the 2,2'bipyridyl complexes mentioned above are schematically drawn along wi th that of the 2!' 'bipyridylamine complex. It should be noted that the equatorial $\mathrm{N}-\mathrm{Cu}-\mathrm{N}$ bond angles of the nitrito complex and the 2,2'bipyridylamine iodide complex are similarly reduced.

An alternative explanation for the equatorial angular asymetry as well as the reduction of the equatorial $\mathrm{N}-\mathrm{Cu}-\mathrm{N}$ bond angle would be that the trigonal bipyramid is distorting toward a square pyramid with $N(3)$ at the apex. This view is supported by the large $N(4)-C u(1)-I(1)$ angle, while all but the $N(3)-C u(1)-I(1)$ angles involving $N(3)$ are within $12^{\circ}$ of the $90^{\circ}$ angle expected for the square pyramid. It should also be noted that Lancaster et al., on the basis of electronic spectra, had predicted a square pyramid with the iodide at the apex for iodobis (2, 2'bipyridylamine) copper(II) iodide perchlorate. 5 
Figure 8. Comparison of coordination geometries of similar 2,2'bipyridyl complexes with that of the 2,2'bipyridylamine complex 


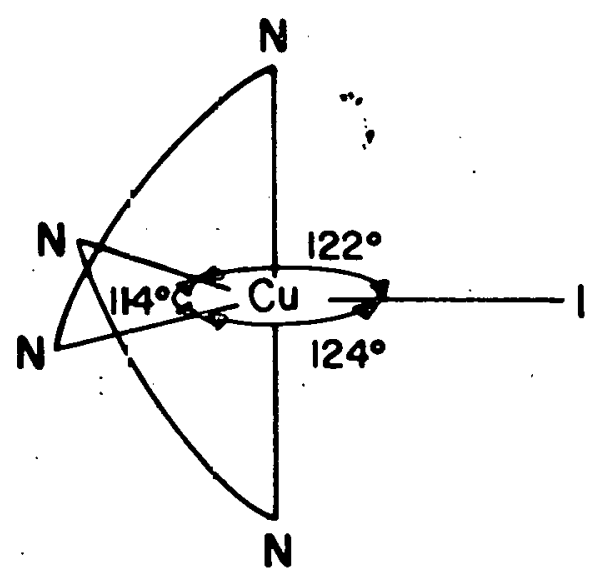

[Cubipy ${ }_{2}^{\prime}$ ]।

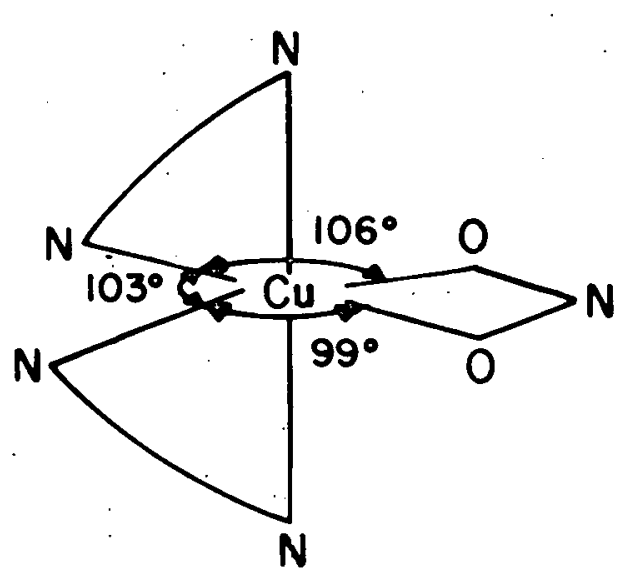

$\left[\right.$ Cubipy $\left.{ }_{2} \mathrm{NO}_{2}\right] \mathrm{NO}_{3}$

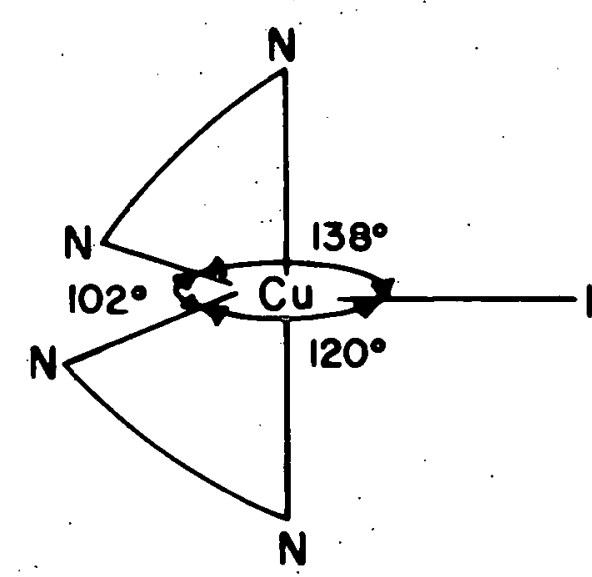

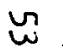

$\left[\text { Cubipyam }{ }_{2}\right]_{2} \mathrm{IClO}_{4}$ 
Table $X$. Nonbonded intramolecular distances ( $\AA$ )

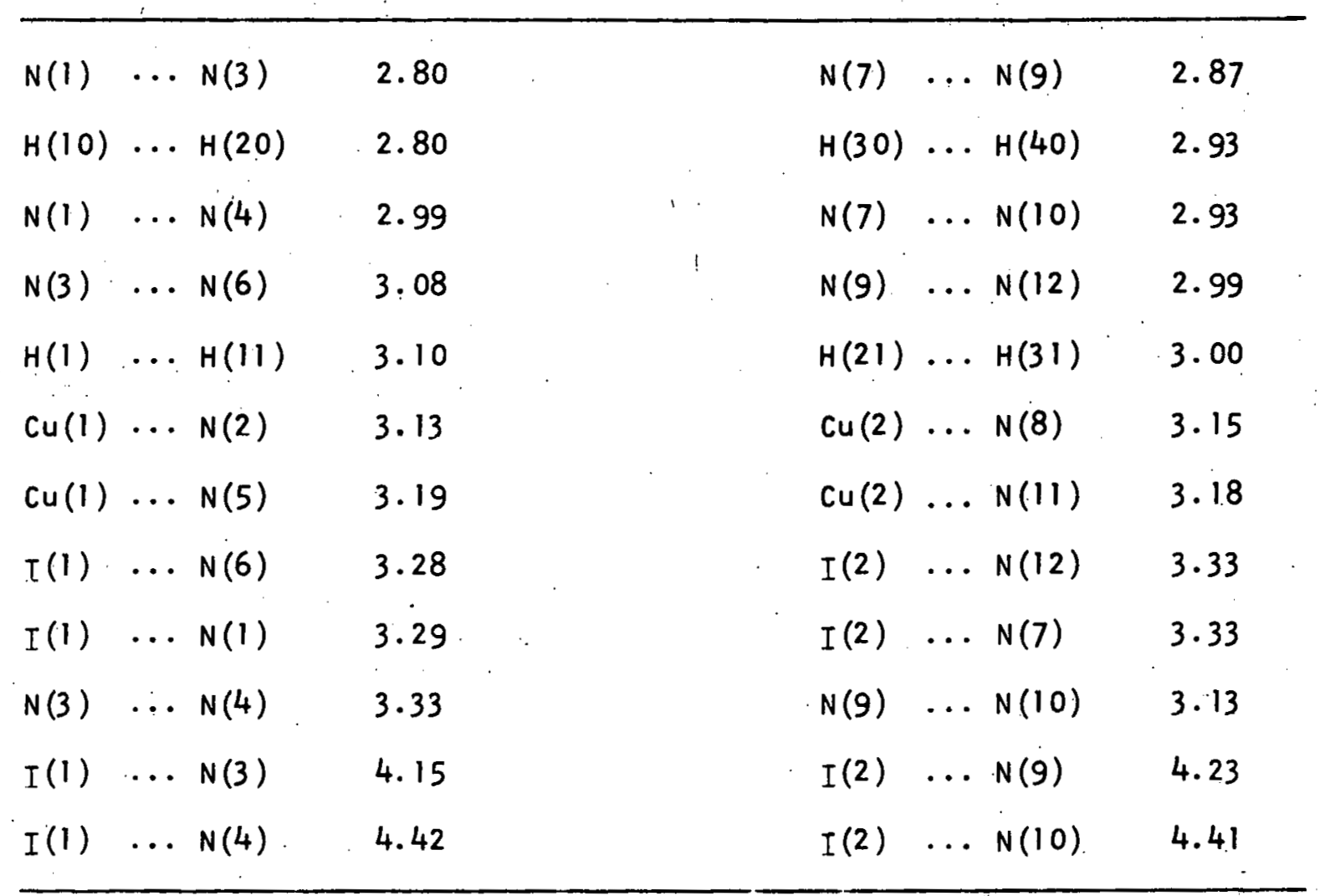


THE STRUCTURE OF DIISOTHIOCYANATOBIS $(2,2$ 'BIPYRIDYLAMINE)

COPPER (II) ISOTHIOCYANATOBIS (2,2'BIPYRIDYLAMINE)

COPPER (II) PERCHLORATE

\section{Introduction}

As part of a series of structural investigations of metal complexes with the ligand 2,2'bipyridylamine, the preparation and structural characterization of $\mathrm{CuL}_{2} \mathrm{NCSClO}_{4}(L=2,2$ 'bipyridylami ne) were undertaken. Subsequent analysis showed this to be a mixture of $\mathrm{CuL}_{2}$ (NCS) 2 and $\mathrm{CuL}_{2} \mathrm{NCSClO}_{4}$

\section{Experimental}

The preparation reported by McWhinnie for $\mathrm{CuL}_{2} \mathrm{NCSClO}_{4}$, was followed ${ }^{4}$ and the reaction appeared to proceed as expected yielding small dark green crystals as had been found by McWhinnie. However, the preliminary single crystal data were not consistent with the simple stoichiometry reported by McWhinnie. Subsequently, the crystals were shown to be a co-crystallized mixture of dilsothiocyanatobis (2, 2 'bipyridylamine) copper (II), [ $\left.\mathrm{CUL}_{2}(\mathrm{NCS})_{2}\right]$, and i so thiocyanatobis (2, 2' bi pyridylamine) copper(II) perchlorate, $\left[\mathrm{CuL}_{2} \mathrm{NCSClO}_{4}\right]$, hereafter referred to as compound I and II respectively.

Crystal Data. $--\mathrm{C}_{43} \mathrm{~N}_{15} \mathrm{H}_{36} \mathrm{Cu}_{2} \mathrm{~S}_{3} \mathrm{ClO}_{4} \dot{M}_{I}=522.10 \mathrm{~g} / \mathrm{m}, M_{I I}=563.47 \mathrm{~g} / \mathrm{m}$ monoclinic, $\underline{a}=12.74 \pm .02, \underline{b}=14.48 \pm .01, \underline{c}=19.33 \pm .03 \AA, \beta=93.84 \pm$ $.40^{\circ}, V=3558 \AA^{3}, D_{m}=1.59 \mathrm{~g} / \mathrm{cc}, Z_{I}=2, Z_{I I}=4, D_{c}=1.55 \mathrm{~g} / \mathrm{cc}$, $F(000)=1810 \mathrm{e}$, space group $P_{2} / c^{\prime}\left(C_{2 h}{ }^{5}\right)$ from systematic 


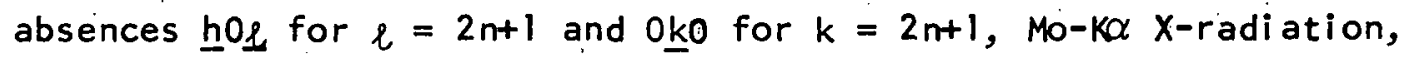
$\lambda=0.7107 \AA \mu(M o-K \alpha)=11.32 \mathrm{~cm}^{-1}$. The unit cell parameters were determined from repeated measurements of $2 \theta$ values of high order reflections whose centers were determined by left-right top-bottom beam splitting on a previously aligned Hilger and Watts four-circle diffractometer (Mo-k $\alpha$ radiation $\lambda=0.7107 \AA$ ). The observed density was determined by floatation in carbon tetrachloride.

A crystal having approximate dimensions $.24 \times .12 \times .062 \mathrm{~mm}$ was mounted with the b axis $(.24 \mathrm{~mm})$ aligned along the spindle axis. Data were collected at room temperature utilizing a Hilger and Watts fourcircle diffractometer equipped with a scintillation counter and using Zr-filtered Mok $\alpha$ radiation. Within a $2 \theta$ sphere a $40^{\circ}$ all data in the hkl and $\underline{h} \underline{f} \mathcal{L}$ octants were recorded using a $\theta-2 \theta$ step-scan technique wi th a take-off angle of $4.5^{\circ}$. Symmetric scan ranges of $1.00^{\circ}$ in $2 \theta$ at low two-theta values to $2.00^{\circ}$ at high two-theta values were used. Stationary crystal-stationary counter background measurements were made at the beginning and end of the scan, each measurement being made for one-half the total scan time. The counting rate was $0.2048 \mathrm{sec}$ per step of $0.02^{\circ}$ in two-theta. A total of 3501 reflections were measured in this way. Three standard reflections were observed periodically and these observations indicated that no decomposition occurred during the data collection.

The intensity data were corrected for Lorentz-polarization effects and for effects due to absorption. The absorption correction was made using a modified version of $O R A B S ;^{28}$ the maximum and minimum 
transmission factors were 0.93 and 0.79 respectively. The estimated error in each intensity was calculated by

$$
[\sigma(I)]^{2}=\left[C_{T}+c_{B}+\left(K_{T} C_{T}\right)^{2}+\left(K_{B} C_{B}\right)^{2}+\left(K_{B} C_{R}\right)^{2}\right] / A^{2}
$$

where $C_{T}, C_{B}, C_{R}$, and $A$ are total count, background count, net count, and transmission factor while $K_{T}, K_{B}$, and $K_{R}$ are estimated non-statistical errors in $C_{T}, C_{B}$, and $C_{R}$. $K_{T}$ and $K_{B}$ were assigned values of .05 and $K_{R} \cdot 03$. The equivalent values of the intensities were then averaged. The estimated standard deviations in each structure factor was calculated from the mean deviation in intensity by the method of finite differences. ${ }^{8}$. The reciprocals of the structure factor variances were used as weights in the least squares refinement. The results reported are based on 1855 observed reflections which had an intensity greater than $3 \sigma(I)$, a criteria that appeared valid from measurements of intensities of symmetry extinct reflections.

\section{Solution of the Structure}

From the symmetry of the monoclinlc space group $P_{2 / c}$ and the presence of approximately six molecules of stoichiometry $\mathrm{CuL}_{2} \mathrm{NCSClO}_{4}$ per unit cell, two of the six molecules must necessarily possess a center of symmetry, which would be impossible for ordered $\mathrm{CuL}_{2} \mathrm{NCSClO}_{4}$, assuming a monomeric species with a copper at a $T$ site. Thus, the stoichiometry was immediately suspect. A copper atom was assumed at $0.5,0.0,0.5$, and the other copper atom in the asymmetric unit was 
readily located from a sharpened Patterson map; ${ }^{21}$ all other nonhydrogen atoms were subsequently found by successive structure factor and electron density map calculations. Wi th all atoms isotropic, the structure refined to $16.4 \%$. At this point a difference electron density map indicated appreciable ani sotropic motion, especially of the copper, chlorine, and sulfur atoms. Refinement with these heavy atoms anisotropic produced an $R$ factor of $14.0 \%$ and weighted $R$ factor $R_{\omega}=\left[\Sigma \omega\left(\left|F_{0}\right|-\left|F_{c}\right|\right)^{2} / \Sigma \omega\left|F_{0}\right|^{2}\right]^{\frac{1}{3}}$ of $14.4 \% .^{13}$ A difference electron density map at this stage showed no significant peaks, indicating all nonhydrogen atoms had been located. Hydrogen positions for the aromatic rings were calculated assuming a benzoid structure with a $\mathrm{C}-\mathrm{H}$ bond distance of $1.07 \AA$. Each hydrogen atom was asșigned the i sotropic temperature factor of the carbon to which it was attached. The scattering factors used were those of Hansen et al. 11 with. copper, chlorine, and sulfur modified for the real and imaginary parts of anomalous dispersion. ${ }^{12}$ The final values of the observed and calculated structure factors $(\times 10)$ are listed in Figure 9. The final positional and thermal parameters for the nonhydrogen atoms are given in Tables XI and XII. The calculated hydrogen positions are given in Table XIII. Bond distances and angles about the copper(II) ions are given in Table XIV, along with the average distances for chemically equivalent bond lengths in the individual ligands. Results for least squares planes calculations involving the metal ions are provided in Table XV. 
Figure 9. Observed and calculated structure factors (x 10) for $\mathrm{CuL}_{2}(\mathrm{NCS})_{2} \mathrm{CuL}_{2} \mathrm{NCSClO}_{4} \cdot\left(L=2,2^{\prime}\right.$ bi pyridylamine $)$ 

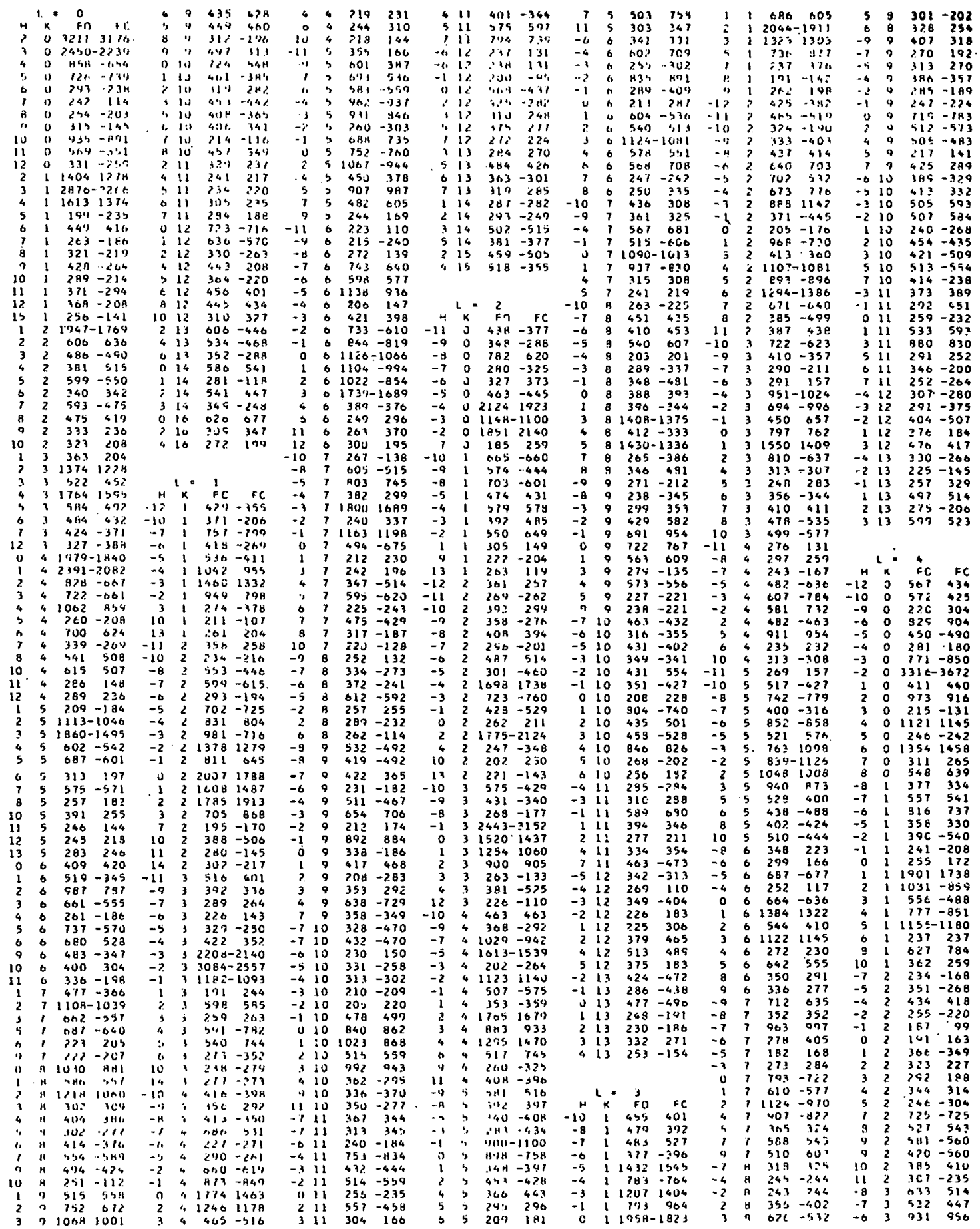

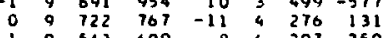

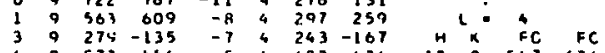

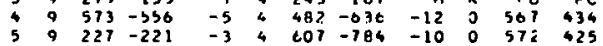

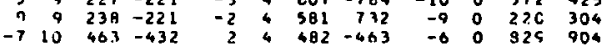

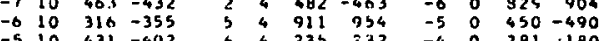

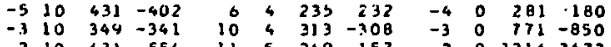

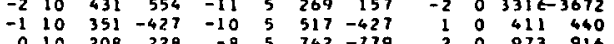

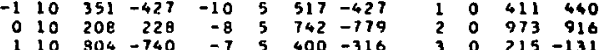

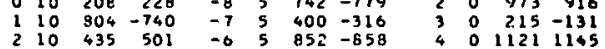

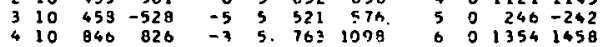

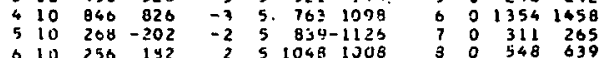

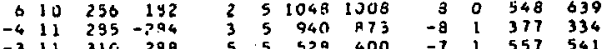

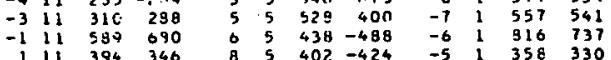

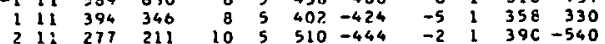

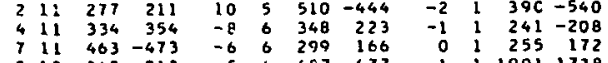

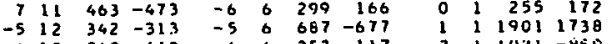

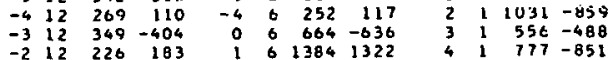

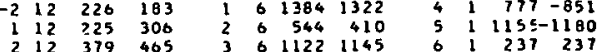

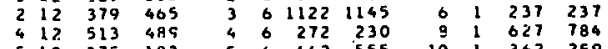

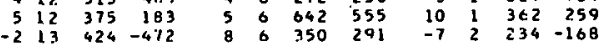

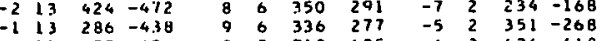

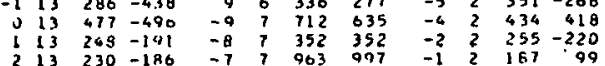

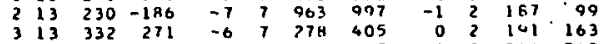

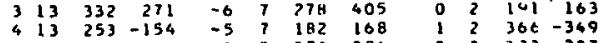

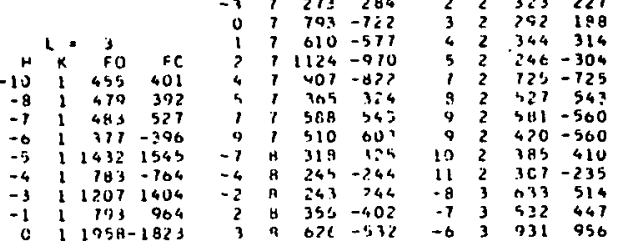



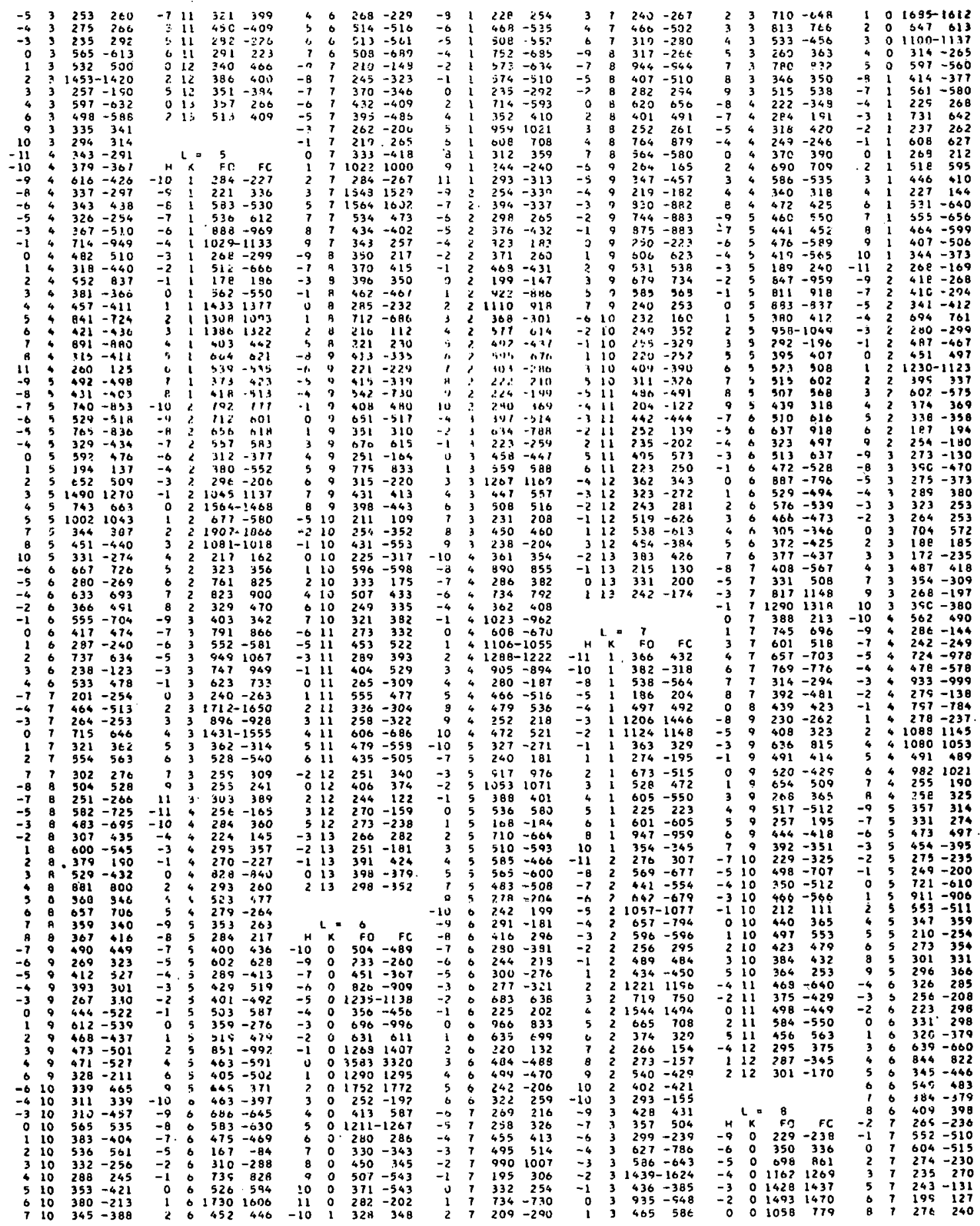

Figure 9 (Continued) 


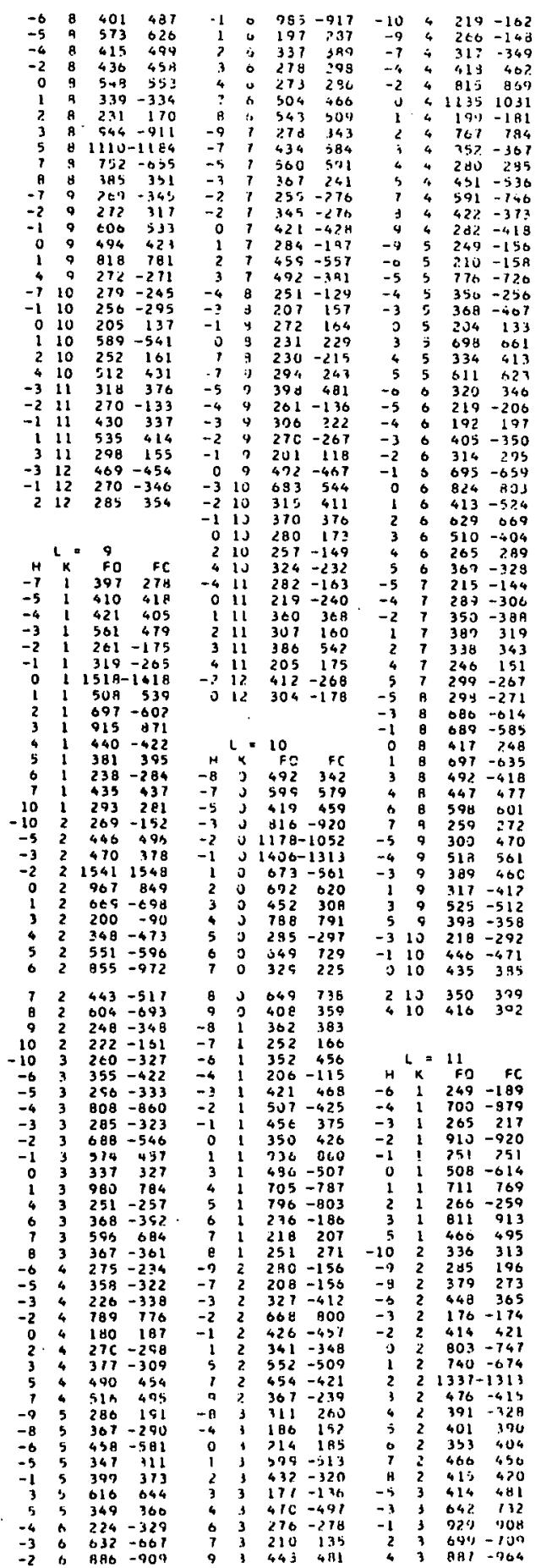

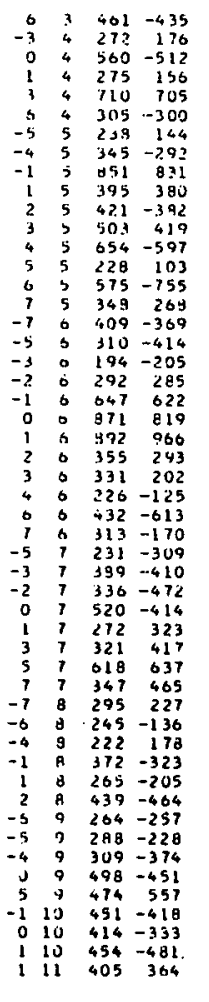

$L_{k}=12$

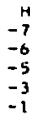

$\begin{array}{llll}-6 & 0 & 586 & -385 \\ -5 & 0 & 724 & -729 \\ -3 & 0 & 129 & -559\end{array}$

\begin{tabular}{cccc}
-3 & 0 & 913 & -857 \\
-1 & $j$ & 510 & 529 \\
\hline & 0 & 509 & 100
\end{tabular}

$\begin{array}{llrr}3 & 0 & 1088 & 1106 \\ 1 & 0 & 500 & 416\end{array}$

$2 \quad 3 \quad 12201295$

$\begin{array}{cccc}3 & 5 & 346 & -474 \\ 4 & 0 & 692 & 782 \\ 5 & 0 & 481 & -576\end{array}$

\begin{tabular}{rrrr}
5 & 0 & 481 & -576 \\
-8 & 1 & 259 & 183 \\
\hline & 1 & \\
\hline & & 257 & -31
\end{tabular}

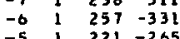

$\begin{array}{llll}-5 & 1 & 221 & -265 \\ -4 & 263 & -25 \mathrm{~A} \\ -2 & 1 & 024 & -506\end{array}$

$\begin{array}{rrrr}-2 & 1 & 2624 & -506 \\ 0 & 1 & 792 & -770 \\ 0 & 1 & 223 & -196\end{array}$

$\begin{array}{llll}1 & 1 & 223 & -186 \\ 2 & 1 & 442 & -461\end{array}$

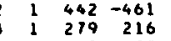

$\begin{array}{llll}4 & 1 & 402 & 408 \\ 5 & 1 & 563 & 596\end{array}$

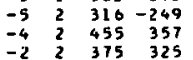

$\begin{array}{cccc}-2 & 2 & 315 & 325 \\ -1 & 2 & 200 & -110 \\ 1 & 2 & 200 & -110\end{array}$

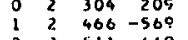

$\begin{array}{rrrr}3 & 2 & 511 & -469 \\ -2 & 3 & 928 & -869 \\ -1 & 3 & 542 & -519\end{array}$

$\begin{array}{rrrr}-2 & & 928 & -869 \\ -1 & 3 & 542 & -539 \\ -1 & 3 & 532 & -529 \\ 0 & 3 & 336\end{array}$

$\begin{array}{llll}-1 & 3 & 542 & -519 \\ -4 & 4 & 256 & 200 \\ -6 & 4 & 429 & 421\end{array}$

$\begin{array}{llll}-6 & 429 & 421 \\ -4 & 529 & 530 \\ -2 & 341 & 23\end{array}$

$\begin{array}{cccc}-2 & 4 & 341 & 23 \\ -1 & 4 & 29 & -743\end{array}$

$\begin{array}{rlll}-1 & 4 & 192 & -743 \\ 0 & 4 & 310 & -251 \\ 1 & 4 & 987-1001 \\ 2 & 4 & 180-251\end{array}$

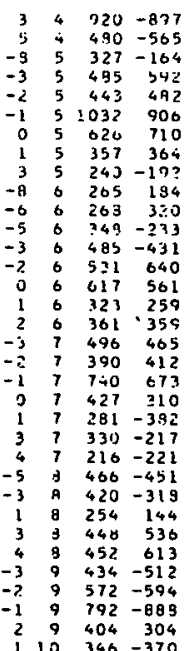

$$
1=13
$$

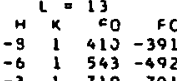

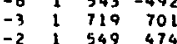

$\begin{array}{llll}-2 & 1 & 549 & 474 \\ -1 & 1 & 545 & 640 \\ & & & \end{array}$

$0 \quad 1485400$

\begin{tabular}{llll}
3 & 1 & 320 & 412 \\
\hline & 1 & 200 & 172
\end{tabular}

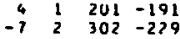

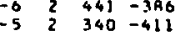

$\begin{array}{lllll}-4 & 2 & 340 & 123-007 \\ -7 & 2 & 123 & -007\end{array}$

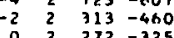

$\begin{array}{lllll}-7 & 3 & 330 & 246 \\ - & 3 & 309 & \end{array}$

$\begin{array}{llll}-5 & 3 & 309 & 221 \\ -4 & 3 & 309 & -35 \\ -4 & 3 & 306 & -35\end{array}$

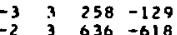

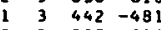

$\begin{array}{cccc}0 & 3 & 925 & -530 \\ -5 & 4 & 382 & 514 \\ -4 & & 562 & -20\end{array}$

$\begin{array}{llll}-4 & 4 & 418 & -344 \\ -2 & 4 & 267 & -202 \\ -4 & 5 & 502 & -498\end{array}$

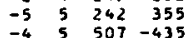

$\begin{array}{cccc}-3 & 5 & 349 & 292 \\ -2 & 5 & 867 & -934 \\ -1 & 5 & 896\end{array}$

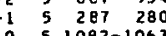

$\begin{array}{rlll}-6 & 6 & 205 & 242 \\ -4 & 0 & 240 & \end{array}$

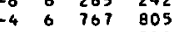

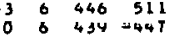

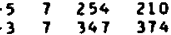

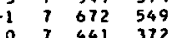

-2 e $269-273$

$\begin{array}{llll}-1 & 8 & 279 & 340 \\ 0 & 8 & 345 & 210\end{array}$

$\begin{array}{cccc}-3 & 0 & 345 & 2107 \\ -2 & 9 & 301 & 289 \\ -2 & 9 & 289 & -155 \\ -1 & 9 & 29 & \end{array}$

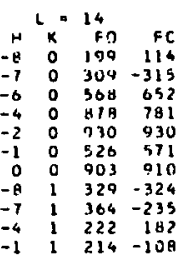

$\begin{array}{rrrr}0 & 1 & 353 & 390 \\ -7 & 2 & 330 & -303\end{array}$

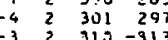

$\begin{array}{llll}-2 & 2 & 336 & 2 \geq 5 \\ -1 & 2 & 305\end{array}$

$\begin{array}{cccc}-1 & 2 & 305 & -23 \\ 0 & 2 & 492 & 409 \\ -3 & 2 & 490 & 4045\end{array}$

$\begin{array}{lll}-4 & 270 & 275 \\ -3 & 359 & 149 \\ -3 & 250 & 0\end{array}$

$\begin{array}{llll}-2 & 3 & 257 & 260 \\ -0 & 3 & 240 & 0\end{array}$

$\begin{array}{llll}-5 & 4 & 291 & -362 \\ - & 4 & 390 & -339\end{array}$

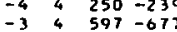

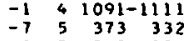

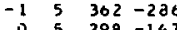

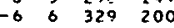

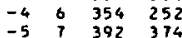

-7 $279-306$

$\begin{array}{rrrr}-1 & 1 & 28 & 124 \\ -1 & 8 & 339 & 252 \\ -1 & 0 & 742 & 319 \\ 0 & 0 & & \end{array}$

$L=15$

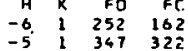

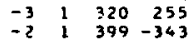

$\begin{array}{llll}c & 1 & 489 & -414 \\ -6 & 2 & 284 & -16\end{array}$

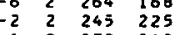

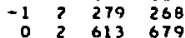

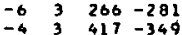

$\begin{array}{llll}-3 & 3 & 417 & -354 \\ -2 & & -354\end{array}$

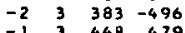

(5) 205212

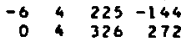

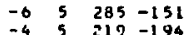

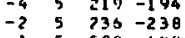

-155988 oug

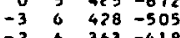

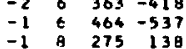

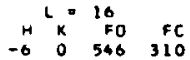

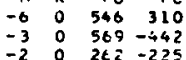

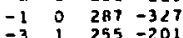

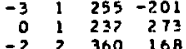

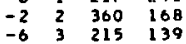

$\begin{array}{llll}-4 & 3 & 350 & 471 \\ -4 & 3 & 35 & -14\end{array}$

$\begin{array}{llll}-1 & 3 & 256 & -114 \\ -5 & 4 & 238 & -203 \\ -4 & 4 & 230 & -2030\end{array}$

$-4,4 \quad 267 \quad 300$

$\begin{array}{llll}-2 & 4 & 347 & 411 \\ -1 & 4 & 239 & -280\end{array}$

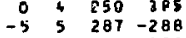

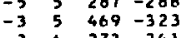

$\begin{array}{rrrr}-1 & 6 & 545 & -501 \\ 0 & 6 & 237 & 270\end{array}$

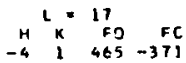

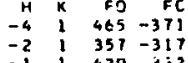

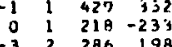

$\begin{array}{llll}-1 & 3 & 210 & 28 \\ -1 & 3 & 390 & 331 \\ -1 & 5 & 284 & 312 \\ & 2 & 112 & 12\end{array}$

$4{ }^{2}-18$ F

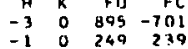

O

$\begin{array}{llll}-2 & 1272 & 217 \\ -1 & 1 & 217 \\ -1 & 3 & -312 & -312\end{array}$

Figure 9 (Continued) 
Table XI. Final atomic coordinates and isotropic thermal parameters with standard deviations in parentheses

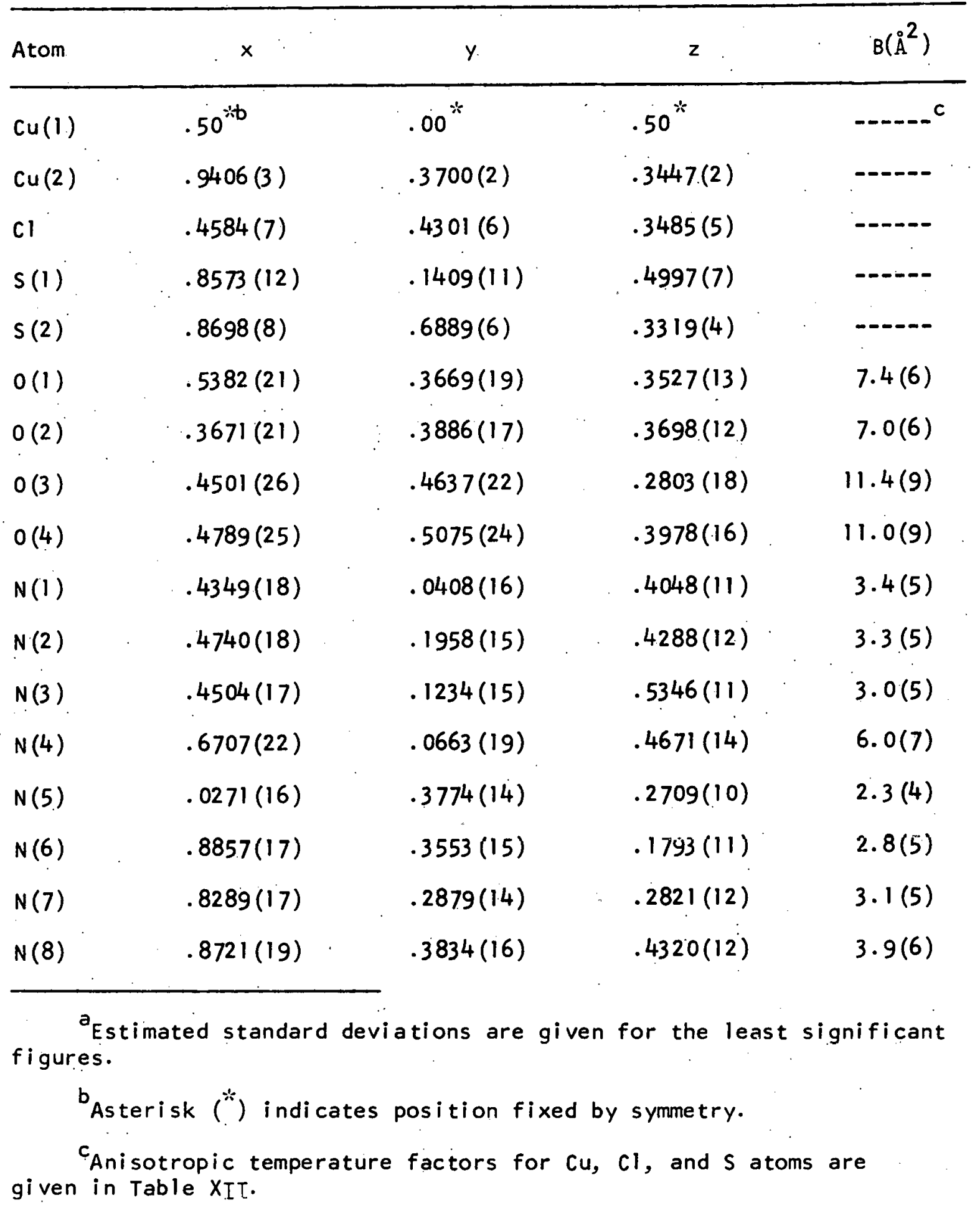


64

\begin{tabular}{|c|c|c|c|c|}
\hline Atom & $x$ & $y$ & $z$ & $B\left(\AA^{2}\right)$ \\
\hline$N(9)$ & .0308 (19) & $.3410(17)$ & $.5011(12)$ & $3.8(6)$ \\
\hline$N(10)$ & $.0384(20)$ & $.2710(18)$ & $.3895(13)$ & $4.8(6)$ \\
\hline$N(11)$ & $.8953(19)$ & $.5001(19)$ & $.3195(12)$ & $4.4(6)$ \\
\hline$c(1)$ & $.3859(25)$ & $-.0313(20)$ & $.3628(15)$ & $4.2(7)$ \\
\hline$c(2)$. & $.3501(25)$ & $-.0038(24)$ & $.2933(17)$ & $4.9(8)$ \\
\hline$c(3)$ & $.3668(23)$ & $.0889(20)$ & $.2723(15)$ & $3.5(7)$ \\
\hline$c(4)$ & $.4124(22)$ & $.1535(18)$ & $.3170(15)$ & $3.2(7)$ \\
\hline$c(5)$. & $.4319(20)$ & $.1291(19)$ & $.3897(14)$ & $2.7(6)$ \\
\hline$c(6)$ & $.4559(19)$ & $.1989(18)$ & $.4984(14)$ & $2.3(6)$ \\
\hline$c(7)$ & $.4410(24)$ & $.2888(21)$ & $.5340(17)$ & $.4 .1(8)$ \\
\hline$c(8)$ & $.4051(27)$ & $.2961(24)$ & $.6002(19)$ & $5.9(9)$ \\
\hline$c(9)$ & $.3986(26)$ & $.2108(22)$ & $.6308(16)$ & $4.8(8)$ \\
\hline$c(10)$ & $.4169(22)$ & $.1257(22)$ & $.6017(15)$ & $3.9(7)$ \\
\hline$c(11)$ & $.7538(17)$ & $.1151(14)$ & $.4875(11)$ & $0.10(6)$ \\
\hline$c(12)$ & $.1271(30)$ & $.4085(23)$ & $.2778(18)$ & $5.5(9)$ \\
\hline$c(13)$ & $.1924(31)$ & $.4375(26)$ & $.2292(21)$ & $6.7(10)$ \\
\hline$c(14)$ & $.1493(26)$ & $.4571(22)$ & $.1578(17)$ & $4.8(8)$ \\
\hline$c(15)$ & $.0398(27)$ & $.4270(21)$ & $.1462(17)$ & $4.4(8)$ \\
\hline$c(16)$ & . $9829(29)$ & $.3851(23)$ & . $1971(18)$ & $5.7(9)$ \\
\hline$c(17)$ & $.8292(25)$ & $.2986(21)$ & $.2098(17)^{\circ}$ & 4.1.17) \\
\hline$c(18)$ & $.7475(28)$ & $.2390(23)$ & $.1707(17)$ & $5.3(8)$ \\
\hline
\end{tabular}


Table XI (continued)

\begin{tabular}{lcccc}
\hline Atom & $x$ & $y$ & $z$ & $B\left(\AA^{2}\right)$ \\
\hline$C(19)$ & $.6806(25)$ & $.1892(21)$ & $.2083(17)$ & $4.2(7)$ \\
$C(20)$ & $.6877(31)$ & $.1737(26)$ & $.2793(21)$ & $6.8(10)$ \\
$C(21)$ & $.7613(25)$ & $.2334(22)$ & $.3157(16)$ & $4.2(8)$ \\
$C(22)$ & $.7694(25)$ & $.4197(20)$ & $.4312(16)$ & $4.0(7)$ \\
$C(23)$ & $.7290(26)$ & $.4475(23)$ & $.4884(18)$ & $5.1(8)$ \\
$C(24)$ & $.7825(27)$ & $.4436(22)$ & $.5450(17)$ & $5.0(8)$ \\
$C(25)$ & $.8854(24)$ & $.4096(20)$ & $.5550(15)$ & $3.8(7)$ \\
$C(26)$ & $.9351(23)$ & $.3778(19)$ & $.4963(15)$ & $3.3(7)$ \\
$C(27)$ & $.0654(24)$ & $.2759(21)$ & $.4600(16)$ & $3.9(7)$ \\
$C(28)$ & $.1407(23)$ & $.2056(19)$ & $.4890(15)$ & $3.4(7)$ \\
$C(29)$ & $.1699(27)$ & $.1381(24)$ & $.4451(18)$ & $5.6(9)$ \\
$C(30)$ & $.1364(25)$ & $.1316(23)$ & $.3724(17)$ & $5.0(8)$ \\
$C(31)$ & $.0641(23)$ & $.2018(21)$ & $.3501(15)$ & $3.6(7)$ \\
$C(32)$ & $.8791(27)$ & $.5772(25)$ & $.3249(17)$ & $4.9(8)$ \\
\hline &. & $y$ & & \\
\hline
\end{tabular}


Table XII. Anisotropic temperature factors ${ }^{a}$ with standard deviations in parentheses

\begin{tabular}{lllllll}
\hline Atcm & $\beta_{11}$ & $\beta_{22}$ & $\beta_{33}$ & $\beta_{12}$ & $\beta_{13}$ & $\beta_{23}$ \\
\hline $\mathrm{Cu}(1)$ & $97(5)$ & $21(2)$ & $13(2)$ & $8(3)$ & $-19(2)$ & $-1(2)$ \\
$\mathrm{Cu}(2)$ & $64(3)$ & $27(2)$ & $17(1)$ & $2(3)$ & $-9(1)$ & $1(1)$ \\
$\mathrm{Cl}$ & $58(7)$ & $58(5)$ & $41(4)$ & $19(6)$ & $-5(4)$ & $14(4)$ \\
$s(1 !$ & $202(18)$ & $135(12)$ & $67(6)$ & $-70(12)$ & $34(8)$ & $29(7)$ \\
$s(2 !$ & $140(11)$ & $77(5)$ & $22(3)$ & $4(6)$ & $-26(5)$ & $3(3)$ \\
\hline
\end{tabular}

${ }^{a}$ The $\beta_{i j}$ and their standard errors are $\times 10^{4}$. The $\beta_{i j}$ are defined by:

$\dot{T}=\exp \left[-\underline{h}^{2} \beta_{11}+\underline{k}^{2} \beta_{22}+\underline{\ell}^{2} \beta_{33}+2 \underline{h} \underline{k} \beta_{12}+2 \underline{h} \underline{\ell} \beta_{13}+2 \underline{k} \underline{\ell} \beta_{23}\right]$. 
Table XIII: Calculated hydrogen atom positions ${ }^{a}$

\begin{tabular}{|c|c|c|c|c|}
\hline Atom ${ }^{b}$ & $x$ & & $y$ & z \\
\hline$H(1)$ & .377 & 1 & -.099 & .381 \\
\hline$H(2)$ & .312 & & -.051 & .259 \\
\hline$H(3)$. & .344 & & .109 & .221 \\
\hline$H(4)$ & .433 & & .219 & .299 \\
\hline$H(7)$ & .458 & & .350 & .508 \\
\hline$H(8)$ & .386 & & .359 & .624 \\
\hline$H(9)$ & .377 & & .210 & .682 \\
\hline$H(10)$ & .406 & & .065 & .629 \\
\hline$H(12)$ & .045 & & .412 & .269 \\
\hline$H(13)$ & .273 & & .446 & $: .243$ \\
\hline$H(14)$ & $: 192$ & & .489 & .120 \\
\hline$H(15)$ & .002 & & .438 & .097 \\
\hline$H(18)$ & .743 & & .236 & .116 \\
\hline$H(19)$ & .616 & & .159 & .180 \\
\hline$H(20)$ & .644 & & .123 & .304 \\
\hline$H(21)$ & .764 & & .235 & .370 \\
\hline$H(22)$ & .724 & & .425 & .384 \\
\hline$H(23)$ & .652 & & .474 & .484 \\
\hline$H(24)$ & .748 & & .464 & .600 \\
\hline$H(25)$ & . 929 & & .407 & .603 \\
\hline$H(28)$ & .170 & & .208 & .541 \\
\hline$H(29)$ & .221 & & .089 & .466 \\
\hline$H(30)$ & .163 & & .080 & .339 \\
\hline$H(31)$ & .029 & & .198 & .299 \\
\hline
\end{tabular}

${ }^{a}$ Hydrogen positions were calculated assuming a benzoid structure and a bond length of $1.07 \AA$.

${ }^{b}$ The atom number is that of the carbon atom to which the hydrogen is attached. 
Table XIV. Selected interatomic distances and angles for $\mathrm{CuL}_{2}(\mathrm{NCS})_{2}$ $\mathrm{CuL}_{2} \mathrm{NCSClO}_{4}$

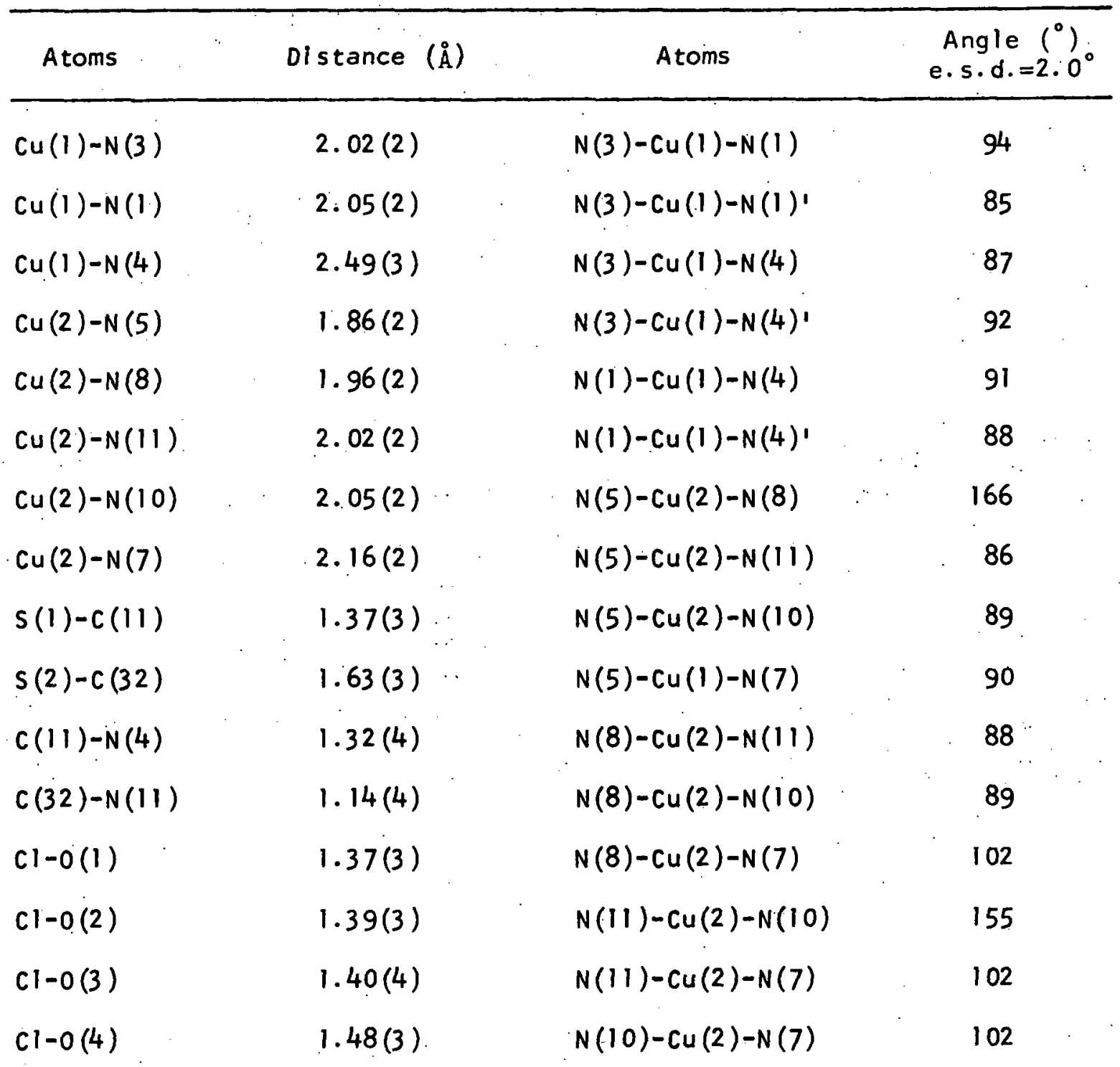




$$
\begin{aligned}
& \text { Mean Distances for Chemically Equivalent Bonds } \\
& \text { ligand } 1[c(1) \ldots c(10) N(1) \ldots N(3)] \\
& \text { mean } \mathrm{C}-\mathrm{C} \quad 1.42(3) \\
& \text { mean } \mathrm{C}-\mathrm{N} \text { (pyridyl) } 1.36(3) \\
& \text { mean } \mathrm{C}-\mathrm{N} \text { (bridge) } 1.35(3) \\
& \text { ligand } 2[c(12) \ldots c(21) N(5) \ldots N(7)] \\
& \text { mean } \mathrm{C}-\mathrm{C} \quad 1.42(4) \\
& \text { mean } \mathrm{C}-\mathrm{N} \text { (pyridyl) } 1.41(4) \\
& \text { mean } \mathrm{C}-\mathrm{N} \text { (bridge) } 1.30(4) \\
& \text { ligand } 3[c(22) \ldots c(31) N(8) \ldots N(10)] \\
& \text { mean } \mathrm{C}-\mathrm{C} \quad 1.41(4) \\
& \text { mean } \mathrm{C}-\mathrm{N} \text { (pyridyl) } 1.39(4) \\
& \text { mean } \mathrm{C}-\mathrm{N} \text { (bridge) } 1.33(4)
\end{aligned}
$$


Table XV. Least squares planes ${ }^{a}$

\begin{tabular}{ccccc}
\hline Plane & $\mathcal{m}$ & $\underline{m}$ & $\underline{n}$ & $\underline{k}$ \\
1 & .879 & .424 & -.220 & 2.94 \\
2 & .672 & .562 & .481 & -14.4
\end{tabular}

\section{Deviations from Plane}

\begin{tabular}{lll} 
Atom & Plane 1 & Plane 2 \\
$\mathrm{Cu}(1)$ & 0.00 & $-.33^{* * c}$ \\
$\mathrm{Cu}(2)$ & & \\
$N(1)$ & 0.00 & \\
$N(3)$ & 0.00 & \\
$N(11)^{b}$ & 0.00 & -.10 \\
$N(5)$ & & $-2.48^{*}$ \\
$N(7)$ & -.10 \\
$N(8)$ & .10 \\
$N(10)$ & & .10 \\
$N(11)$ & & \\
\hline
\end{tabular}

${ }^{a}$ The planes $x^{\prime} X^{\prime}+m Y^{\prime}+n Z^{\prime}+k=0$ are referred to orthogonal axes. The transformation form fractional cell coordinates $(x, y, z)$ is $X^{\prime}=a x+c z(\cos \beta), Y^{\prime}=y b$, $Z^{\prime}=z V / a b$.

${ }^{b}$ Primed atoms related to unprimed atoms by the symmetry operation $1-x,-y, 1-z$.

${ }^{c}$ starred atoms were not included in least squares plane. 
Description of the Structure and Discussion

The crystal structure of the co-crystallized complexes dii sothiocyanatobis (2,2'bipyridylamine) copper(II) and isothiocyantobis (2,2'bipyridylamine) copper(II) perchlorate consists of two monomeric molecules in the asymmetric unit. The first species $\mathrm{CuL}_{2}(\mathrm{NCS})_{2}$ utilizes a centrosymmetric special position of the space group, while $\mathrm{CuL}_{2} \mathrm{NCSClO}_{4}$ is in a four-fold general position. The geometry of $\mathrm{CuL}_{2}$ (NCS) 2 and $\mathrm{CuL}_{2} \mathrm{NCS}^{+}$are shown in Figures 10 and 11 , respectively, while Figure 12 is a view of the formula unit.

In $\mathrm{CuL}_{2}$ (NCS) ${ }_{2}$, the copper(II) ion is in a tetragonally distorted octahedral environment with $T$ symmetry. Hence, the 2,2'bipyridylamine ligand coordinates in a bidentate fashion with $\mathrm{Cu}-\mathrm{N}$ bond lengths of 2.02 and $2.05 \AA$, whi le the isothiocyanate groups are trans to each other with a CU-N distance of $2.50 \AA$. N(1), N(3), N(1)', N(3)' are coplanar wi th the copper atom within standard deviations (see Table XV and Figure 9). There is very little angular distortion from true octahedral geometry, with the elongated isothiocyanate nitrogen forming nearly $30^{\circ} \mathrm{N}-\mathrm{Cu}-\mathrm{N}$ bond angles with the nitrogens of the bidentate ligand. The intraligand $\mathrm{N}-\mathrm{Cu}=\mathrm{N}$ angle is $85^{\circ}$, reflecting the geometric requirements of the ligand.

In the five coordinate species the copper is bound to the pyridyl nitrogen atoms of two bidentate ligands and to the isothiocyanate group in a configuration that is best described as square pyramidal. The atoms in the base consist of $N(5), N(8), N(10) ; N(11)$ with $N(7)$ at the apex. The copper nitrogen bond distances in the base are normal 
Figure 10. A view displaying the tetragonally distorted geometry of the di-isothiocyanatobis (2,2'bipyridylamine) copper(II) moiety 


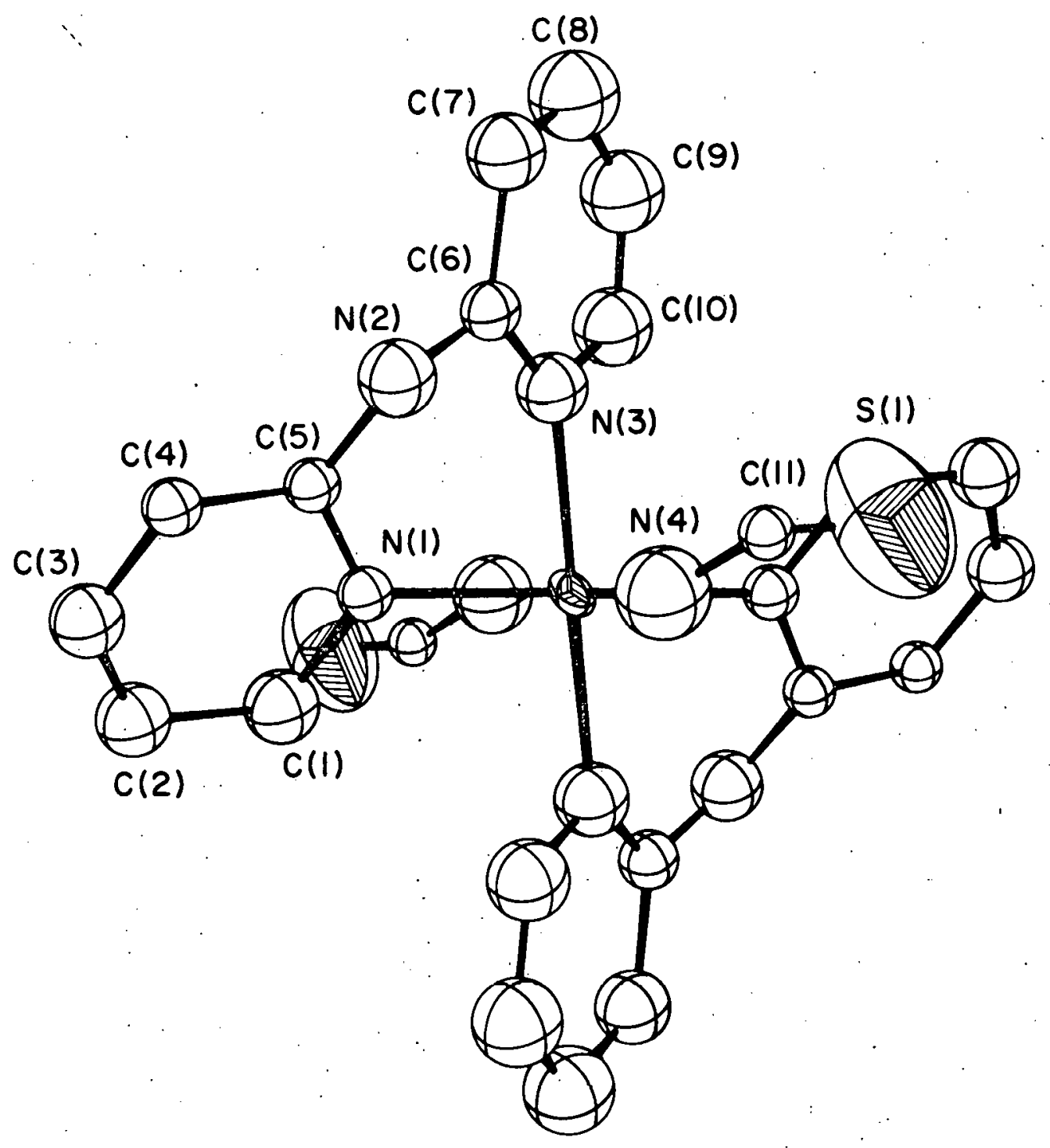


Figure 11. A view of the isothiocyantobis (2,2'bipyridylamine) copper(II) ion, displaying the square pyramidal geometry 


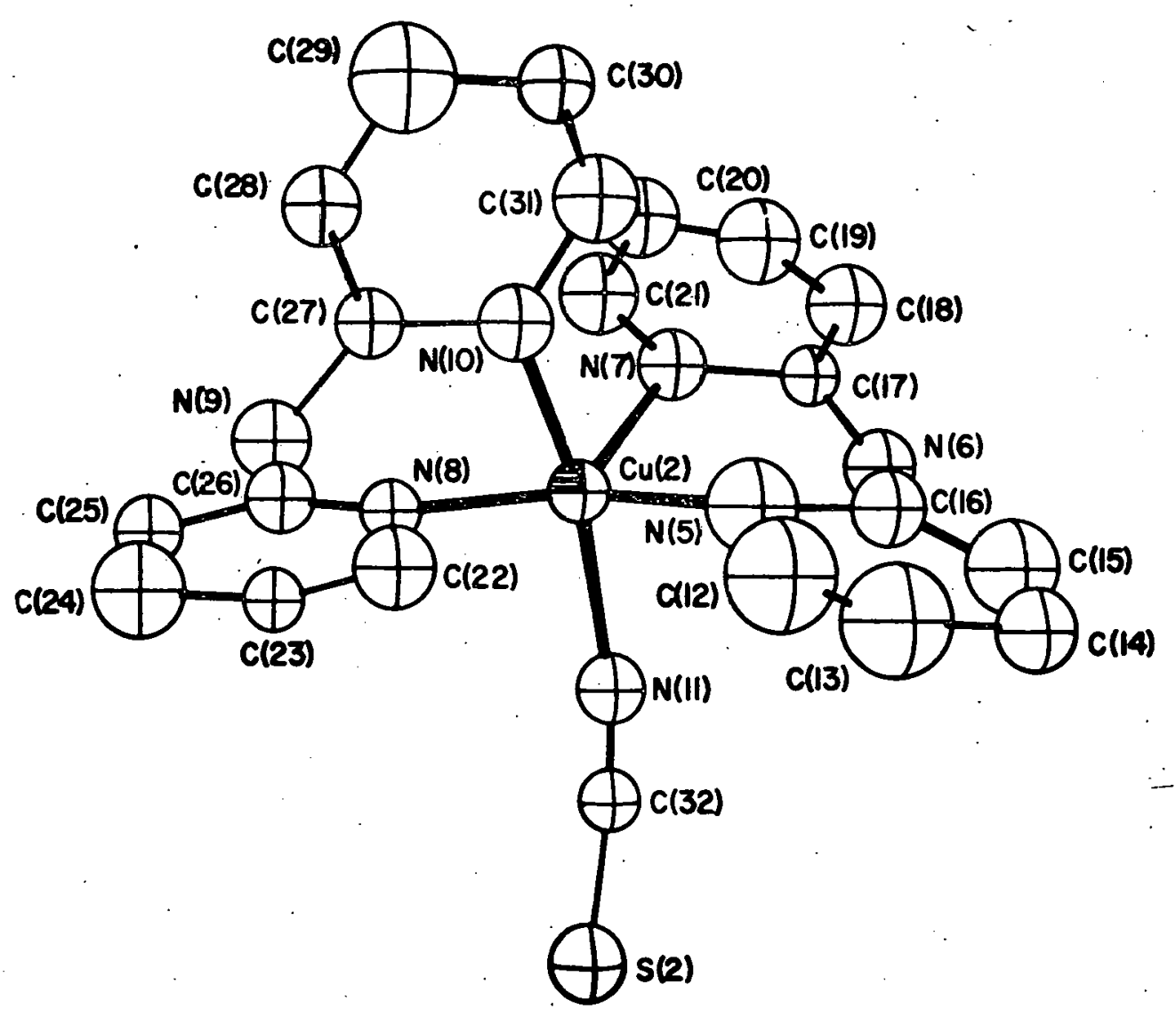


Figure 12. A formula unit of $\mathrm{CuL}_{2}(\mathrm{NCS})_{2} \mathrm{CuL}_{2} \mathrm{NCSClO}_{4}(\mathrm{~L}=2,2$ 'bipyridylamine $)$ 


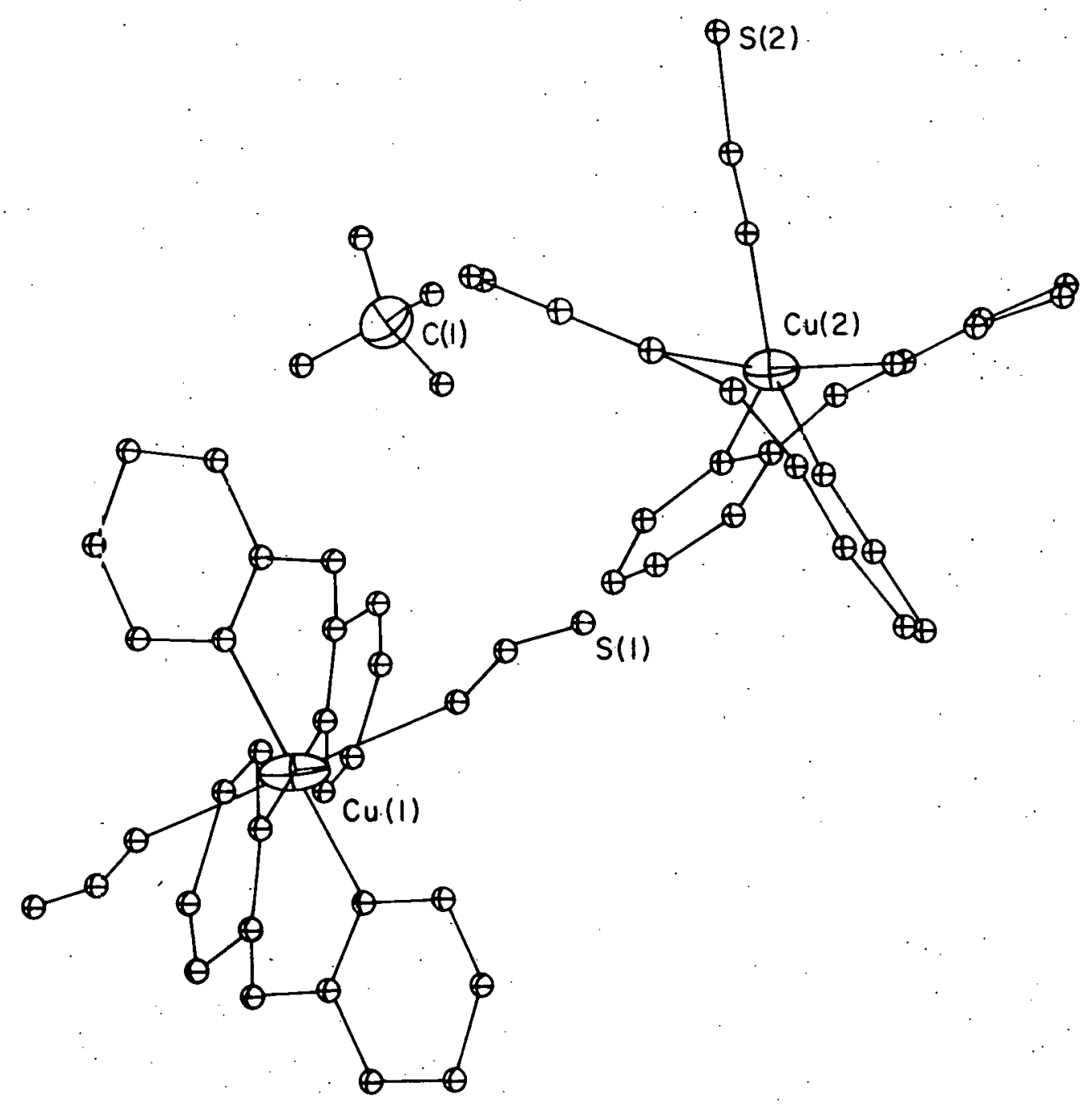


except $\mathrm{Cu}(2)-\mathrm{N}(5)$ at $1.86 \AA$. (Since the crystal was a poor diffractor, there were a large number of small reflections with associated large relative errors. It is likely that this anomalously short distance is due to a systematic effect from this poor diffraction data and therefore should be viewed with skepticism. Such effects can also be seen in other bond distances in the a direction in particular. The overall stereochemistry is well established, however.) 'The choice of basal atoms is supported by the near planarity of the four atoms (Table XV) and the bond angles of approximately $90^{\circ}$ formed by $N(10)-C u(2)-N(8) \cdot\left(89^{\circ}\right), N(8)-C u(2)-N(11)\left(89^{\circ}\right), N(5)-C u(2)-N(11)\left(87^{\circ}\right)$, and $N(10)-C u(2)-N(5)\left(89^{\circ}\right)$. The copper atom is above the plane of the base by $.33 \AA$ and forms a bond of $2.14 \AA$ with $N(7)$; this vector is perpendicular, within experimental error, to the basal plane. This distance is quite typical of the apex distance found in other copper(II) square pyramidal complexes, as is the position of the copper atom above the plane of the base. ${ }^{3}$

The 2,2'bipyridylamine ligands of both chromophores are bent considerably about the bridging nitrogen. In the centrosymmetric complex the dihedral angle between the two pyridine rings is $38^{\circ}$ and thereby reduces the crowding between the two ligands. The distance between $C(10)$ and $C\left(1^{\prime}\right)$ is $2.90 \AA$ while the distance between the associated hydrogen atoms is $2.83 \AA$. The dihedral angle in this chromophore is identical to the similar angle found in the square planar palladium complex with this ligand. ${ }^{6}$ In the five coordinate species the dihedral angles for ligands 2 and 3 (defined in Table XIV) 
are slightly different from 1 igand 1 at $25^{\circ}$ and $35^{\circ}$, respectively. In $\left(\mathrm{CuL}_{2} \mathrm{I}\right)_{2} \mathrm{IClO}_{4}(\mathrm{~L}=2,2$ 'bipyridylamine), a five-coordinate trigonal bipyramidal complex, the angles are $38^{\circ}$ and $33^{\circ}$, while in the distorted tetrahedral complex, $\mathrm{CuL}_{2}\left(\mathrm{ClO}_{4}\right)_{2}$, the ligand is nearly planar with a $9.6^{\circ}$ dihedral angle. The six-membered chelate rings in these complexes are quite similar, all showing approximately the same degree of folding in the boat conformation. For ligands 1, 2; and 3 (defined in Table XIV) the copper atom is .77,.68, and . $78 \AA$ below the plane defined by the other four atoms, while the nitrogen atoms are $.41, .18$, and $.19 \AA$ below the plane.

The average carbon-carbon bond distance in the ligand is $1.42 \AA$, while the average $C-N$ distance in the pyridyl ring is $1.39 \AA$ and the average $\mathrm{C}-\mathrm{N}$ bridging distance is unusually short at $1.34 \AA$.

The isothiocyanate group bound to $\mathrm{Cu}(1)$ forms a $\mathrm{Cu}-\mathrm{N}-\mathrm{C}$ bond angle of $144^{\circ}$, considerably distorted from the normal linear configuration. Smaller angles have been reported, however, for the isothiocyanate group bound to a transition metal, the smallest being $140^{\circ} .29$ The $\mathrm{N}-\mathrm{C}$ and $\mathrm{C}-\mathrm{S}$ distances found in the isothiocyanate group in molecule I do not agree well with accepted literature values. Unusual behavior of the thermal parameters for $S(1)$ and $c(11)$ lead to the conclusion that this group is also effected by the poor data mentioned earlier. The isothiocyanate group in molecule II, however, is qui te normal in distances and is more nearly linear with a $\mathrm{Cu}(2)-\mathrm{N}(11)-\mathrm{C}(32)$ bond angle of $161^{\circ}$. 
Lancaster has recently pointed out that the infrared spectra for $\mathrm{CuL}_{2} \mathrm{NCSClO}_{4}$ is indicative of two crystallographically unique isothiocyanate groups. 25 This leads to the speculation that the compound originally reported by McWhinnie may indeed be the same as the mixture in this study.

The observed crystal structure is stabilized by hydrogen bond formation (Table $X V_{I}$ ) involving as receptor atoms the sulfur atoms of the isothiocyanate groups in each chromophore and an oxygen atom of the perchlorate group. In each case the linkage is with an amine hydrogen atom. The $N(2) \ldots O(1)$ distance of $3.08 \AA$ is within that normally found for $\mathrm{N}-\mathrm{H} \ldots \mathrm{O}$ hydrogen bond formation. Also the bond angles $O(1)-N(2)-C(5)\left(114^{\circ}\right)$ and $O(1)-N(2)-C(6)\left(100^{\circ}\right)$ indicate the near linearity of the linkage. In the crystal structure of the parent uncoordinated ligand, which is also stabilized by hydrogen bonding, the $\mathrm{C}-\mathrm{N}-\mathrm{H}$ bond angle is $114^{\circ}$.

Hydrogen bonding also occurs between $S(1)$ and $N(6)$ at a distance of $3.49 \AA$ and bond angles of 117 and $107^{\circ}$ for $C(17)-N(6)-S(1)$ and $C(16)-N(6)-S(1)$, respectively. An additional hydrogen bond links the two positive ions, the $S(2) \ldots N(9)$ distance being $3.44 \AA$ wi th bond angles of $111^{\circ}$ and $113^{\circ}$ for $C(27)-N(9)-S(2)$ and $C(26)-N(9)-S(2)$. Crystallization is a commonly used technique for purification and separation of materials. It is unusual to find two such metal complexes co-crystallizing. The hydrogen bonds between the neutral complex and the two ions of compound II may well account for this behavior. 
Table XVI. Hydrogen bonds a in $\mathrm{CuL}_{2}(\mathrm{NCS})_{2} \mathrm{CuL}_{2} \mathrm{NCSClO}_{4}$

\begin{tabular}{ccc}
\hline $\begin{array}{c}\text { Bond } \\
N-H \ldots Y\end{array}$ & $\begin{array}{c}\text { Distance }(\AA) \\
N-Y\end{array}$ & Angles $^{c}\left({ }^{\circ}\right)$ \\
\hline$N(2)-H^{b} \ldots O(1)$ & 3.02 & 114,110 \\
$N(6)-H \ldots S(1)^{I}$ & 3.47 & 117,107 \\
$N(9)-H \ldots S(2)^{I I}$ & 3.42 & 111,113 \\
\hline
\end{tabular}

${ }^{a}$ Roman numerals refer to the following symmetry transformation: $I: \quad x, \frac{1}{2}-y, z-\frac{1}{2} ;$ II: $1-x, 1-y, 1-z$.

${ }^{b}$ Hydrogen atom positions were not located.

${ }^{C}$ All hydrogen bond linkages are to amine hydrogen atoms. The bond angles referred to are the $\mathrm{C}-\mathrm{N} \ldots \mathrm{Y}$ for the two carbon atoms bound to the nitrogen. In the parent uncoordinated ligand a hydrogen bond of this type stabilizes the crystal structure and a $\mathrm{C}-\mathrm{N}-\mathrm{H}$ bond angle of $114^{\circ}$ was found. 
THE STRUCTURE OF 2,2'BIPYRIDYLAMINE

\section{Introduction}

The structural study of 2,2'bipyridylamine was undertaken to obtain accurate structural parameters for this moiety since it has been finding wide use as a ligand in transition metal complexes. McWhinnie has recently reviewed this aspect of its ligand chemistry. The compound itself was first reported in 1923 by Wibaut and Dingemanse. 30 Two crystalline modifications of the compound are known, one melting at $84^{\circ}$ and a second melts at $94^{\circ}$. The structure of the low melting polymorph was determined in this study.

\section{Experimental}

Crystal Data. --2,2'bipyridylamine, $C_{10} \mathrm{H}_{9} \mathrm{~N}_{3}, M=171 \mathrm{~g} / \mathrm{m}$ Orthorhombic, $P_{c c n}$ a $=18.416 \pm .005, \underline{b}=12.294 \pm .005$, $\underline{c}=7.691 \pm .007 \AA, V=1741.3 \AA^{3}, \rho_{c}=1.31 \mathrm{~g} / \mathrm{cc}, z=8, F(000)=720 \mathrm{e}$, $\operatorname{MoK}_{\alpha}(\lambda=0.7107 \AA), \mu=1.03 \mathrm{~cm}^{-1}$, M.P. $=84^{\circ}$.

Recrystallization of reagent grade 2,2 ! bipyridylamine from carbon tetrachloride yielded large colorless crystals of rectangular needlelike habit and well-formed faces. Precession and Weissenberg photographs exhibited $\mathrm{mm} \mathrm{m}$ Laue symmetry with the following systematic extinctions: hol when $l=2 n+1$, Okl when $l=2 n+l$, and hko when $h+k=2 n+l$. These absences uniquely determine the space group as $P_{c c n}$. The unit cell parameters and thelr standard deviations were determined by a least squares fit to 12 independent reflection angles ${ }^{19}$ whose centers were determined by left-right, top-bottom beam splitting on a previously aligned four-circle diffractometer. 
For data collection a crystal of dimensions $.10 \times .25 \times .50 \mathrm{~mm}$ along the $a, b$, and c crystal axes respectively was mounted such that the c axis was along the spindle axis of the goniometer. Since crystal decomposition in the atmosphere had previously been noticed, the crystal was housed in a thin-walled Lindemann glass capillary. Data were collected at room temperature $\left(24^{\circ} \mathrm{C}\right)$ utilizing an automated fourcircle diffractometer designed and built in the Ames Laboratory. The upper full circle was purchased from Stoe and equipped wi th encoders (Baldwin Optical) and drive motors. The base was so designed that encoders could be directly connected to the main $\omega$ and $2 A$ shafts, using solid and hollow shaft encoders, respectively. The diffractometer is interfaced to a PDP-15 computer and is equipped with a scintillation counter. Two equivalent octants of data were collected within a $2 \theta$ sphere of $40^{\circ}$. The $\theta-2 \theta$ step scan technique, .01\% step counting for $.10 \mathrm{sec} / \mathrm{step}$, was employed wi th a takeoff angle of $3^{\circ}$. To improve the efficiency of the data collection process, variable-step symetricscan ranges were used. The scan varied from $1.12^{\circ}$ in $2 \theta$ at low twotheta. values to $1.72^{\circ}$ at large two-theta angles. Stationary-crystal, stationary-counter back-round counts of one-half the time required to scan the peak were taken at the beginning and end of each scan. Before the scan was made each peak was maximized in $\omega$. Also if the reflection did not exceed the backround by seven counts or more, which corresponds to approximately three standard deviations in the backround for larger values of $2 \theta$, no further measurements were made on the reflection. 
As a general check on electronic and crystal stability, the intensities of three standards were remeasured every twenty-five reflections. These standards showed no decrease over the entire period of data collection. A total of 1771 reflections were recorded in the hkl and $\bar{h} k \ell$ octants.

The intensity data were corrected for Lorentz-polarization effects. Because of the small linear absorption coefficient, no absorption correction was made. The minimum and maximum transmlssion factors were .95 and .99 , respectively. The individual values of $F_{0}{ }^{2}$ from the equivalent octants were averaged to yield 809 unique $F_{0}{ }^{2}$ values. The standard deviation in each intensity was estimated from the average total count and backround values by

$$
[\sigma(I)]^{2}=\left[c_{t}+c_{b}+\left(0.05 c_{t}\right)^{2}+\left(0.05 c_{b}\right)^{2}\right]
$$

of the 809 unique reflections, 567 had $F_{0}^{2} \geq 3.0 \sigma(I)$. The estimated standard deviation in each structure factor was calculated by the method of finite differences. The reciprocals of the squares of the structure factor variances were used as weights in the least squares refinement.

\section{Solution and Refinement}

Normalized structure factors ${ }^{31}$ were calculated preliminary to a direct method structure determination attempt. However, the Wilson plot from which the scale factor and temperature factor were obtained 
gave quite a poor fit to a straight line. Subsequent phasing via the $\Sigma^{-2}$ relation lead to a chemically satisfying model, but one which would not refine.

At this stage it was noticed that the eeo and eoo parity groups had average values of $|E|^{2}$ significantly below 1.0 . These parity groups were arbitrarily rescaled to 1.0 and the program MULTAN ${ }^{32}$ was employed to obtain phases for all reflections with E's greater than 1.0. The E-map computed unambiguously showed the positions of all 13 heavy atoms in the structure. The model originally produced by the $\Sigma^{-2}$ application was related to the true structure by a two-fold rotation about the point $x=1 / 2$ and $y=3 / 4$. Wi th all atoms but the bridging nitrogen input as carbons, four cycles of least squares refinement produced a crystallographic discrepancy factor of $13.2 \%$. The ring nitrogen positions were readily determined by their low temperature factors and by their shorter bond distances." With all atoms isotropic, $R$ was $11.00 \%$, and the weighted $R$ factor, $R_{\omega}=\left[\Sigma \omega\left(\left|F_{0}\right|-\left|F_{c}\right|\right)^{2} / \Sigma \omega\left|F_{0}\right|^{2}\right]^{\frac{1}{3}}$, was $12.90 \%$ for the 567 observed reflections. The scattering factors used for the carbon and nitrogen were those of Hansen et al. 11 A difference electron density map at this stage showed that all nonhydrogen atoms had been accounted for, but some anisotropic motion was evident. Three additional cycles of anisotropic refinement of all heavy atoms reduced the discrepancy factor to $9.8 \%$ and $R_{\omega}$ to $11.3 \%$. A subsequent difference map clearly indicated all nine hydrogen atom positions. 
At this stage two reflections, 202 and 220 , appeared to be severely effected by extinction and were removed from the refinement. The hydrogen positions were input lowering the agreement factor to 4. $1 \%$, however, some of the isotropic thermal parameters went negative. This was attributed to the use of the isolated hydrogen atom scattering factors leading to an undesirable interaction between the thermal parameter and the aspherical electron density distribution for bound hydrogen; as described by Jenson and Sundarlingam. 33 Using the contracted hydrogen atom scattering factor of Stewart, Davidson, and simpson, 34 positive isotropic thermal parameters were derived. With these scattering factors refinement gave a final discrepancy factor of $3.8 \%$ was obtained, wi th $R_{\omega}=4.3 \%$ for the 565 observed reflections. At this point two final cycles of least squares were run with all 807 uniquely measured reflections yielding $R=6.2 \%$ and $R_{\omega}=5.3 \%$. No appreciable shifts in atom positions occurred. The final value of $\left[\Sigma_{N}^{2} /\left(N_{N}-V N\right)\right]^{\frac{1}{3}}$ was $\cdot 7823$.

In Table $X V I I$ are listed the final positional and thermal parameters of the heavy atoms along with their standard deviations. The refined positional and isotropic thermal parameters and their standard deviations for the hydrogen atoms are given in Table XVIII. Standard deviations given were obtained from the inverse matrix of the final least-squares refinement cycle. A 1 ist of all 807 unique recorded and calculated structure factors $(x 10)$ is found in Figure 13 . The bond lengths and bond angles with standard deviations are given in Tables $X I X$ and $X X$ and in Figure 14. Significant nonbonded distances 
Table XVII. Final: heavy atom atomic coordinates and thermal parameters for. 2, 2! bipyridylaminea

\begin{tabular}{|c|c|c|c|c|c|c|c|c|c|}
\hline Atom & $x$ & $y$ & $z$ & $\beta_{11}$ & $\beta_{22}$ & $B_{33}$ & $\beta_{12}$ & $B_{13}$ & $\beta_{23}$ \\
\hline$c(1)$ & $0.4805(2)$ & $0.8697(4)$ & $0.2168(5)$ & $31(2)$ & $85(4)$ & $259(10)$ & $11(2)$ & $-7(3)$ & $1(5)$ \\
\hline$c(2)$ & $0.4524(2)$ & $0.7692(4)$ & $0.1838(5)$ & $30(2)$ & $94(4)$ & $240(9)$ & $-3(2)$ & $-12(3)$ & $-24(5)$ \\
\hline$c(3)$ & $0.4955(2)$ & $0.6806(4)$ & $0.2183(5)$ & $43(2)$ & $73(4)$ & $253(10)$ & $-5(2)$ & $-8(3)$ & $-25(5)$ \\
\hline$c(4)$ & $0.5635(2)$ & $0.6964(3)$ & $0.2846(5)$ & $34(2)$ & $61(3)$ & $249(9)$ & $3(2)$ & $-15(3)$ & $-20(5)$ \\
\hline$C(5)$ & $0.5876(2)$ & $0.8018(3)$ & $0.3162(4)$ & $22(1)$ & $69(3)$ & $173(8)$ & $6(2)$ & $2(2)$ & $-8(4)$ \\
\hline$c(6)$ & $0.6912(2)$ & $0.9073(3)$ & $0.4451(4)$ & $26(1)$ & $55(3)$ & $172(7)$ & $O(2)$ & $0(3)$ & $5(4)$ \\
\hline$c(7)$ & $0.6558(2)$ & $1.0030(3)$ & $0.4934(5)$ & $31(2)$ & $69(3)$ & $218(9)$ & $11(2)$ & $-6(3)$ & $-14(4)$ \\
\hline$c(8)$ & $0.6964(2)$ & $1.0868(3)$ & $0.5580(5)$ & $39(2)$ & $66(3)$ & $24.1(9)$ & $10(2)$ & $-6(3)$ & $-15(5)$ \\
\hline$c(9)$ & $0.77 .04(2)$ & $1.0761 .(3)$ & $0.5742(5)$ & $42(2)$ & $66(4)$ & $224(9)$ & $-5(2)$ & $-4(3)$ & $-8(5)$ \\
\hline$c(10)$ & $0.8007(2)$ & $0.9783(3)$ & $0.5273(5)$ & $28(2)$ & $82(4)$ & $231(9)$ & $-2(2)$ & $-8(3)$ & $2(5)$ \\
\hline$N(1)$ & $0.5469 .(2)$ & $0.8888(2)$ & $0.2825(4)$ & $25(1)$ & $75(3)$ & $249(7)$ & $5(1)$ & $-10(2)$ & $-4(3)$ \\
\hline$N(2)$ & $0.6 .564(2)$ & $0.8157(3)$ & $0.3834(4)$ & $26(.1)$ & $54 .(3)$ & $257(8)$ & $7(2)$ & $-6(2)$ & $-4(4)$ \\
\hline$N(3)$ & $0.7630(2)$ & $0.8946(2)$ & $0.4624 .(4)$ & $26(1)$ & $59(2)$ & $226(7)$ & $1(1)$ & $-4(2)$ & $1(3)$ \\
\hline
\end{tabular}

astandard deviations of the cpordinates are for the least significant figure. The $\beta_{i j}$ and their standard deviations are $\times 10^{4}$. The $\beta_{i j}$ are defined by:

$$
T=\exp \left[-\left(h^{2} \beta_{11}+\underline{k}^{2} \beta_{22}+\ell^{2} \beta_{33}+2 h k \beta_{12}+2 h \ell \beta_{13}+2 k \ell \beta_{23}\right)\right] \text {. }
$$


Table XVIII. Refined hydrogen atom parameters ${ }^{a}$

\begin{tabular}{lcccc}
\hline Atom & $x$ & $y$ & $z$ & $B\left(\AA^{2}\right)$ \\
\hline$H(1)$ & $0.454(2)$ & $0.935(3)$ & $0.190(4)$ & $4.5(9)$ \\
\hline$(2)$ & $0.403(2)$ & $0.763(3)$ & $0.131(4)$ & $5.1(9)$ \\
$H(3)$ & $0.479(2)$ & $0.611(3)$ & $0.190(5)$ & $6.4(10)$ \\
$H(4)$ & $0.594(2)$ & $0.635(3)$ & $0.307(4)$ & $4.0(8)$ \\
$H(5) b$ & $0.681(2)$ & $0.756(3)$ & $0.396(4)$ & $4.1(9)$ \\
$H(7)$ & $0.605(2)$ & $1.008(2)$ & $0.481(4)$ & $4.0(8)$ \\
$H(8)$ & $0.668(2)$ & $1.156(3)$ & $0.589(5)$ & $6.5(10)$ \\
$H(9)$ & $0.800(2)$ & $1.135(3)$ & $0.622(5)$ & $6.3(10)$ \\
$H(10)$ & $0.850(2)$ & $0.967(3)$ & $0.541(4)$ & $3.7(8)$ \\
\hline
\end{tabular}

${ }^{a}$ The number of the hydrogen atom is that of the carbon to which it is attached.

$b_{H(5)}$ is the amine hydrogen attached to $N(2)$. 
Figure 13. Observed and calculated structure factors $(x 10)$ for 2, 2 'bipyridylamine 

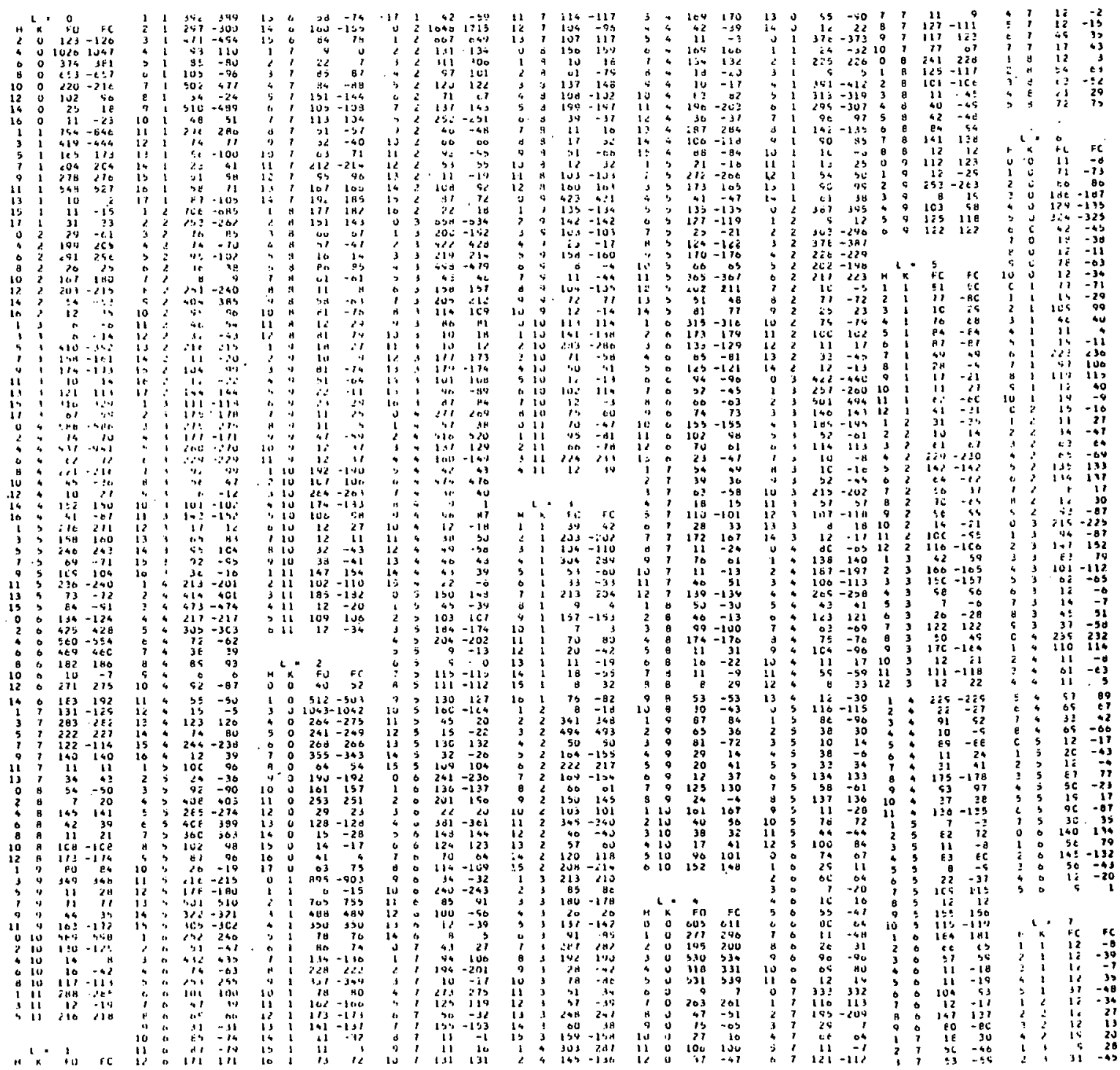
Table XIX. Interatomic distances and angles in 2,2'bipyridylamine

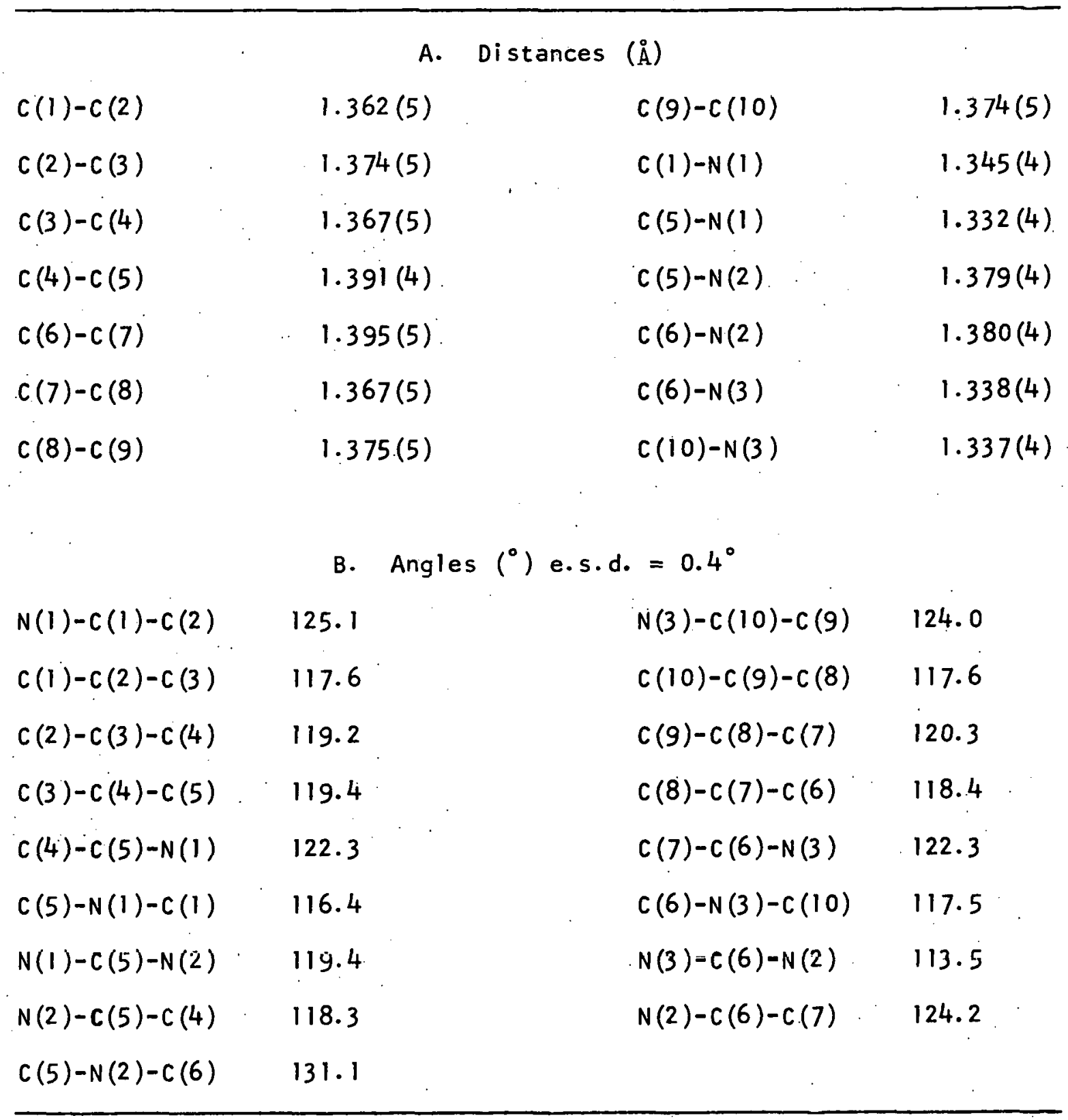


Table XX. Interatomic distances and angles involving hydrogen atoms

\begin{tabular}{lccr}
\hline & A. Distances $(\AA)$ e.s.d. $=.03 \AA$ & \\
$C(1)-H(1)$ & .96 & $C(10)-H(10)$ & .92 \\
$C(2)-H(2)$ & .99 & $C(9)-H(9)$ & 1.03 \\
$C(3)-H(3)$ & .94 & $C(8)-H(8)$ & .94 \\
$C(4)-H(4)$ & .95 & $C(7)-H(7)$ & 2.18 \\
$N(2)-H(5)$ & .87 & $H(5) \ldots N(3)^{a}$ &
\end{tabular}

B. Angles e.s.d. $=2.0^{\circ}$

$\begin{array}{llll}H(1)-C(1)-N(1) & 113 & H(10)-C(10)-N(3) & 116 \\ H(1)-C(1)-C(2) & 122 & H(10)-C(10)-C(9) & 120 \\ H(2)-C(2)-C(1) & 120 & H(9)-C(9)-C(8) & 121 \\ H(2)-C(2)-C(3) & 123 & H(9)-C(9)-C(10) & 121 \\ H(3)-C(3)-C(2) & 119 & H(8)-C(8)-C(7) & 116 \\ H(3)-C(3)-C(4) & 121 & H(8)-C(8)-C(9) & 124 \\ H(4)-C(4)-C(5) & 121 & H(7)-C(7)-C(6) & 120 \\ H(4)-C(4)-C(3) & 119 & H(7)-C(7)-C(8) & 122 \\ H(5)-N(2)-C(5) & 114 & H(5)-N(2)-C(6) & 114\end{array}$

'Hydrogen bond. $N(3)$ ' is related to $N(3)$ by the symmetry operation $3 / 2-x, 3 / 2-y, z$. 
Figure 14. A dimeric unit of 2,2'bipyridylamine displaying the two-fold symmetry 


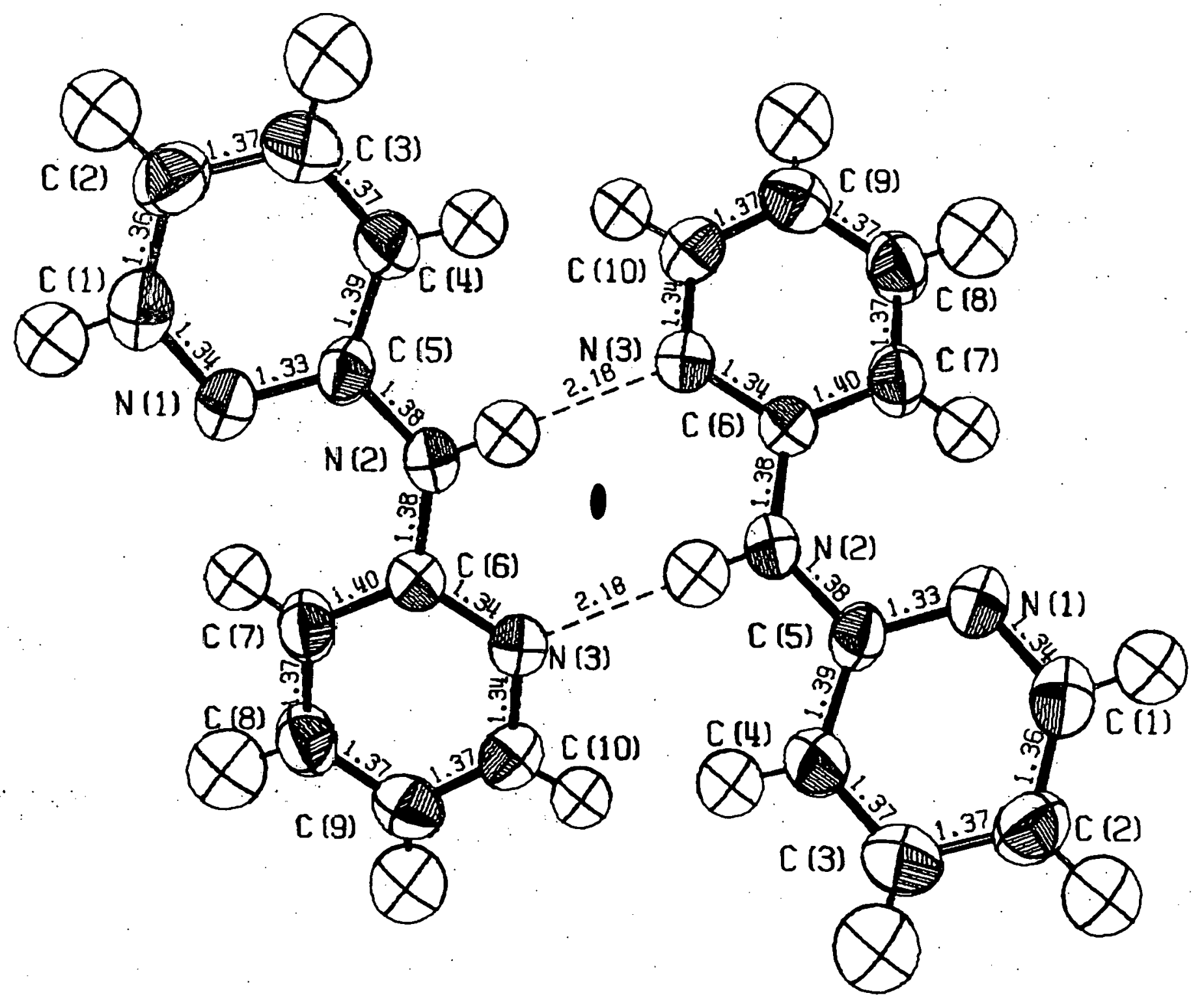


are listed in Table XXI, with least squares plane information provided in Table XXII.

\section{Description of the Structure and Discussion}

The low melting polymorph of 2,2! bipyridylamine contains pairs of molecules hydrogen bonded to one another, the dimeric unit possessing two-fold crystallographic symmetry. Within the molecule the carboncarbon bonds adjacent to the bridgehead nitrogen are found to be significantly different in length $(1.395(5) \AA)$ from the remaining carbon-carbon distances $(1.369(5) \AA)$. The latter are somewhat shorter than pyridine $C-C$ distances previously reported. 35 The carbon-nitrogen distances in the pyridine rings average $1.338(4) \AA$ with no significant deviations and are virtually identical to the $1.340 \AA \mathrm{C}-\mathrm{N}$ distance reported for pyridine. 35 The two bridging $\mathrm{C}-\mathrm{N}$ bond distances are identical at $1.380 \AA$. The bond angles within the pyridine rings vary between $117.6^{\circ}(c(1)-c(2)-c(3), c(8)-c(9)-c(10))$ and $125.1^{\circ}$ $(N(1)-C(1)-C(2))$. The bond angles about chemically equivalent atoms in the two pyridine rings are equal within standard deviations. Bond angles involving the bridging nitrogen are reasonable in the light of repulsive and attractive forces present. The $C(6)-N(2)-C(5)$ angle of $131.1^{\circ}$ reflects the nonbonded repulsions between $H(7)$ and $N(1)$ at $2.38 \AA$. The hydrogen bonding between the moieties probably accounts for the $113.5^{\circ}$ angle found for the $N(3)-C(6)-N(2)$. The carbon-hydrogen bond distances range from .92 $\AA(C(10)-H(10))$ to $1.03 \AA(C(8)-H(8))$, the average being $.96 \AA$. The $\mathrm{N}-\mathrm{H}$ distance is 
Table XXI. Nonbonded interatomic distances ( $\AA$ ) for 2,2'bipyridylamine

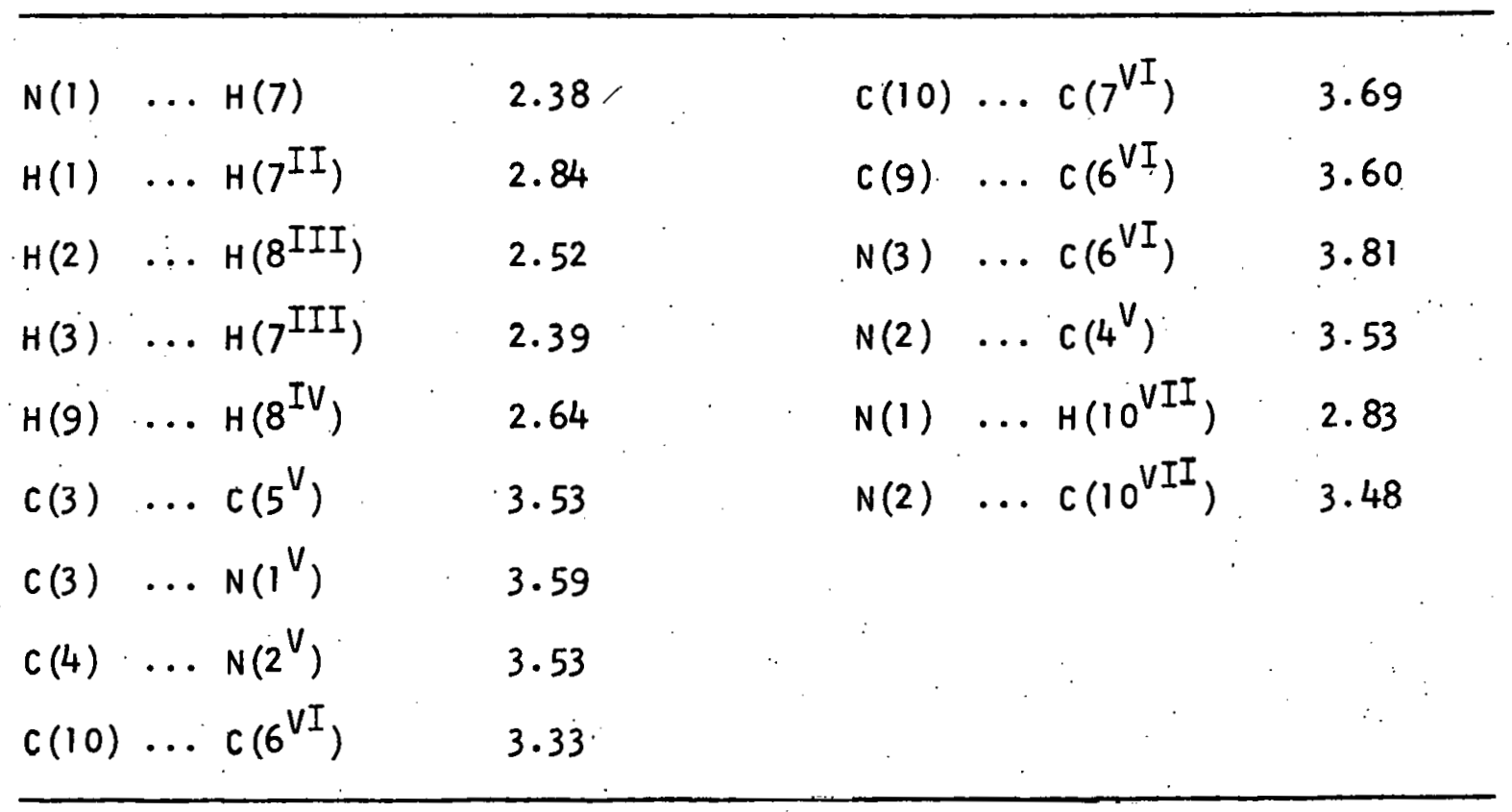

a Roman numerals denote the following symmetry transformations: $I=3 / 2-x, 3 / 2-y, z ; \quad I I=1-x, 2-y, 1-z ;$ III $=-1 / 2+x, 1-y$, $1 / 2-z ; \quad I V=3 / 2-x, 5 / 2-y, z ; \quad V=x, 3 / 2-y, 1 / 2+z ; \quad V I=3 / 2-x$, $y, 1 / 2+z ; \quad V I I=3 / 2-x, y, 1 / 2+z$. 
Table XXII. Least squares planes ${ }^{a}$ for 2,2'bipyridylamine

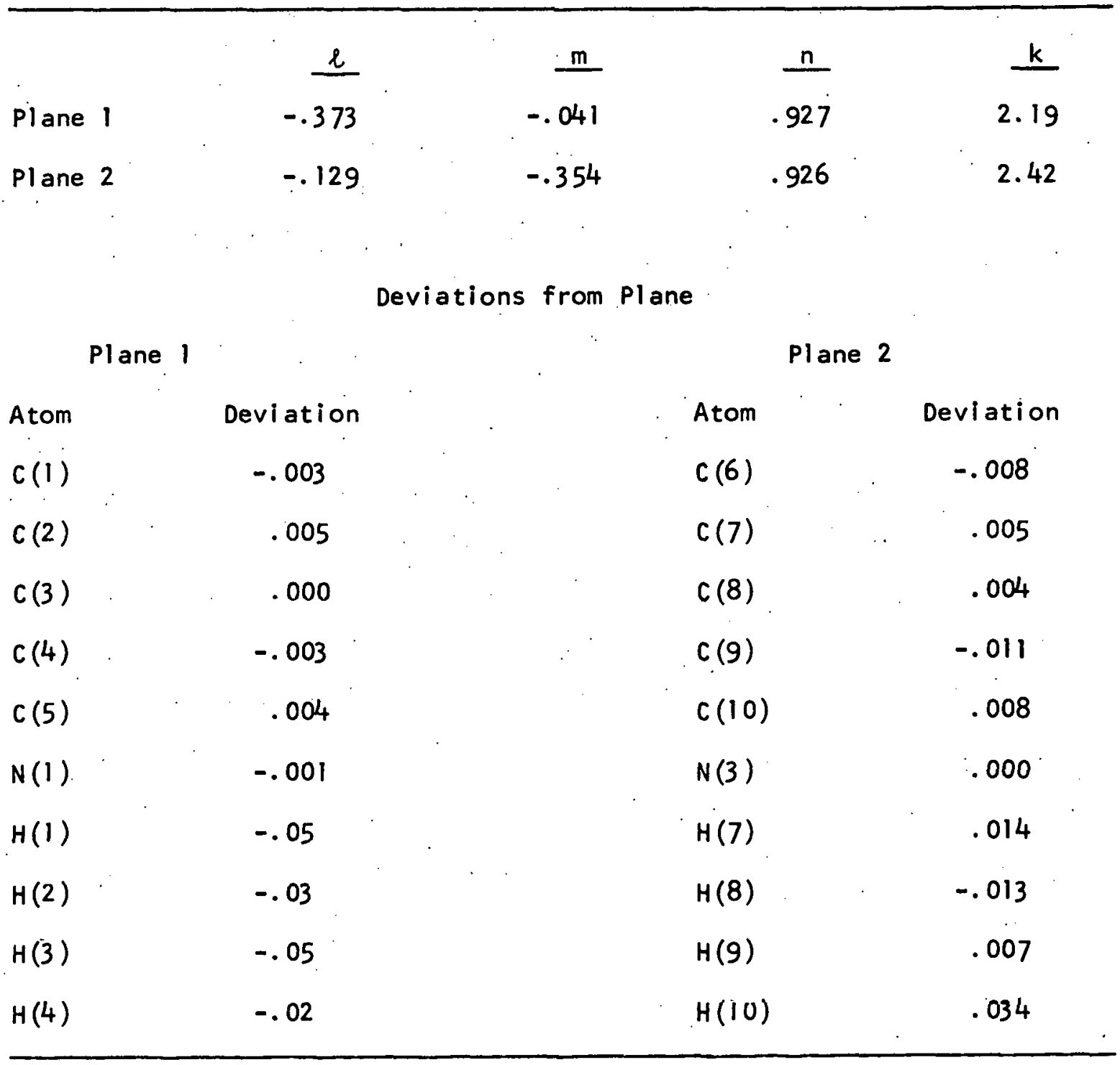

${ }^{a}$ The planes $l X^{\prime}+m Y^{\prime}+n Z^{\prime}+k=0$ are referred to or thogonal axes. The transformation from fractional cell coordinates $(x, y, z)$ is $X^{\prime}=X a, Y^{\prime}=y a$, and $Z^{\prime}=z c$. 
$.87 \AA$ wi th $\mathrm{H}-\mathrm{N}-\mathrm{C}$ bond angles of $114^{\circ}$ (Table $\mathrm{XX}$ ).

The rings in the molecule are approximately parallel to the ab plane. As expected, the largest component of anisotropic thermal motion of the heavier atoms is in a direction perpendicular to this plane, with approximately equal, root mean. square deviations in this direction for all the heavy atoms. The hydrogen isotropic thermal parameters range from $3.7 \AA^{2}(H(10))$ to $6.5 \AA^{2}(H(8))$.

The pyridine ring containing $N(1)$ is strictly planar with a maximum deviation of $.004 \AA$ from the mean plane, while in the second ring $c(9)$ is displaced by $.011 \AA$ from the mean plane, a deviation of borderline significance.

Steric hindrance within the ligand is relieved by a twist of the two rings giving rise to a $23^{\circ}$ dihedral angle between them (Figure 15).

The hydrogen bond joining the two molecules is nearly linear with a $N\left(3^{\prime}\right) \ldots H(5)-N(2)$ angle of $172^{\circ}$. The distance between the hydrogen and receptor atom is $2.18 \AA$ while the $N\left(3^{\prime}\right) \ldots N(2)$ distance is $3.02 \AA$. In spite of the short distance between $N(1)$ and $H(7), 2.38 \AA$ it is unlikely that there is an appreciable linkage between these atoms due to the unfavorable $N(1)-H(7)-C(7)$ angle of $117^{\circ}$.

The crystallographic two-fold axes at $x=1 / 4, y=1 / 4$, and $x=3 / 4, y=3 / 4$ are those running through the center of the dimeric units and these units are layered approximately perpendicular to the $z$ direction (Figure 15). The distance between these layers is nearly $3.7 \AA$ a value typical of layered aromatic structures. Distances between dimeric units in the same layer approximate those 
Figure 15. A stereographic view of the unit cell of 2,2'bipyridylamine. The origin is in the lower left corner wi th $x$ up, $y$ across, and $y$ into the page 

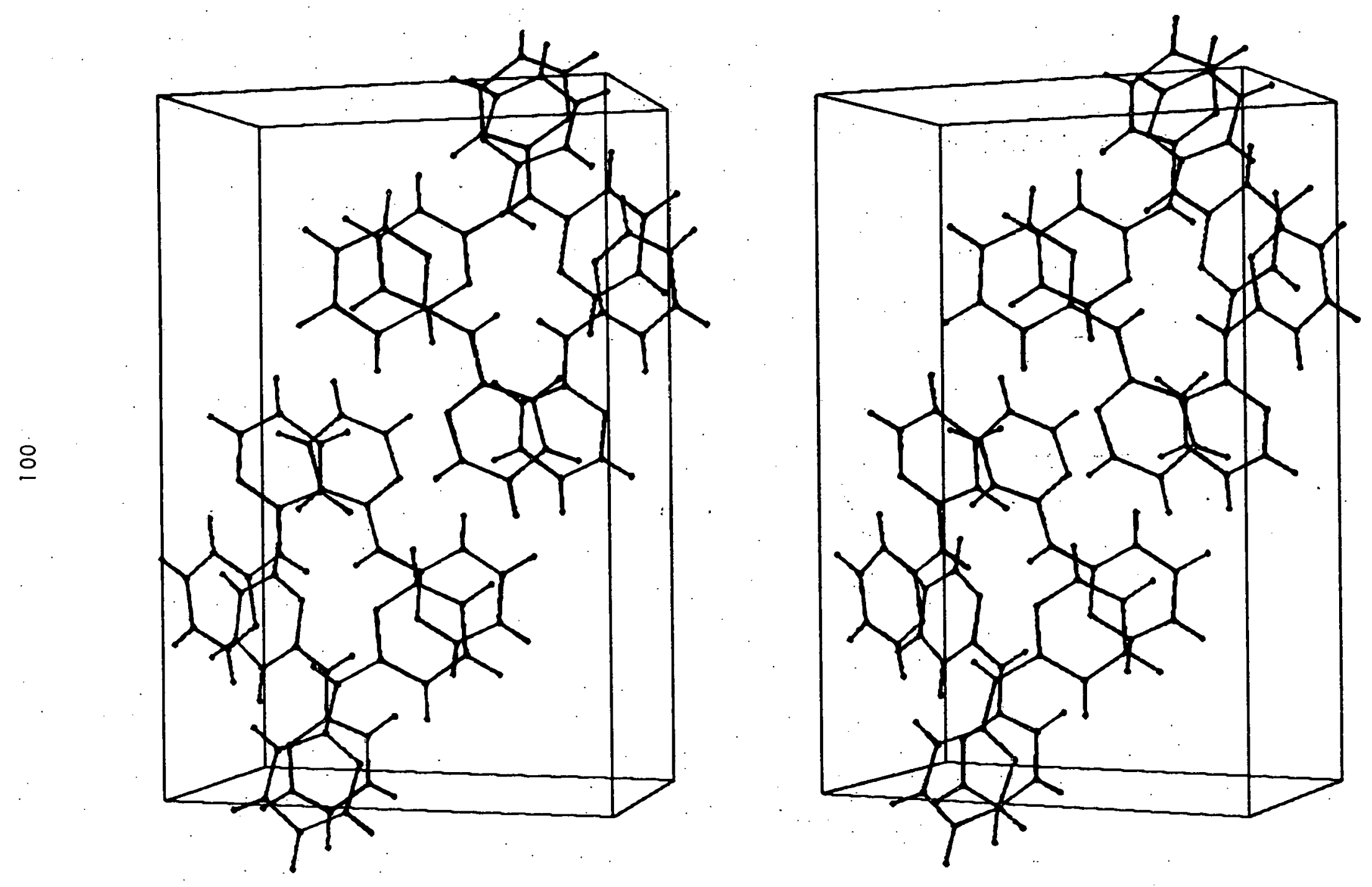
values expected for Van der Waal's contacts, the shortest being $2.39 \AA$. between $H(3)$ and $H(7)$. All short intermolecular contacts are listed in Table XXI.

it is interesting to speculate on the structural changes that may occur in the transformation of the low melting form to the high melting form of 2,2'bipyridylamine. If the ring containing $N(1)$ is rotated about the $N(2)-C(5)$ bond to attempt to bring $N(1)$ and $H(10)$ into proximity, the distance between $H(4)$ and $H(7)$ would be reduced to approximately $1.6 \AA$ making this an unacceptable configuration. If the dimeric units remain in the high melting form, only $\mathrm{C}-\mathrm{H} \ldots$... type hydrogen bonds could be formed. It seems likely therefore that the high melting form undergoes a significant change in structure relative to the low melting form.

With the structural data presently available for transition metal complexes with 2,2'bipyridylamine, it is not possible to make a meaningful comparison between the coordinated and free ligand. It is hoped that future structure determinations ( $x$-ray and/or neutron) of metal complexes with this ligand will provide structural parameters with errors comparable to those in the present study. 


\section{LITERATURE CITED}

1. McWhinnie, W. R., Coord. Chem. Rev., 5, 293 (1970).

2. Mckenzie, E. D., Coord. Chem. Rev., 6, 187 (1971).

3. Hathaway, B. J. and D. E. Billing, Coord. Chem. Rev., 5, 143 (1970).

4. MoWhinnie, W. R., J. Chem. Soc., 5165 (1964).

5. Lancaster, J. C., W. R. McWhinnie, and P. L. Welham, J. Chem. Soc., Sec. A, 1742 (1971).

6. Freeman, H. C. and M. R. Snow, Acta Cryst., 18, 843 (1965).

7. Geldard, J. F. and F. Lyons, J. Amer. Chem. Soc., 84, 2262 (1962).

8. Lawton, S. L. and R. A. Jacobson, Inorg. Chem., I, 2124 (1968).

9. Rodgers, J. and R. A. Jacobson, "ALF, A General Fourier Program in PL I for Triclinic, Monoclinic, and Orthorhombic Space Groups," U.S. Atomic Energy Commission Report 15-2155 (lowa State University and Institute for Atomic Research, Ames, lowa). 1969.

10. Howells, E. R., D. C. Phillips, and D. Rogers, Acta Cryst., $\underline{3}, 210$ (1950).

11. Hansen, H. P., F. Herman, J. D. Lee, and S. Skillman, Acta Cryst., 17. $1040(1964)$.

12. Templeton, D. H., "International Tables for X-Ray Crystallography," Vol. 111 , The Kynock Press, Birmingham, England, 1962, pp. 215, 216, Table 3.3.2C.

13. Busing, W. R., K. O. Martin, and H. A. Levy, "OR FLS, A Fur Liaii Crystallographic Least-Squares Program," U.S. Atomic Energy Commission Report ORNL-TM-305 (Oak Ridge National Laboratory, Oak Ridge, Tennessee). 1962.

14. Johnson, C. K., "OR TEP: A Fortran Thermal-Ellipsoid Plot Program for Crystal Structure IIlustrations," U.S. Atomic Energy Commission Report ORNL-3794 (Oak Ridge National Laboratory, Oak Ridge, Tennessee). 1965.

15. Busing, W. R, K. O. Martin, and H. A. Levy, "OR FFE: A Fortran Crystallographic Function and Error Program," U.S. Atomic Energy Commission Report ORNL-TM-306 (Oak Ridge National Laboratory, Oak Ridge, Tennessee): 1964. 
16. Procter, 1. M. and F. S. Stephens, J. Chem. Soc., Sec. A, 1248 (1969).

17. Bak, B., L. Harisen, and J. Rastrup-Andersen, J. Chem. Phys., 22, 2013 (1954).

18. Dudley, R. J., B. J. Hathaway, and P. S. Hodgson, J. Chem. Soc., Sec. A, 882 (1972).

19. Williams, D. E., "LCR-2: A Fortran Lattice Constant Refinement Program," U.S. Atomic Energy Commission Report IS-1052 (lowa State University and Institute for Atomic Research, Ames, lowa). 1964.

20. Alexander, L. E. and G. S. Smith, Acta Cryst., 15, 983 (1962).

21. Hubbard, C. R., C. O. Quicksall, and R. A. Jacobson, "The Fast Fourier Algorhythm and the Programs ALFF, ALFFDP, ALFFPROJ, ALFFT, and FRIEDEL," U.S. Atomic Energy Commission Report IS-2625 (Iowa State University and Institute for Atomic Research, Ames, lowa). 1971.

22. Pippy, M. E, and F. R. Ahmed, "NRC Crystallographic Programs for the IBM 360 System," (National Research Councll of Canada, Ottawa 7, Canada). 1968.

23. Huq, F. and A. C. Skapski, J. Chem. Soc., Sec. A, 1927 (1971).

24. Raymond, K. N., D. W. Meek, and J. A. Ibers, Inorg. Chem., I, 1111 (1968).

25. Barclay, G. A., B. F. Hoskins, and C. H. L. Kennard, J. Chem. Soc., 5691 (1963):

26. Elliot, H., B. J. Hathaway, and R. C. Slade, J. Chem. Soc., Sec. A, $1443(1966)$.

27. Procter, 1. M., B. J. Hathaway, D. E. Billing, R. Dudley, and P. Nicholls, J. Chem. Soc., Sec. A, 1192 (1969).

28. Wehe, D. J., W. R. Busing, and H. A. Levy, "OR ABS': A Fortran Program for Calculating Single Crystal Absorption Corrections," U.S. Atomic Energy Commission Report ORNL-TM-229 (Oak Ridge National Laboratory, Oak Ridge, Tennessee). 1962.

29. Brown, B. W. and E. C. Lingafelter, Acta Cryst., 16, 753 (1963).

30. Wibaut, J. P. and E. Wibaut, Rec. Trav. Chim., 42, 243 (1923).

31. Karle, J. and H. Hauptmann, Acta Cryst., 2, 635 (1956). 
32. Main, P., M. M. Woolf son, and G. Germain, "MULTAN: A Computer Program for the Automatic Solution of Crystal Structures," (Department of Physics, University of York, York, England). 1971.

33. Jenson, L. and M. Sundarlingam, Science, 145, 1185 (1964).

34. Stewart, R. F., E. R. Davidson, and W. T. Simpson, J. Chem. Phys., 42, $3175(1965)$.

35. Kennard, 0., "International Tables for X-Ray Crystallography," Vol. III, The Kynock Press, Birmingham, England, 1962, p. 275, Table 4.2.

36. Hoppe, W., Naturwi ssenshaften, 49, 536 (1962).

37. Main, P. and M. M. Woolfson, Acta Cryst., 16, 1046. (1963).

38. Woolfson, M. M., "An Introduction to X-Ray Crystallography," Cambridge University Press, Cambridge, England, 1970, pp. 112-117.

39. Hoppe, W., Acta Cryst., 16, 1056 (1963).

40. Mighell, A. D. and R. A. Jacobson, Acta Cryst., 16, 443 (1963).

41. Gorres, B. T and R. A. Jacobson, Acta Cryst., 17, 1599. (1964).

42. Simpson, P. G., R. D. Dobrott, and W. N. Lipscomb, Acta Cryst., 18, 169 (1965).

43. Hamilton, W. C., Acta Cryst., 18, 866 (1965).

44. Jacobson, R. A., "Crystallographic Computing," Munksgaard, Copenhagen, Denmark, 1970.

45. Dakin, R. J., Acta Cryst., B26, 2112 (1970).

46. Lesk, A. M., Acta Cryst., A28, 55 (1972).

47. Gass, S. K., "Linear Programming," McGraw-Hill, Inc., New York, 1969.

48. "Mathematical Programming System/360 Version 2, Linear and Separable Programing-Users Manual," IBM Manual GH20-0476-2, IBM, White Plains, New York, 1971.

49. Sayre, D., Acta Cryst., 5, 60 (1952).

50. Hurley, T. J. and M. A. Robinson, Inorg. Chem., I, 33 (1968). 


\section{ACKNOWLEDGMENTS}

The author wishes to express his sincere appreciation to Professor Robert Jacobson for inspiration, discussion, and guidance during the course of this work; to James Benson for competent, if ego reducing, experimental assistance; to Fred Hollenbeck for advice and technical assistance; to Robert Wismer for accurate, if cantankerous programming assistance, and to the faculty and graduate students, especially the students in X-ray Group 1 , for providing an atmosphere favorable for the expression and discussion of scientific ideas.

The author thanks his mother-in-law and father-in-law and other friends in Ames for their support during his graduate education and his parents and family whose constant support, moral and financial, have aided him immeasurably during his entire education.

For her devotion, love, and understanding during the last four years, the author expresses his deepest appreciation to his wife Mary. 


\section{APPENDIX A: DIRECT. PHASE DETERMINATION \\ BY USE OF LINEAR PROGRAMMING}

Introduction
Use of linear equations to directly determine the phases of structure factors for centrosymmetric crystallographic problems was first discussed by Hoppe 36 and shortly after by Main and Woolfson. 37 in both cases relations were established in reciprocal space making use of null points in the Patterson function. Both methods involve the convolution $^{38}$ of the electron density function with a function repre-? senting the null points in the Patterson; however, the manner in which the null points are used is quite different as are the resulting equations. 39 solution of these linear equations employed standard least squares techniques. However, such techniques can, and of ten do provide results that are physically unreasonable.

In the present work linear equations are set up in real space, that is, employing directly the Fourier expansion of the electron density function, and use is made of nuli points in the Patterson or symmetry map. $|0-4|$. The linear equations are solved, however', by linear programming algorithms which allow the solutions to be constrained to physically reasonable values.

During the time this work was being performed two papers appeared in which linear programing techniques were used in the solution of the phase problem. The first paper, by Dakin, ${ }^{45}$ employs equations quite different from the present work, while the recent paper by Lesk 46 is similar but not identical to the present approach. 
An outline of the mathematical formulation will be presented as well as some preliminary results obtained in a test of the method on a known structure.

\section{Theory}

The following discussion will be for a one-dimensional casse but can be readily generalized to three dimensions.

The Fourier expansion of the electron density for a centrosymmetric crystal structure is given by:

$$
\rho(x)=\frac{1}{L}\left(F_{0}+2 \sum_{h=1}^{\infty}\left|F_{h}\right| S_{h}: \cos 2 \pi h x\right)
$$

where $\rho(x)$ is the electron density at point $x, L$ is the length of the unit cell (the volume would be used in three dimensions), $F_{0}$ is the number of electrons in the unit cell, $\left|F_{h}\right|$ is the magnitude of the structure factor and $S_{h}$ is the sign of the structure factor. The magnitude of the structure factor is obtainable from experiment, but the signs are not. In practice the number of terms in the infinite Fourier series is limited by the experimental availability of structure factors and is further restricted by the number that can be conveniently handled in the solution of the problem. To reduce the errors associated with such truncation, use is made of an artificial temperature factor which effects the magnitude of the structure factor but not its phase. By choosing a temperature factor that decreases the resolution of the electron density function to a given value, e.g., $2.0 \AA$, it is only necessary to use data that significantly contributes to the $2.0 \AA$ 
structure within the desired error limitations. From the null points in the Patterson or symmetry map; it is possible to derive positions in space where the electron density is effectively zero, i.e., $\rho(x) \cong 0$. The number of such points is usually quite large and each point results in an equation. These equations are in a form that can be readily solved by linear programing techniques.

The algorithms and principles of linear programming are discussed in many textbooks 47 and package programs are avai lable for solving problems of this type $;^{48}$ therefore only a brief statement of the linear programing technique will be given here. To use the linear programming method, one must have a mathematically expressible objective function, a set of linear constraints, and a lower bound of zero on the solutions (the non-negativity constraint). In general the problem has more variables than equations, as explained below, and the variables are adjusted in an iterative fashion to satisfy the linear constraints whi le simult taneously maximizing or minimizing the objective function. In linear programming the equations approximating equalities for the null points in space are allowed to vary from an exact equality in order to maintain the desired constraints. To accomplish this extra variables, known as slack variables, are added to each equation. The solution to this problem must lie within the specified bounds for physical reality while simultaneously reducing the residuals in the linear constraints to a minimum. The choice of objective function assures the minimizations of the residuals. 
As an example, assume $n$ nuli points in electron density space, j structure factors suitably chosen and modified to reduce truncation error, and $k$ structure factors whose phases have previously been determined. In general, three structure factors may be assigned signs to fix the origin, or some structure factors might have been determined in a previous run at lower resolution. If some information regarding an atom position is available (e.g., a heavy atom position determined from the Patterson, but of insufficient size to phase the structure), this information may also be included. Substitution of $\left(x_{h}-1\right)$ for $s_{h}$ is made in (1), to satisfy the non-negativity constraint, and the equation is transformed to place all known quantities on the right-hand side, yielding

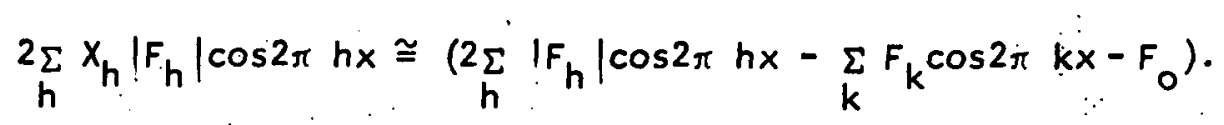

Three types of linear constraints are now available: n null point equations similar to (2), j constraints bounding the solutions, and possibly a contraint accounting for an atom position that is known. The problem to be solved by the algorithm appears as follows:

$$
\begin{aligned}
& \underset{h}{2 \sum_{h}} x_{h}\left|F_{h}\right| \cos 2 \pi h x+\epsilon_{i}-\epsilon_{i}^{\prime}= \\
& \quad \underset{h}{2}\left|F_{h}\right| \cos 2 \pi h x- \\
& \quad \underset{k}{2 \sum_{k} \cos 2 \pi k x-F_{0},} \\
& x_{h} \leq 2.0,
\end{aligned}
$$




$$
\underset{h}{2 \sum_{h}}\left|F_{h}\right| X_{h} \cos 2 \pi h x+\epsilon_{m}-\epsilon_{m}^{\prime}=C+R
$$

where $R$ is the right-hand side of equation (3) and $C$ is the numerical value expected for the electron density of the known atom at the particular degree of resolution, a quantity determined by trial. The epsilons are the slack variables mentioned earlier, each equation containing two such variables to account for the non-negativity constraint. It is the sum of these slack variables that are minimized in the objective function.

The problem in this form is readily solved by the IBM Mathematical Programming System. ${ }^{48}$ The solutions consist of values of $x_{h}$ between zero and two (signs between +1 and -1 ) and values of the slack variables indicating the errors in the equality approximations for each null point. Only values of $x_{h}$ corresponding to the integer positive or negative sign are used for definite phase assignment.

\section{Experimental}

Although the results reported below do not show conclusive evidence for the effectiveness of the method, it does show the potential of the technique. The structure used for a test case was $\left(\mathrm{CuL}_{2} \mathrm{I}_{2} \mathrm{IClO}_{4}\right.$ where $L=2,2^{\prime}$ bipyridylamine, space group $P_{2 / / c}$ with 248 atoms in the unit cell. With 59 reflections, 72 null points, one peak position, and a temperature factor resolution of $2.0 \AA$, the linear programming method yielded integer values of $x_{h}$. (zero or two) for 34 reflections, of which 32 were correct. From these results it was possible by a 
phase refinement procedure, to obtain the correct signs of all the input reflections and subsequently solve the structure. The time of solution for this test case, containing 136 rows, 339 variables, and converging after 442 iterations, was 2.21 minutes c.p.u. time, using $96 \mathrm{~K}$ bytes of storage on the IBM $360 / 65$ computer.

\section{Discussion}

While the results obtained are not conclusive, the general approach of the problem seems promising. The primary advantage of the method outlined is that the structure can be solved in various degrees of resolution, keeping the amount of data to a manageable quantity. This is particularly. important for large biological structures. In addition, the method allows structural information available from any other :" approach to be built into the phase determining process, i.e., the position of the heavy atom in the typical protein.

Future work should include extensive testing of the method with particular emphasis on formulation of a more powerful objective function, as the constraints placed on the variables seem quite adequate with most of the solutions clusterlng at the inicger valuos of zero and two. An objective function similar to the equation derived by Main and Woolfson ${ }^{37}$ has been examined, in which the electron density is convoluted with a symetry map function, the result being an objective function that is minimized containing the known coefficients of the Fourier expansion of the symmetry map function and the magnitudes of the structure factors. The results obtalned using this objective 
function were, however, less satisfactory than those obtained using the minimization of the residuals. Unfortunately, the type of objective function having potentially the greatest power, such as the maximization of the cube of the electron density function, 45 an expansion similar to the $\Sigma^{-2}$ relation, 49 results in nonlinear functions. With the current developments in the area of operations research, however, such a function may be feasible in the near future.

As indicated by the speed of solution for the test case, it is quite possible to increase the size of the problem, adding more nul point constraints and reducing truncation error by including more terms ili the series. Such an increase, in itself, however, has not made a significant improvement in the tests run so far. 


\section{APPENDIX B: RESEARCH PROPOSALS}

The following research proposals regard extensions of work reported in this thesis.

1. Although the coordination geometry of bis $(2,2$ 'bipyridylamine) copper(II) perchlorate has been well established, a careful redetermination of the structure, wi th errors comparable to those in the structure of 2,2'bipyridylamine, would provide data for a comparison between the coordinated and free ligand. The structure determination of

bis(2,2'bipyridylaminato) copper(II), 50 in which the amine protons have been removed leaving the ligand wi th a net negative charge, would allow the comparison to be carried further. Structural differences between the two similar metal complexes would also be of interest.

2. The structure determination of the high melting polymorph of 2,2' bipyridylamine would provide information on the effect of structure on the macroscopic properties of this compound.

3. Further work on the method of phase determination mentioned in Appendix A is warranted with particular emphasis on the furmulation of a more effective objective function. 